\title{
Protein Modification and Degradation \\ in the Cell Cycle of the Yeast Saccharomyces cerevisiae
}

\author{
Dissertation \\ zur Erlangung des Doktorgrades \\ der Mathematisch-Naturwissenschaftlichen Fakultäten \\ der Georg-August-Universität \\ zu Göttingen \\ vorgelegt von \\ Patrick Dieckhoff \\ aus \\ Diepholz
}

Göttingen 2004 
Die vorliegende Arbeit wurde von März 2001 bis Mai 2004 in der Arbeitsgruppe von PD Dr. Stefan Irniger in der Abteilung Molekulare Mikrobiologie und Genetik von Prof. Dr. Gerhard H. Braus am Institut für Mikrobiologie und Genetik der GeorgAugust-Universität zu Göttingen angefertigt.

Teile dieser Arbeit wurden veröffentlicht in:

Patrick Dieckhoff, Melanie Bolte, Yasemin Sancak, Gerhard H. Braus and Stefan Irniger (2004) "Smt3/SUMO and Ubc9 are required for efficient APC/C-mediated proteolysis in budding yeast." Molecular Microbiology, 51(5), 1375-1387.

D7

Referent: Prof. Dr. Gerhard H. Braus

Korreferent: Prof. Dr. H.-U. Mösch

Tag der mündlichen Prüfung: 
Den gesunden Gelehrten:

"Menschen, bei denen Nachdenken keine Krankheit ist."

Frei nach Georg Christoph Lichtenberg 



\begin{tabular}{|c|}
\hline SUMMARY \\
\hline . \\
\hline
\end{tabular}

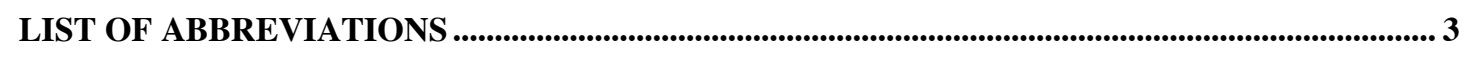

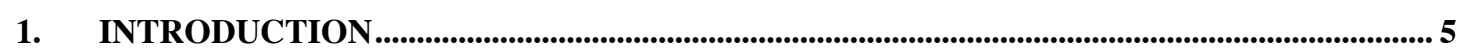

1.1 THE EUKARYOTIC LIFE CYCLE....................................................................................... 5

1.1.1 LIFE CYCLE OF SACCHAROMYCES CEREVISIAE ..............................................................5

1.2 POST-TRANSLATIONAL MODIFICATION WITH SMALL PEPTIDES ............................... 7

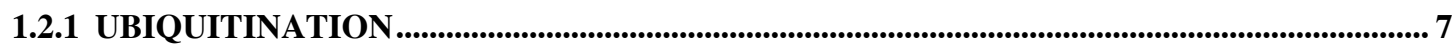

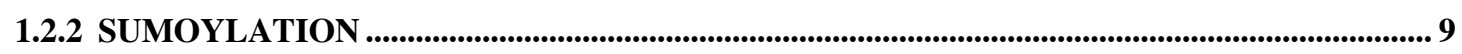

1.2.3 OTHER POST-TRANSLATIONAL MODIFIERS ....................................................................... 13

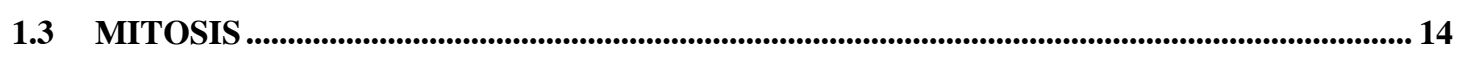

1.3.1 MOLECULAR ASPECTS OF MITOTIC CELL CYCLE CONTROL ....................................... 15

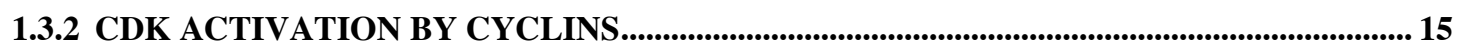

1.3.3 G1 CYCLINS: CLN1, CLN2, CLN3 ...........................................

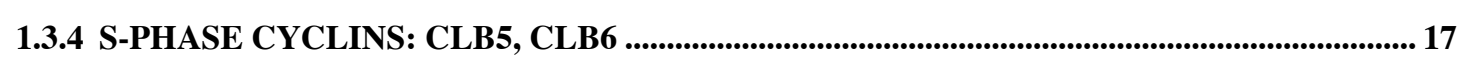

1.3.5 MITOTIC CYCLINS: CLB1, CLB2, CLB3, CLB4 .......................................................................... 17

1.3.6 THE ANAPHASE-PROMOTING COMPLEX (APC/C)................................................................... 18

1.3.7 ACTIVATORS OF THE APC/C: CDC20, CDH1 (HCT1) AND AMA1 ................................ 19

1.3.8 THE DOUBLE OSCILLATOR MODEL OF THE CELL CYCLE......................................... 20

1.3.9 COORDINATION OF DNA REPLICATION WITH CELL DIVISION.................................... 23

1.3.10 THE DNA DAMAGE CHECKPOINT ....................................................................................24

1.3.11 THE SPINDLE ASSEMBLY CHECKPOINT ................................................................................... 24

1.3.12 SPINDLE ORIENTATION CHECKPOINT ........................................................................................ 25

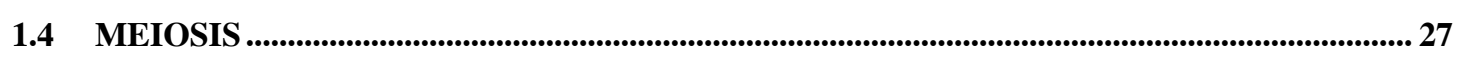

1.4.1 SELECTED FEATURES OF MEIOTIC REGULATION ............................................................... 28

1.4.2 THE MEIOTIC PROTEIN KINASE IME2 ........................................................................... 29

2. AIM OF THIS WORK .

2. AIM OF THIS WORK ............................................................................................................................. 31

3. MATERIALS \& METHODS ..................................................................................................................... 33

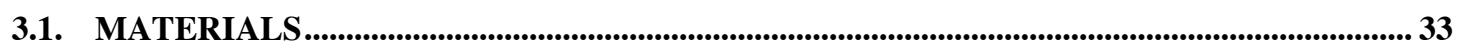

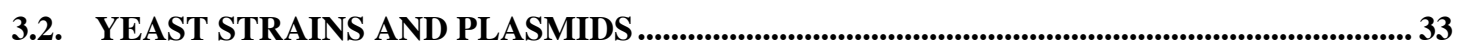




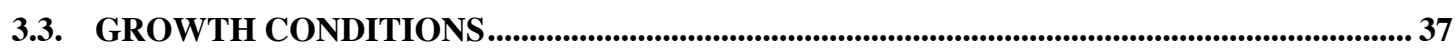

3.3.1. CULTIVATION OF YEAST AND CELL CYCLE ARRESTS ................................................... 37

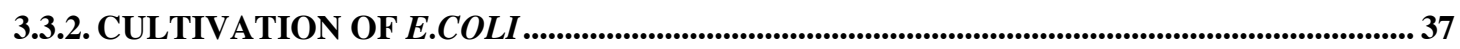

3.4. PROTEIN AND DNA DETECTION METHODS............................................................................. 37

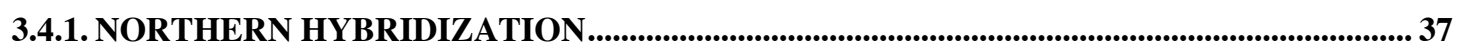

3.4.2. PREPARATION OF CELL EXTRACTS .................................................................................................... 38

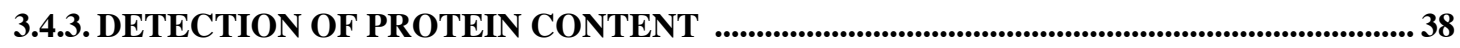

3.4.4. SDS-POLYACRYLAMIDE GEL ELECTROPHORESIS ......................................................... 38

3.4.5. IMMUNOBLOTTING

3.4.6. IMMUNOFLUORESCENCE ANALYSIS ..................................................................................... 39

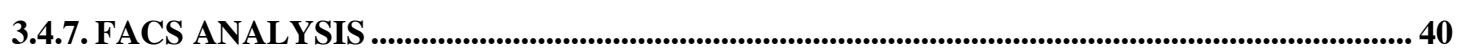

3.4.8. SINGLE-STEP PURIFICATION OF PROTEINS ...................................................................... 40

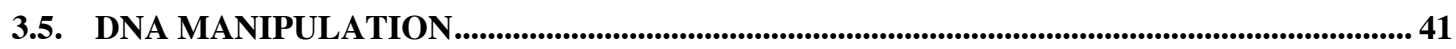

3.5.1. ISOLATION OF PLASMID DNA FROM E.COLI (STET PREP) .............................................. 41

3.5.2. QIAGEN SPIN-PLASMID DNA MINI-PREPARATION .................................................. 41

3.5.3. POLYMERASE CHAIN REACTION (PCR) ............................................................................. 41

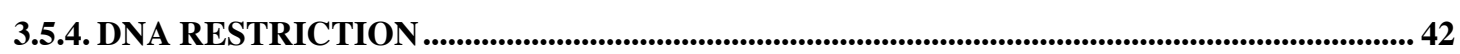

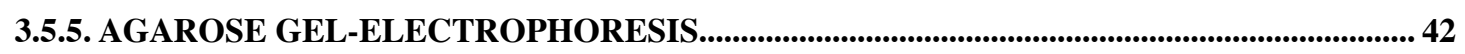

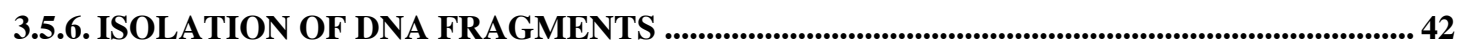

3.5.7. LIGATION OF DNA FRAGMENTS ................................................................................................. 42

3.5.8. QUICK DNA PREPARATION FROM YEAST F..................................................................... 43

3.5.9. SILVER STAINING OF PROTEIN GELS .............................................................................. 43

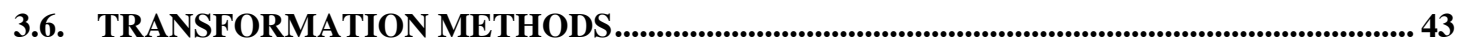

3.6.1. PREPARATION OF COMPETENT E.COLI ...........................................................................43

3.6.2. TRANSFORMATION OF E.COLI ..................................................................................................... 44

3.6.3. ONE-STEP TRANSFORMATION OF SACCHAROMYCES CEREVISIAE ........................... 44

3.6.4. TRANSFORMATION OF LINEARIZED DNA FRAGMENTS FOR INTEGRATION IN SACCHAROMYCES CEREVISIAE .............................................................................................. 44

3.7. OTHER SACCHAROMYCES CEREVISIAE METHODS ............................................................... 45

3.7.1. SPORULATION OF SACCHAROMYCES CEREVISIAE ..................................................... 45 
3.7.2. CROSSING OF YEAST STRAINS AND TETRADE DISSECTION

4. RESULTS

46

4.1. SMT3/SUMO AND UBC9 ARE REQUIRED FOR EFFICIENT SECURIN DEGRADATION IN BUDDING YEAST.

4.1.1. YEAST CELLS DEPLETED OF UBC9 AND SMT3 ARREST WITH SHORT SPINDLES AND HIGH LEVELS OF PDS1. 46

4.1.2. PDS1 DELETION ALLEVIATES ANAPHASE ONSET IN UBC9-DEPLETED CELLS.... 48 4.1.3.UBC9-2 TS-MUTANTS ARE DELAYED IN DEGRADATION OF SECURIN PDS1 AND CYCLIN CLB2 DURING MITOSIS. 49

4.1.4. PROTEOLYSIS OF SECURIN PDS1 DEPENDS ON UBC9 AND SMT3. 52 4.1.5. OTHER UNSTABLE PROTEINS ARE NORMALLY DEGRADED IN UBC9-2 AND SMT3-331 MUTANT STRAINS. 55

4.1.6. APC/C AND PDS1 ARE LOCALIZED TO THE NUCLEUS IN UBC9-2 AND SMT3-331 MUTANT STRAINS. 56

4.2. TWO DIFFERENT MECHANISMS OF CYCLIN CLB5 PROTEOLYSIS. .58 4.2.1. APC/C - INDEPENDENT CLB5 DEGRADATION 59

4.2.2.SCF/CDC34 DO NOT CONTRIBUTE TO APC/C INDEPENDENT CLB5 DEGRADATION 60

4.2.3. APC/C AND SCF/CDC34 UNCOUPLED CLB5 DEGRADATION DOES NOT DEPEND ON A FUNCTIONAL DESTRUCTION BOX. 63 4.2.4. APC/C-MEDIATED DEGRADATION OF CLB5 IS ESSENTIAL, WHEN CLB5 EXPRESSION IS ELEVATED.

4.2.5. ABNORMAL CLB5 EXPRESSION RENDERS APC/C ESSENTIAL FOR $\alpha$-FACTOR INDUCED G1 ARREST

4.3. ANALYSIS OF IME2, A MEIOSIS-SPECIFIC APC/C REGULATOR. 68

4.3.1. OVEREXPRESSION OF TRUNCATED IME2 $\triangle \mathrm{C}$ CAUSES ARREST IN MITOSIS ........... 70 4.3.2. TRUNCATED IME2AC TRIGGERS PHOSPHORYLATION OF CDH1 AND

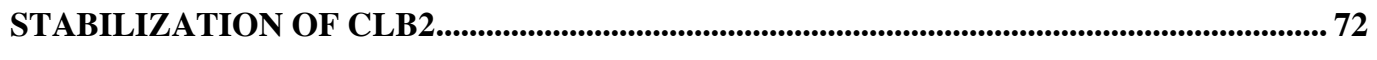

4.3.3. TRUNCATED IME2AC IS STABLE THROUGHOUT MEIOSIS............................................... 74

4.3.4. C-TERMINAL TRUNCATION OF IME2 CAUSES AN ARREST IN MEIOSIS II............... 76

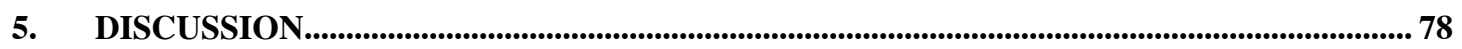

1.5 SMT3/SUMO AND UBC9 ARE REQUIRED FOR EFFICIENT SECURIN DEGRADATION IN BUDDING YEAST ............................................................................................... 78 
5.1.1. A ROLE FOR SUMO IN THE ONSET OF ANAPHASE AND IN CHROMOSOME SEGREGATION

5.1.2. A ROLE FOR SUMO IN APC/C-MEDIATED PROTEOLYSIS................................................ 79

5.2. TWO DIFFERENT MECHANISMS OF CYCLIN CLB5 PROTEOLYSIS 82

5.2.1. APC/C INDEPENDENT CLB5 DEGRADATION SUFFICES UNDER PHYSIOLOGICAL CONDITIONS TO INITIATE EXIT FROM MITOSIS .................................................................. 82

5.2.2. WHAT MIGHT TRIGGER APC/C-INDEPENDENT CLB5 PROTEOLYSIS? ......................... 83

5.2.3. APC/C-MEDIATED CLB5 DEGRADATION BECOMES ESSENTIAL WHEN CLB5 LEVELS ARE ELEVATED 84

5.3. MEIOTIC APC/C REGULATION BY IME2 ............................................................................... 85

5.3.1. TRUNCATION OF 241 C-TERMINAL AMINO ACIDS DOES NOT AFFECT IME2'S KINASE ACTIVITY

5.3.2. STABLE IME2 $\triangle$ C INTERFERES WITH MEIOSIS II. 86

6. OUTLOOK AND SUPPLEMENT............................................................................................................. 89

6.1. CONTINUING THE CHARACTERIZATION OF SUMOYLATION ...................................... 89

6.1.1.STRATEGIES FOR IDENTIFICATION OF YEAST SUMO-TARGETS BY MASS SPECTROMETRY

6.1.2. INITIAL CHARACTERIZATION OF UBCI, AN A.NIDULANS ORTHOLOGUE OF UBC9

6.1.3. FUNCTIONALITY OF THE A.NIDULANS UBCI GENE IN SACCHAROMYCES CEREVISIAE .94

6.1.4. ANALYSIS OF UBCI EXPRESSION IN A.NIDULANS .94 6.1.5. CONSTRUCTION OF A UBCI DELETION CASSETTE ................................................................ 95

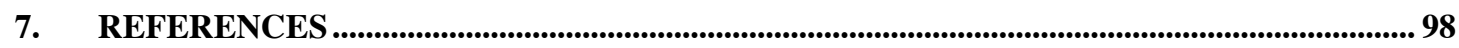

DANKSAGUNG 107

CURRICULUM VITAE 108 


\section{Summary}

The anaphase-promoting complex or cyclosome (APC/C) is a large ubiquitin ligase essential for the mitotic and meiotic cell cycle. It ligates chains of ubiquitin to its target proteins marking them for proteolysis by the $26 \mathrm{~S}$ proteasome. APC/C activity and thereby stagespecific proteolysis are precisely regulated during the cell cycle to maintain the chronology of key events. This work characterized some of the mechanisms involved in APC/C regulation.

In the first part, the requirement of post-translational modification with the small ubiquitinlike modifier SUMO on efficient APC/C-mediated protein degradation was tested. The anaphase inhibitor protein, Pds1, was found to be stabilized in cells defective for SUMOylation and due to this altered degradation, cells displayed defects in chromosome segregation. Furthermore also proteolysis of other APC/C target proteins, such as the mitotic cyclins $\mathrm{Clb} 2, \mathrm{Clb} 3$ and the polo-like kinase $\mathrm{Cdc} 5$, was delayed whereas degradation of unstable proteins that are not APC/C targets was unaffected. SUMOylation does not seem to be required for proteolysis in general but specifically for APC/C-mediated degradation.

In the second part, cyclin $\mathrm{Clb5}$ degradation and its importance for the exit from mitosis was analyzed. Clb5, which was previously identified as a target of the $\mathrm{APC} / \mathrm{C}$, was found to be degraded by a second, alternative mechanism independently of APC/C. It could be shown that the SCF ubiquitin-ligase is not involved in this process. Indeed, Clb5 is unstable even in mutant cells defective in both ubiquitin ligases, APC/C and SCF. The APC/C-independent mechanism remains to be identified, but under physiological conditions, this mechanism is obviously sufficient for Clb5 degradation in the cell cycle. Only under abnormal conditions, such as CLB5 overexpression, APC/C becomes essential for Clb5 degradation.

In the third part of this work the regulation of the $\mathrm{APC} / \mathrm{C}$ in meiosis by the meiosis-specific kinase Ime2 was investigated. Ime2, a negative APC/C regulator, is a highly unstable protein, and thus proteolysis could bear a regulatory mechanism. To investigate this, a truncated Ime 2 protein was analyzed with regard to its functionality to induce a mitotic cell cycle arrest and to phosphorylate Cdh1. We showed that this truncated Ime $2 \Delta \mathrm{C}$, lacking 241 amino acids at its C-terminus, is despite the truncation highly active and stable throughout meiosis. Furthermore, we found that homozygous strains for the truncated IME2 allele display a severe defect in meiosis II. These results indicate that either high Ime2 levels or loss of an unknown function causes the defect in meiosis II. 


\section{Zusammenfassung}

Der "Anaphase-promoting complex", auch "Cyclosom" oder APC/C genannt, ist eine große Ubiquitin-Ligase, die sowohl im meiotischen als auch im mitotischen Zellzyklus benötigt wird. Ihre Aufgabe ist das Anbringen von Ketten des Proteins Ubiquitin, welches die Proteolyse am 26SProteasom auslöst. Die APC/C-Aktivität und dadurch auch die Zellzyklus-abhängige Proteolyse muss präzise reguliert werden, um die Abfolge von Schlüssel-Ereignissen zu gewährleisten. Das Ziel dieser Arbeit war es, einige der Regulations-Mechanismen näher zu charakterisieren.

Im ersten Teil dieser Arbeit wurde analysiert, inwiefern eine funktionelle post-translationelle Markierung mit dem kleinen, ubiquitin-ähnlichen Marker-Protein SUMO für die APC/C-abhängige Proteolyse notwendig ist. Es konnte gezeigt werden, dass das Anaphase-Inhibitor-Protein Pds1 in Zellen mit defekter SUMOylierung stabilisiert wird und diese Stabilisierung zu einer fehlerhaften Chromosomentrennung führt. Zudem stellte sich heraus, dass weitere Substrate des APC/C, wie die Cycline Clb2, Clb3 und die Kinase Cdc5, in SUMO-Mutanten nur mangelhaft abgebaut werden. Im Gegensatz dazu ist der Abbau instabiler Proteine, die nicht Substrate des APC/C sind, von einer defekten SUMOylierung unbeeinflusst. Daraus wurde geschlossen, dass eine intakte SUMOylierung eine notwendige Vorraussetzung, speziell für den APC/C-abhängigen ProteinAbbau ist.

Im zweiten Teil wurden zwei verschiedene Abbauwege für das Cyclin Clb5 und deren Auswirkungen für den Abschluss der Mitose analysiert. Die Ergebnisse zeigen, dass Clb5, welches bereits als APC/C Substrat bekannt war, ebenfalls Ziel eines zweiten, APC/C-unabhängigen Abbauweges ist. Welcher Natur dieser alternative Abbauweg ist, bleibt unklar. Jedoch scheint die Ubiquitin-Ligase SCF nicht beteiligt zu sein, da Clb5 auch in SCF- und APC/C-Doppelmutanten instabil ist. Unter physiologischen Bedingungen ist der APC/C-unabhängige Abbaumechanismus ausreichend, um einen Clb5-Abbau zu gewährleisten. Nur unter künstlichen Bedingungen, wie z.B. einer Überexpression von CLB5, benötigt die Zelle den Abbauweg über den APC/C.

Im dritten Teil wird schließlich die APC/C-Regulation durch die Meiose-spezifische Kinase Ime2 untersucht. Ime2, ein negativer Regulator des APC/C, ist ein sehr instabiles Protein, dessen Proteolyse einen möglichen Regulations-Weg beinhalten könnte. Um das zu untersuchen, wurde eine verkürzte und dadurch stabilisierte Version von Ime2 in Bezug auf ihre Funktionalität untersucht. Es konnte gezeigt werden, dass das um 241 Aminosäuren verkürzte Ime2-Protein immer noch aktiv und durch die gesamte Meiose stabil ist. Zudem zeigen Hefe-Stämme, die für das verkürzte IME2-Allel homozygot sind, eine defekte zweite meiotische Teilung. Dieser Phänotyp ist entweder durch einen erhöhten Ime2-Gehalt oder durch den Verlust einer unbekannten Funktion, die durch die deletierten 241 Aminosäuren codiert wird, zu erklären. 
List of Abbreviations:

$\lambda$

${ }^{\circ} \mathrm{C}$

$\mathrm{Amp}^{\mathrm{R}}$

APC

approx.

bp

C

Cdk

cDNA

$\mathrm{Clb}$

Cln

C-terminus

$\Delta$

DAPI

$\mathrm{db}$

DMSO

DNA

DTT

ECL

EDTA

et al.

Fig.

For

G1-, G2-phase

Gal

GAL

$\mathrm{h}$

HA

Ime $2 \Delta \mathrm{C}$

K

$\mathrm{kd}$

LB-medium

M wavelength

Degree Celsius

Ampicillin resistance

Anaphase-promoting complex

Approximately

Base pairs

Cytosine

Cyclin-dependant kinase

Copy DNA

B-type cyclin

G1 cyclin

Carboxy terminus

Deletion

4'-6'-Diamidino-2' phenylindol

destruction box

Dimethylsulfoxide

deoxyribonucleic acid

Dithiothreitol

Enhanced Chemiluminiscence System

Ethylendiaminotetraacetate

and others

Figure

Forward

Gap-phase 1, Gap-phase 2

Galactose

$G A L$-promoter

Hour

Hemag-glutinin

Ime 2 truncated by the c-terminal 241 amino acids

Lysine

Kilo Dalton

Luria-Bertani-medium

Molar 


\begin{tabular}{|c|c|}
\hline$M A T$ & MAT locus, determining the mating type \\
\hline $\min$ & Minute \\
\hline mRNA & Messenger RNA \\
\hline $\mathrm{n}$ & Set of chromosome \\
\hline N-terminus & Amino-Terminus \\
\hline OD & Optical density \\
\hline ORF & Open reading frame \\
\hline PBS & Protein Block Solution \\
\hline PCR & Polymerase chain reaction \\
\hline PEG & Polyethylene glycol \\
\hline PEST & $\begin{array}{l}\text { Amino acid sequence enriched by proline, } \\
\text { glutamate, serin, threonin }\end{array}$ \\
\hline PMSF & Phenylmethylsulfonylefluoride \\
\hline Raff & Raffinose \\
\hline RT & Room temperature \\
\hline $\mathrm{SCF}$ & SKP1-Cullin-F-Box-Protein \\
\hline SDS & Sodium dodecyl sulfate \\
\hline S-phase & Synthesis phase \\
\hline SPO-medium & Sporulation medium \\
\hline STET & Sucrose/Triton/EDTA-buffer \\
\hline $\mathrm{Tab}$ & Table \\
\hline TAE-buffer & Tris/Acetate/EDTA-buffer \\
\hline TB & Transformation buffer \\
\hline TEMED & $\mathrm{N}^{\prime}, \mathrm{N}^{\prime}, \mathrm{N}^{\prime}, \mathrm{N}^{\prime},-$-Tetramethylethylenediamin \\
\hline \multirow[t]{2}{*}{ TLCK } & N- $\alpha$-p-Tosyl-L-Phenyalanine- \\
\hline & Chlorinemethyleketone \\
\hline TPCK & N- $\alpha$-p-Tosyl-L-Lysin-Chlorinemethyleketone \\
\hline Tris & Tris(hydroxymethyle)aminomethane \\
\hline Tween & Polyoxyethylenesorbitanmonolaureat \\
\hline YP & Yeast extract/peptone \\
\hline
\end{tabular}




\section{Introduction}

\subsection{The Eukaryotic Life Cycle}

The life cycle of a eukaryotic cell includes the major sexual stages, especially in regard to its ploidy. The asexual cell cycle consists of repeated mitotic cell divisions and a growth phase. Mitosis is the process of a living cell (called a mother cell) dividing into a mother and a daughter cell. This leads to growth in multicellular organisms or to vegetative reproduction in unicellular organisms. Mitosis is the most common form among cell divisions.

Sexual reproduction requires the formation of haploid germ cells, which are generated in meiosis. Meiosis is a biological cell division process in eukaryotes by which a diploid parent cell produces four haploid daughter cells. It consists of two cycles of nuclear division, usually accompanied by cell division, preceded by DNA replication.

\subsubsection{Life Cycle of Saccharomyces cerevisiae}

The life cycle of the ascomycete Saccharomyces cerevisiae is a consists either of sexual or asexual reproduction. Thus, the fungus can reproduce asexually by budding as either a haploid or diploid cell. Haploid cells exist in two mating types, "a" and " $\alpha$ " which can mate to form a diploid cell. The two genders secrete mating factors, which are sensed by the opposite mating type. This chemical signaling induces a cell cycle arrest in G1-phase and the induction of genes, which code for proteins involved in the process of mating.

Saccharomyces cerevisiae is able to accommodate to different nutritional conditions: Nitrogen starvation combined with the presence of a non-fermentable carbon source (e.g. acetate) induces sporulation in diploid cells. Under these conditions, diploid cells generate asci with four haploid spores, two $\alpha$ and two a. These spores are able to germinate under sufficient nutrient conditions forming haploid-budding cells, which can mate with each other to restore the diploid state (Stuart 1994).

Lack of nitrogen combined with a sufficient amount of a fermentable carbon source (e.g. glucose) triggers pseudohyphal growth in diploid S. cerevisiae cells (Gimeno et al. 1992). This growth phenotype is characterized by an elongated cell form, and an elongated budding period leading to symmetric cell division, no G1-delay and 
synchronous re-entry into the budding cycle. To create filament-like pseudohyphae, these nutrient-stressed cells do not separate from each other and adhere to the surface (Kron 1997). Haploid cells undergo invasive growth under nitrogen starvation in combination with a fermentable carbon source. These cells are also elongated and not completely separated. But in contrast to pseudohyphally growing diploid cells, the budding pattern is bipolar.

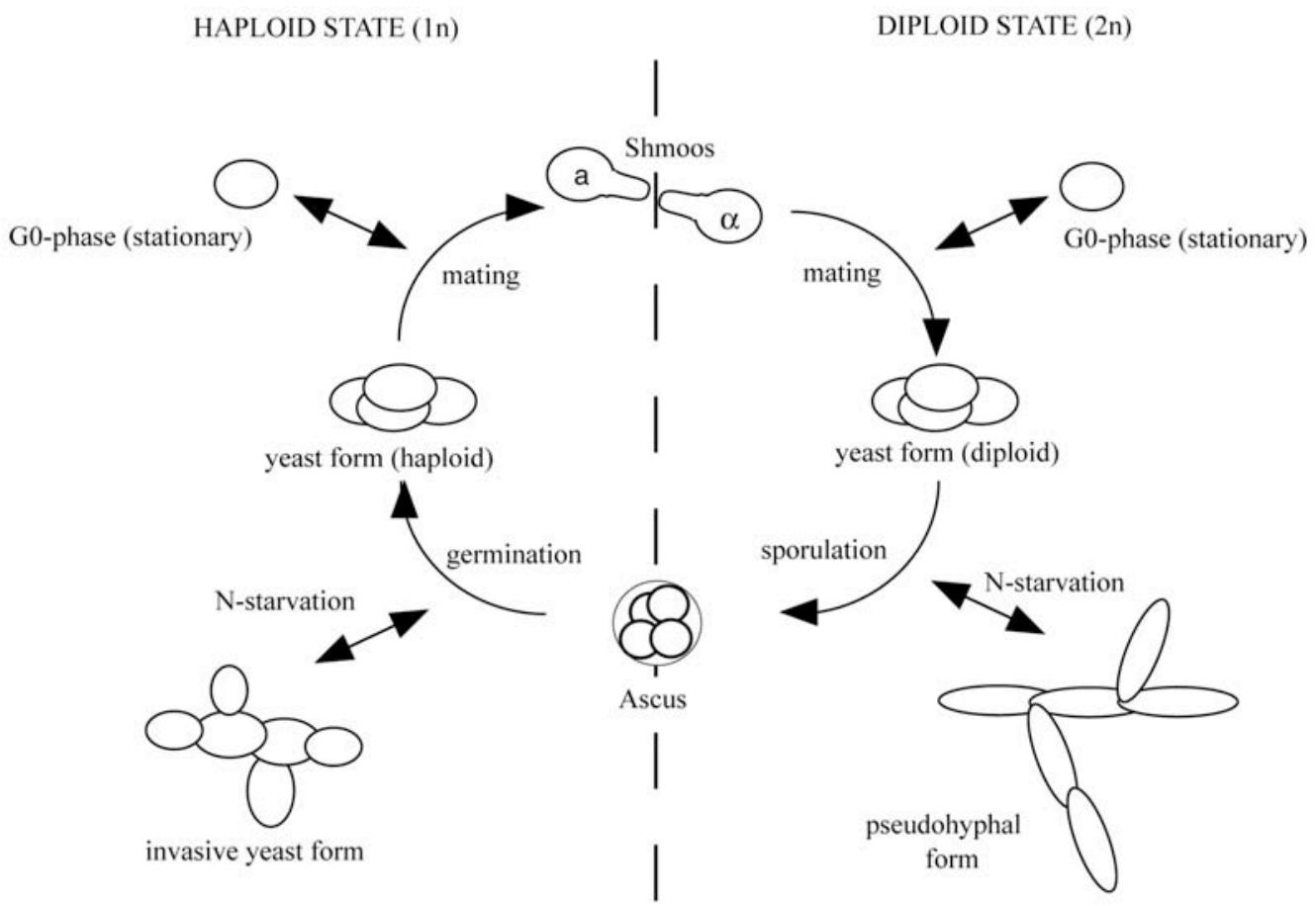

Figure 1: Life Cycle of Saccharomyces cerevisiae

Saccharomyces cerevisiae is able to reproduce as a diploid or haploid cell. Depending on the nutrientconditions the ascomycete responds with different growth patterns. Nitrogen starvation combined with a non-fermentable carbon source triggers sporulation. Insufficient nitrogen in presence of a fermentable carbon source induces invasive or pseudohyphal growth in haploid or diploid cells, respectively. 


\subsection{Post-Translational Modification of proteins with small peptides}

As already mentioned, S.cerevisiae is able to react to different environmental conditions like starvation of nutrients. The adaptive events require a reconstruction of the cellular structure and the relevant processes. For this purpose, numerous proteins have to be altered in their function or to be degraded. The cell achieves this change by different post-translational marking systems: Beside "classical" marks like phosphorylation, acetylation or methylation, a number of different tags consists of small proteins.

\subsubsection{Ubiquitination}

Best understood is protein modification with the 76 amino acid peptide ubiquitin, which triggers degradation at the $26 \mathrm{~S}$ proteasome. The ligation, is carried out by covalent attachment of the ubiquitin $\mathrm{C}$-terminus to a lysine residue of the target protein. This reaction tightly regulated and highly conserved (for review see (Ciechanover and Schwartz 1998; DeSalle and Pagano 2001).

Usually only poly-ubiquitin chains, catenated via lysine 48, trigger the degradation of undesired proteins by the 26S proteasome (see review (Kornitzer and Ciechanover 2000)), which is a large complex of evolutionarily highly conserved proteases. Attachment of ubiquitin to the target protein requires a series of transfer reactions (Figure 2) (Glickman and Ciechanover 2002). Ubiquitin is activated with the consumption of ATP by forming a thioester bond with an E1-activating enzyme. Subsequent transesterification reaction connects ubiquitin to the E2-conjugating enzyme, which finally interacts with the E3-ligating enzyme. This complex brings the ubiquitin molecule and the target protein into close proximity, thereby completing the tagging cascade by forming the isopeptide bond between the two polypeptides. 


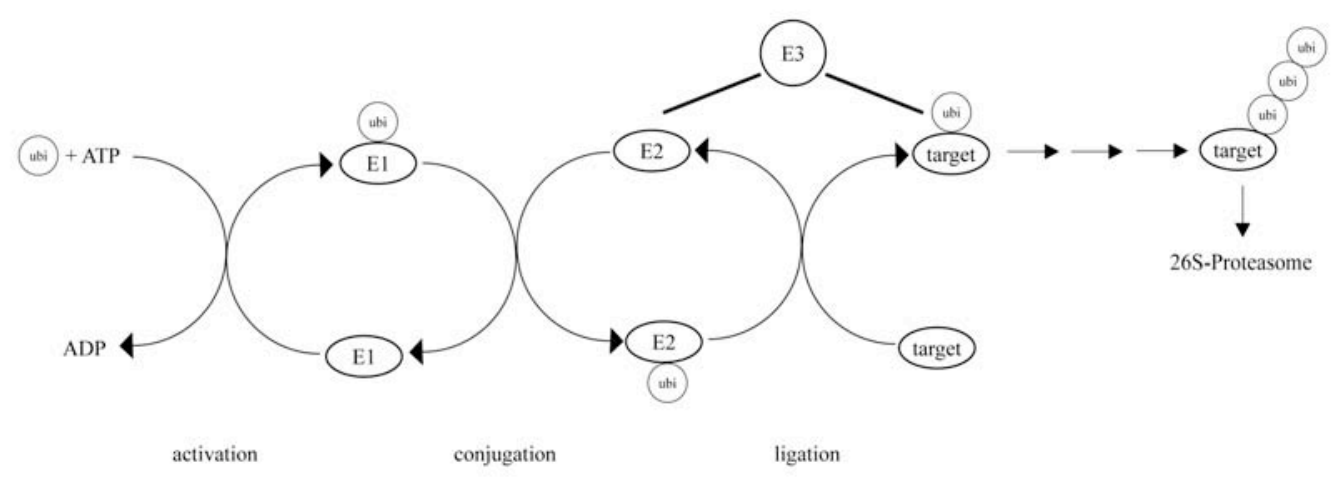

Figure 2: The Ubiquitination Machinery

Ubiquitin is activated under ATP consumption by forming a thioester bond with the E1-activating enzyme. An adjacent transesterification reaction connects ubiquitin to the E2-conjugating enzyme, which finally interacts with the E3-ligating enzyme. This complex brings the ubiquitin molecule and the target protein into close proximity, thereby completing the tagging cascade by forming the isopeptide bond between the two polypeptides.

As controlled proteolysis is crucial for cell cycle progression, especially the last factor of the tagging cascade, the E3-ligating enzyme, is tightly regulated.

Two E3-ligases are essential for triggering mitotic protein degradation by

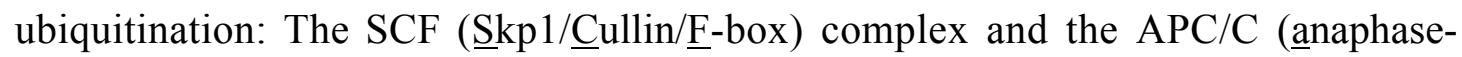
promoting complex) or cyclosome (see review (Peters 2002)).

S-phase proteolysis is mediated by the SCF complex, which marks the Cyclin/Cdc28 inhibitor Sic1 for destruction as well as G1-cyclins. Thus, its primary role is to control G1/S transition. In contrast to the strictly cell cycle regulated APC/C, the SCF is active throughout the cell cycle and has targets involved in cellular processes other than cell cycle, like the transcriptional activator of amino acid biosynthesis Gen4 (Irniger and Braus 2003). SCF target recognition depends on phosphorylation of the substrate (Feldman et al. 1997). Both E3-ubiquitin ligases, the SCF and the APC/C, share not only the ubiquitination work during the cell cycle (Figure 3), but also two important motifs, the cullin and the RING domains, can be found in both E3-ligase complexes (Zachariae et al. 1998; Ohta et al. 1999). 


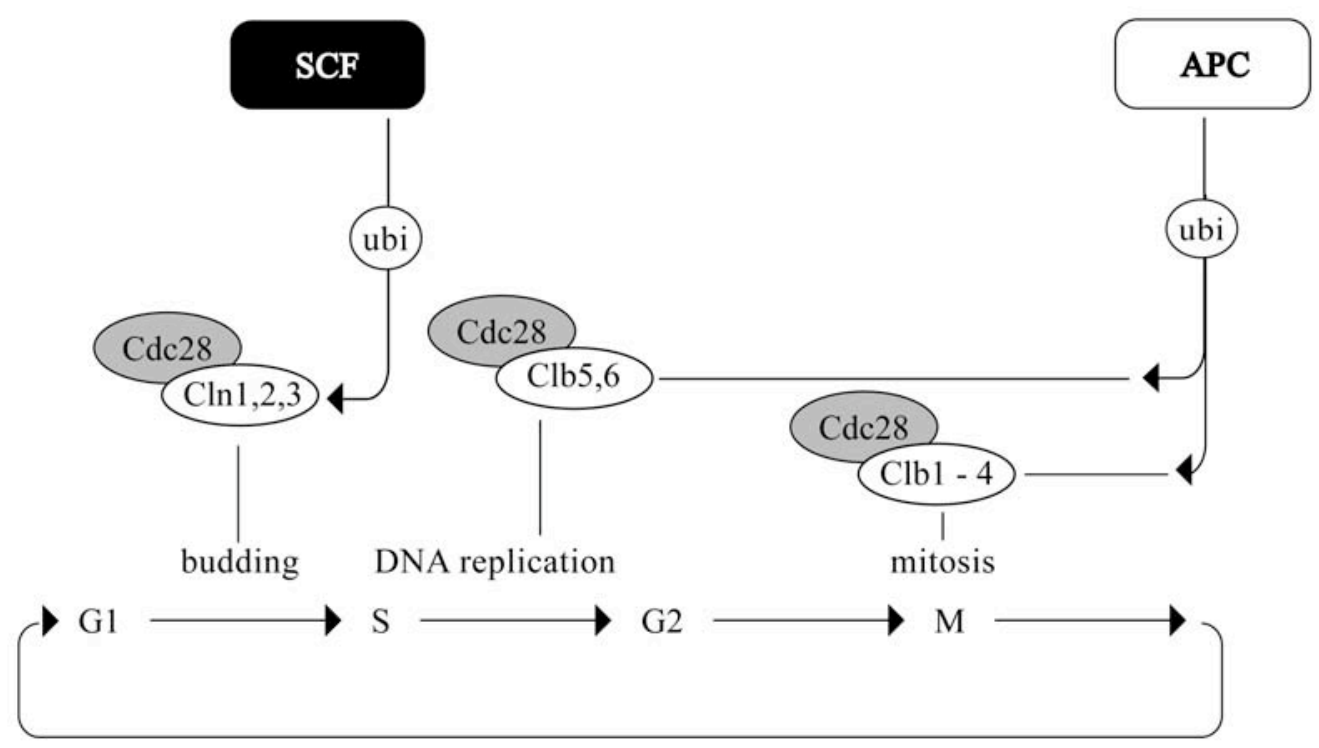

Figure 3: Schematic Presentation of Cyclin Proteolysis During the Cell Cycle

The cell utilizes a tightly regulated and highly conserved mechanism that triggers specific proteolysis by tagging of ubiquitin to the moribund proteins involving two essential E3-ubiquitin ligases: The SCF ( $\underline{S} k p 1 / \underline{C}$ ullin/F-box) complex and the APC/C (anaphase-promoting complex) or cyclosome. Crucial events like budding, DNA replication or mitosis are initiated by proteolysis of short-lived proteins called cyclins.

\subsubsection{SUMOylation}

SUMO is an acronym for small ubiquitin-like modifier and describes an evolutionarily conserved and ancient polypeptide consisting of 101 amino acids, which is posttranslationally attached to its target proteins by a system analogous to but distinct from ubiquitylation. The sequence identity between SUMO and ubiquitin is only $18 \%$, but these proteins share a similar three-dimensional structure (Bayer et al. 1998). 


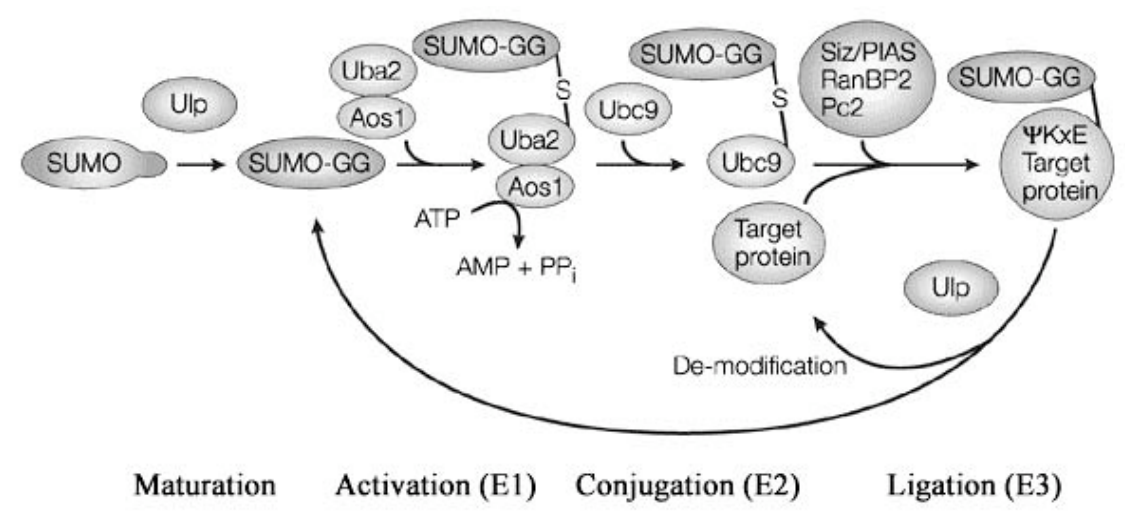

Figure 4: Pathway of SUMOylation (modified from (Seeler and Dejean 2003))

SUMO is translated as an immature protein, which undergoes truncation of the last three amino acids by Ulp1 (Ubiquitin-like protease), so that the C-terminal glycine residue is exposed. With ATP consumption, SUMO is bound to the dimeric activating E1-enzyme Uba2/Aos1 as a thioester. In a transesterification reaction, SUMO is passed over to the conjugating E2-enzyme Ubc9 at its active site Cys 93, from which it is ligated to a lysine residue of the target protein. Recent studies (Johnson and Gupta 2001; Takahashi et al. 2001) (Pichler et al. 2002) revealed the existence of several E3-ligating Siz/PIAS-RING-finger proteins. SUMOylation is a reversible process as SUMO can be cleaved off by isopeptidases, providing an important regulatory mechanism to control both the amount of free mature SUMO protein and the modified substrates.

Budding yeast has a single SUMO gene, known as the essential SMT3 gene, whereas three members of the SUMO family have been identified in vertebrates (for review see (Kim et al. 2002)). The pathway of SUMO conjugation, termed SUMOylation, is similar to ubiquitylation, but requires different enzymes (see Figure 4).

SUMO is first bound to a heterodimeric E1 composed of Aos1 and Uba2. It is then transferred to Ubc9, the only known SUMO-conjugating enzyme, which in turn catalyses the formation of an isopeptide bond between the C-terminus of SUMO and a $\varepsilon$-lysine residue of a target protein. Ubc9 shares structural similarities with ubiquitinconjugating enzymes (Johnson and Blobel 1997) but unlike these E2s, Ubc9 contains a positively charged surface. SUMO is connected to a $\varepsilon$-lysine residue within the $\Psi \mathrm{KXE}$ ( $\Psi$ stands for a large hydrophobic acid) consensus motif of the target protein (Bayer et al. 1998).

By analogy with ubiquitylation, E3 SUMO ligases were recently identified in yeast and mammals (Johnson and Gupta 2001); (Takahashi et al. 2001); (Pichler et al. 2002). None of the known three types of E3-SUMO ligases (Siz/PIAS, RanBP2, Pc2) forms a thioester with its substrate as the E3-ubiquitin ligases do (Jackson 2001). 
Thus, the E3-SUMO-ligating enzymes seem to function as additional platforms that bring the charged E2 to the substrate protein. As all types of SUMO ligases show association with specific components of the cellular structure (e.g. septins), these E3ligases are thought to confer the substrate specificity in their ancestral subcellular compartment (Seeler and Dejean 2003).

The large variety of SUMO ligases seems to allow SUMO's diverse functions as in contrast to ubiquitylation; the modification of proteins with SUMO does not result in their proteolytic degradation. Instead, multiple other effects of SUMOylation have been described, for example the modulation of the subcellular localization of proteins, of protein-protein interactions or of the activity of transcription factors (Lehembre et al. 2001); (Wilson and Rangasamy 2001b).

Table 1: Selected Targets for SUMO

\begin{tabular}{|c|c|c|}
\hline Process & Modif.Protein & Function of SUMOylation \\
\hline \multirow[t]{3}{*}{ Protein Targeting } & RanGAP1 & $\begin{array}{l}\text { Translocation of RanGAP1 to nuclear pore complex } \\
\text { (Matunis et al. 1996) or mitotic spindles/kinetochores } \\
\text { (Joseph et al. 2002) }\end{array}$ \\
\hline & E1B & $\begin{array}{l}\text { Enable nucleocytoplasmic transport (Endter et al. } \\
\text { 2001) }\end{array}$ \\
\hline & Mek1 & Enable nuclear export (Sobko et al. 2002) \\
\hline \multirow[t]{4}{*}{ Transcription } & GRIP1 & $\begin{array}{l}\text { Enhance transcriptional co-activation (Kotaja et al. } \\
\text { 2002) }\end{array}$ \\
\hline & Myb, IRF etc. & $\begin{array}{l}\text { Represses transcriptional activity (Bies et al. 2002; } \\
\text { Nakagawa and Yokosawa 2002) }\end{array}$ \\
\hline & p53 & $\begin{array}{l}\text { Enhances transcriptional activation (Megidish et al. } \\
\text { 2002) }\end{array}$ \\
\hline & IB & $\begin{array}{l}\text { Antagonizes SUMOylation prevents degradation } \\
\text { (Hay et al. 1999) }\end{array}$ \\
\hline \multirow[t]{3}{*}{ Genomic integrity } & PCNA & Regulates DNA repair (Hoege et al. 2002) \\
\hline & WRN & Unknown (Enomoto 2001) \\
\hline & TopI & Unknown (Mao et al. 2000a; Mao et al. 2000b) \\
\hline Chromatid segregation & TopII & $\begin{array}{l}\text { Prevents premature chromatid separation (Bachant et } \\
\text { al. 2002) }\end{array}$ \\
\hline
\end{tabular}

Table 1 shows a selection of various proteins in which SUMO influences the conformational structure, antagonizes ubiquitylation or affects the stability of large complexes. Intensively studied SUMO substrates are, for example, mammalian RanGAP1, a factor required for nucleocytoplasmic transport, and the tumor suppressor p53 (Gostissa et al. 1999). SUMO targets RanGAP1 to nuclear pores and stimulates the transcriptional and apoptotic activities of p53 (Rodriguez et al. 1999). Previous studies have also revealed a functional link between SUMOylation and 
ubiquitylation. In the case of IB, an inhibitor of the NF- $\kappa b$ transcription factor, SUMOylation was shown to antagonize ubiquitylation, thus preventing the degradation of the protein by the ubiquitin pathway (Hay et al. 1999).

SUMO's only conjugating enzyme $U B C 9$ was first described when Seufert and coworkers investigated mutants defective in the degradation of B-type cyclins caused by a temperature-sensitive mutation in the $U B C 9$ gene (Seufert et al. 1995). Due to structure homology and its assumed function in protein degradation, they baptized the

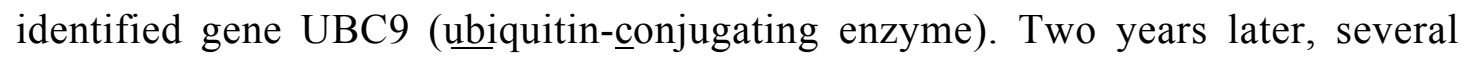
reports (Johnson and Blobel 1997) (Desterro et al. 1997) (Schwarz et al. 1998) clarified that Ubc9 exclusively connects SUMO and not ubiquitin to its target proteins. But a link between SUMOylation and ubiquitin-mediated proteolysis remained in the stabilization of cyclins.

The structure of Ubc9 shows important differences compared with the structures of known ubiquitin-conjugating enzymes (Giraud et al. 1998). At the N-terminal helix, the structural and sequence alignments identify one amino acid giving Ubc9 a different recognition surface compared to ubiquitin-conjugating enzymes. This is accompanied by a profound change in the electrostatic surface of the molecular interface. A high-resolution co-crystal structure of Ubc9 bound to its substrate RanGAP1 gave insights in how Ubc9 recruits its target proteins (Hochstrasser 2002) and passes the cysteine-bound SUMO on. Ubc9 binds directly to the $\Psi \mathrm{KXE}$-motif of its target, bringing it in close proximity to the Ubc9 active site where the cysteinebound SUMO is located. Because SUMO is bound as an activated thioester with an electrophilic carbon center, the presence of a weakly nucleophile substrate $\varepsilon$-amino group is sufficient to form the peptide bond.

Up to now, several reports have implicated important functions for SUMO during Mphase of the cell cycle. Yeast cells depleted of $U B C 9$ were impaired in mitosis, and temperature-sensitive smt3 mutants, defective in the yeast SUMO gene, were identified in a screen for mutants defective in chromosome segregation (Biggins et al. 2001). Schizosaccharomyces pombe cells lacking the SUMO gene pmt3 and the $U B C 9$ homologue hus 5 strains also displayed defects in chromosome segregation (alKhodairy et al. 1995; Tanaka et al. 1999). 


\subsubsection{Other post-translational modifiers}

In the recent years, several posttranslational modifiers similar to ubiquitin were found such as Rub1/Nedd8, Isg15, Aut7 and Apg12 (for review see (Schwartz and Hochstrasser 2003)). Among these modifiers, especially protein modification with Nedd8 is well understood. RUB1, an acronym for Protein Related to Ubiquitin, is the Nedd8 homologue in yeast and encodes for an 81 amino acid peptide, which is $60 \%$ identical to ubiquitin. It is structurally more closely related to ubiquitin as SUMO. Furthermore, $C D C 53 /$ cullin, a common subunit of the multifunctional SCF ubiquitin ligase, is a major substrate for Rub1 conjugation. This indicates that the Rub1conjugation pathway is functionally tied to the ubiquitin/proteasome system and may play a regulatory role. Conjugation of RUB1 is not essential for normal cell growth and appears to be selective for a small set of substrates (Liakopoulos et al. 1998). 


\subsection{Mitosis}

The eukaryotic cell cycle normally involves a series of stages: G1 (Gap1-phase), the first growth phase; S (DNA synthesis-phase), when the genetic material is duplicated; G2 (Gap2-phase), the second growth phase; and M (mitotic phase), in which the replicated chromosomes are distributed equally between mother and daughter which are as a result genetically identical (Stuart 1994; Hagan et al. 2001).

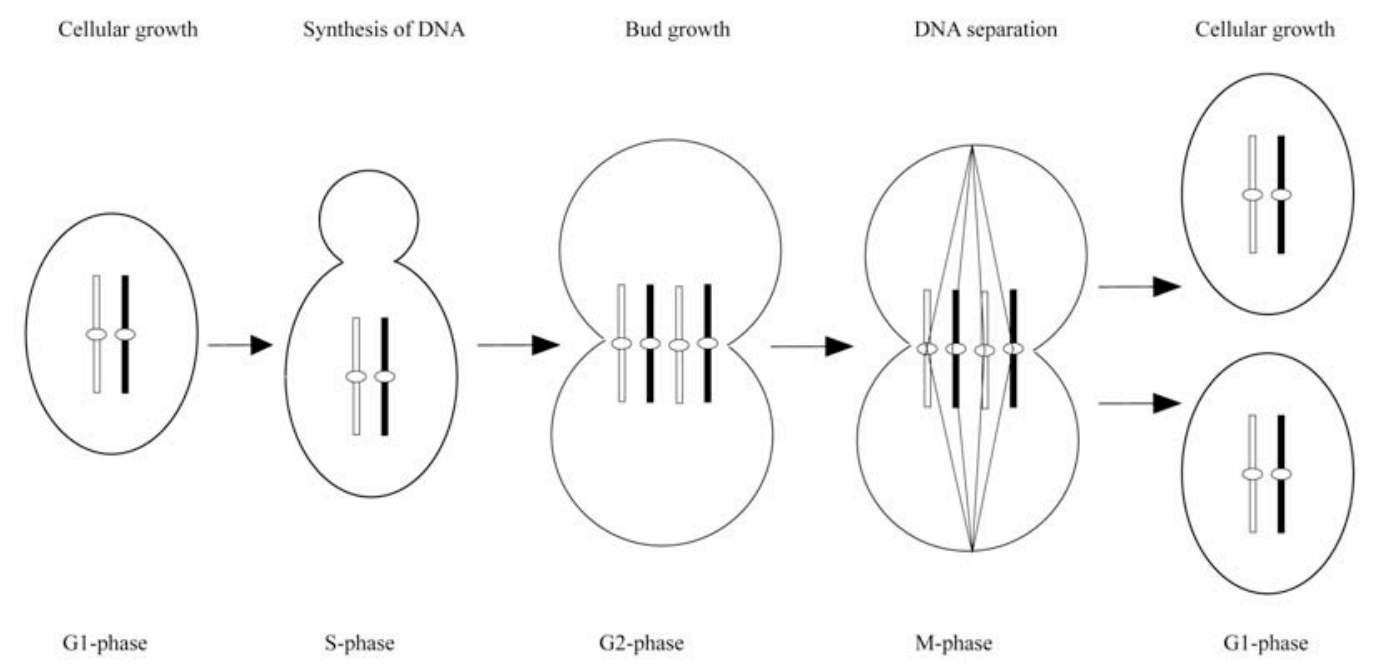

Figure 5: Mitotic Phase of Saccharomyces cerevisiae (Schematic Presentation)

G1 (Gap1-phase), the first growth phase; S (synthesis-phase), where the genetic material is duplicated; G2 (Gap2-phase), the second growth phase; and M (mitotic phase), in which the replicated chromosomes are distributed equally between mother and daughter which are as a result genetically identical.

Mitosis is divided into prophase, prometaphase, metaphase, anaphase, and telophase. During prophase the DNA, which normally exists in the form of chromatin, condenses into a highly ordered chromosome. In metaphase the microtubules find and attach to kinetochores; they begin to line up in the middle of the cell. A proper segregation can begin when every kinetochore is attached to a microtubule and the chromosomes have lined up along the middle of the spindle. Then, the cell proceeds to anaphase, which is divided into two stages. First, the proteins that bind the sister chromatids together are cleaved, allowing them to separate. They are pulled apart by the microtubules towards the respective centrioles. Next, the spindle axis elongates, driving the centrioles and the set of chromosomes to which they are attached apart to the opposite ends of the 
cell. These two stages are called 'early' and 'late' anaphase. The chromosomes finally decondense in telophase when the two cells disperse by separating their nuclei and cytoplasm.

\subsubsection{Molecular Aspects of Mitotic Cell Cycle Control}

The cell cycle hast to be tightly controlled on the molecular level to guarantee its proper progression. One of the major problems is to coordinate the "cell-growthcycle" with the "DNA-division-cycle". The central regulator of the cell cycle is the Cdc28 kinase, whose activity is switched on and off by a family of regulatory proteins called cyclins. Their cell cycle stage specific transcription and degradation modulates Cdc28 kinase activity that oscillates to maintain the proper chronology of cell cycle events.

At the same time the cell has to be able to respond to environmental changes, which influence the cell division (e.g. mating pheromones in G1 or radiation in S-phase). This is managed by a series of checkpoints (Figure 9), which ensure e.g. a sufficient cell size before the DNA replications starts or check the fidelity of DNA replication and chromosome separation before cytokinesis. These checkpoints, first identified in yeast, halt the cell cycle when errors are detected.

\subsubsection{Cdk Activation by Cyclins}

Cyclins were described in 1983 as proteins, which appeared and vanished in synchrony with embryonic cell division in sea urchins (Evans et al. 1983). The existence of cyclins in Saccharomyces cerevisiae was discovered in 1990 and their physical activating interaction with so-called cyclin dependent-kinases was described (Wittenberg et al. 1990). Cyclins are simply defined as proteins binding Cdks, in most cases by a conserved motif called a "cyclin box" (Morgan 1995). The activity and substrate specificity of the highly conserved Cdks varies throughout the cell cycle depending on the bound cyclin.

In Saccharomyces cerevisiae five Cdks are found, whereof $\mathrm{Cdc} 28$ is the most prominent and the best studied. It is regarded as the key regulator of the complex system controlling the coordination and timing of the yeast cell cycle events. As the amount of Cdc28, which usually is present in excess, does not change during the cell 
cycle (Betting and Seufert 1996), the control of its kinase activity is regulated posttranslationally by association with cyclins, stoichiometric inhibitors and accessory factors, as well as by activating and inhibitory phosphorylations (reviewed by (Morgan 1997; Mendenhall and Hodge 1998)).

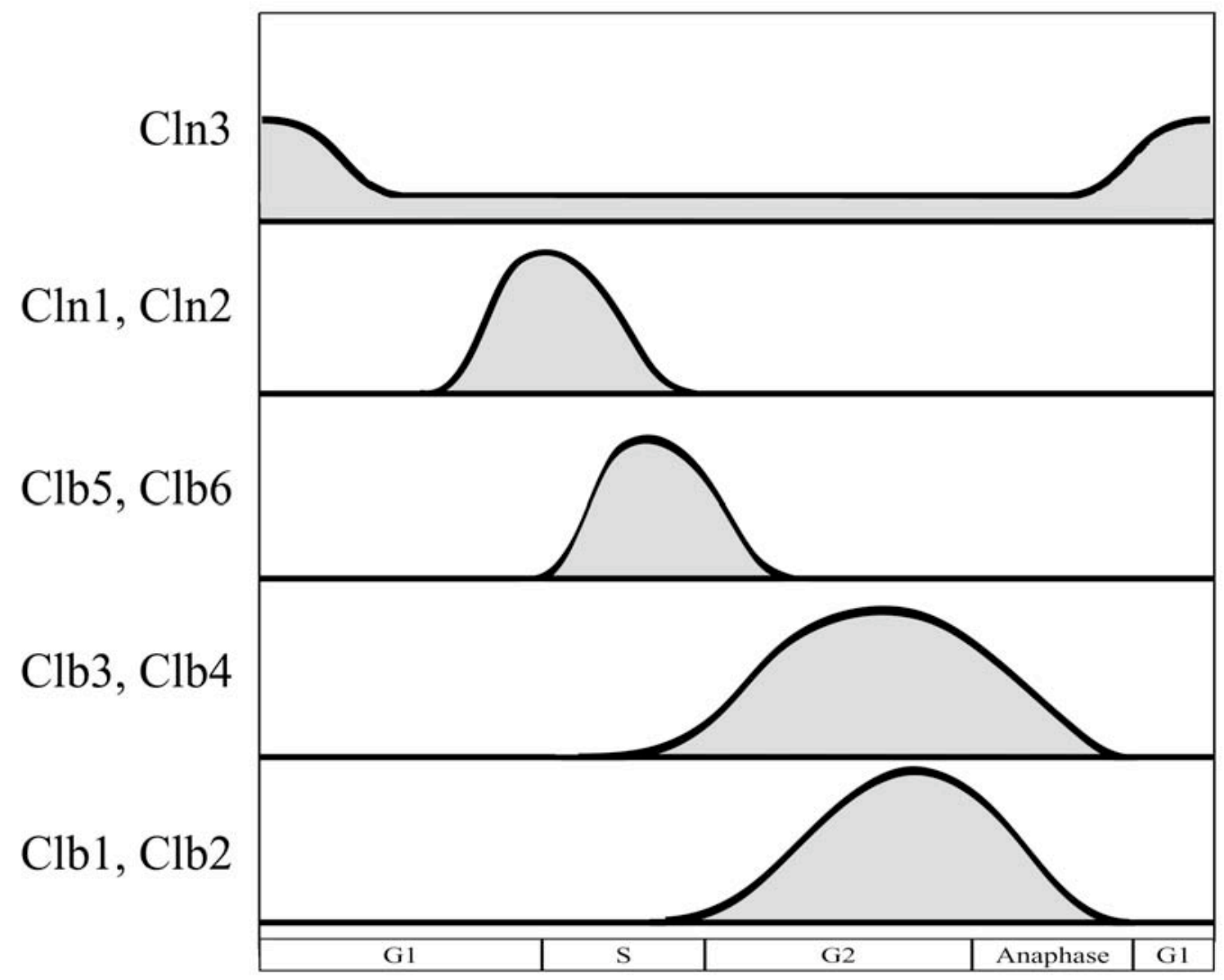

Figure 6: Activity of Cdc28/Cyclin Complexes in the Course of the Cell Cycle

The timing of Cdc28 activation by different cyclins depends on their presence in the cell, which is influenced on the one hand by transcription and on the other by cell cycle stage-specific proteolysis (Morgan 1995).

With the exception of $\mathrm{Cln} 3$, all cyclins are encoded by pairs of closely related genes sharing an overlapping function and a similar timing of their accumulation being the basis of the classification into different subfamilies: Cln 1-3 are referred to as "G1cyclins", Clb5 and Clb6 as "S-phase cyclins" and Clb1 to Clb4 as "mitotic cyclins" (Figure 6). 


\subsubsection{G1 Cyclins: Cln1, Cln2, Cln3}

Triple knockout strains of the G1 cyclins are lethal but each single G1-cyclin is able to restore viability. However, $\mathrm{Cln} 1$ and $\mathrm{Cln} 2$, which share a strong homology and overlapping functions, differ considerably from $\mathrm{Cln} 3$ in periodicity of expression and the associated kinase activity (Cross 1995). Thus it was proposed that the $\mathrm{Cln} 3 / \mathrm{Cdc} 28$ complex triggers transcription of CLN1 and CLN2, which in turn initiate DNA replication, spindle pole body duplication and budding (Tyers et al. 1993). Finally, a high $\mathrm{Cln} / \mathrm{Cdc} 28$ activity heralds the end of G1-phase by phosphorylating the Clbinhibitor Sic1, thereby triggering its degradation (Deshaies and Ferrell 2001). $\mathrm{Cln} / \mathrm{Cdc} 28$ complexes do not only promote S-phase onset by initiating Sic1 degradation, but also promote the transcription of the two S-phase cyclins Clb5 and Clb6 by the Cln3/Cdc28 complex in late G1 (Toone et al. 1997).

\subsubsection{S-phase Cyclins: Clb5, Clb6}

The destruction of Sic1 leads to the formation of active Clb5/Clb6-Cdc28 complexes, which initiate S-phase functions such as bud emergence or the replication of DNA. So the primary role of S-phase cyclins is to initiate the onset of S-phase in a timed fashion (Schwob et al. 1994).

In the absence of Clb5 and Clb6, the mitotic cyclins $\mathrm{Clb} 3$ and $\mathrm{Clb} 4$ are also able to initiate S-phase functions, although with a delayed DNA replication (Schwob and Nasmyth 1993). The destruction of Clb5 was thought to be essential for the exit from mitosis but recent studies disproved this theory (Wasch and Cross 2002).

\subsubsection{Mitotic Cyclins: Clb1, Clb2, Clb3, Clb4}

CLB3 and CLB4 transcripts peak near the beginning of S-phase and remain at a high level until late anaphase, whereas the Clb3-Cdc28 complex provides most of the kinase activity in asynchronous cultures. In contrast, $\mathrm{Clb} 4-\mathrm{Cdc} 28$ is only a minor component (Fitch et al. 1992). Clb3 and Clb4 play a role in spindle formation, an event that can also be accomplished by the "late" mitotic cyclin Clb1 and its more prominent partner $\mathrm{Clb} 2$. Clb3, Clb4 and $\mathrm{Clb} 5$ in association with the Cdc28-kinase suppress the efficiency of $\mathrm{Clb} 2$ proteolysis, thereby allowing its accumulation, which is required for the onset of mitosis (Yeong et al. 2001). Clb2 is the most important B- 
type cyclin as clb2 $2 \Delta$ deletion mutants show the most precise phenotype with an increased cell size and enriched budded G2-phase cells (Epstein and Cross 1992). The Clb2-Cdc28 complex is important for spindle elongation but blocks bud emergence and the transcription of G1-cyclins (Amon et al. 1993). Its deactivation by APC/Cmediated proteolysis is required for the exit from mitosis (1.3.8).

\subsubsection{The Anaphase-Promoting Complex $(A P C / C)$}

As already mentioned, the anaphase-promoting complex is a large E3-ubiquitin ligase consisting of eleven essential subunits: Apc1, Apc2, Apc4, Apc5, Apc9, Apc10, Apc11, Cdc16, Cdc23, Cdc26 and Cdc27. Two additional subunits (Apc13, Mnd2) are only found in an APC/C subpopulation.

An important module of the E3-function is the cullin/RING-H2 module composed of two subunits Apc2 and Apc11. These proteins form the ubiquitin ligase core, which has the ability both to bind E2s and to stimulate the ubiquitination activity (Gmachl et al. 2000).

Table 2: APC/C Subunits: Their Functions and Motifs (modified from (Harper et al. 2002))

\begin{tabular}{|c|c|c|}
\hline $\begin{array}{l}\text { Saccharomyces } \\
\text { ceravisiae }\end{array}$ & Function & Motifs \\
\hline Apc1 & & Rpn1/2 \\
\hline Apc2 & $\begin{array}{l}\text { Scaffold, binds Apc2 } \\
\text { and Ubcs }\end{array}$ & $\begin{array}{l}\text { Cullin homology } \\
\text { domain }\end{array}$ \\
\hline $\mathrm{Cdc} 27$ & & $\begin{array}{l}\text { TPR repeats, Cdk } \\
\text { phospharylation }\end{array}$ \\
\hline \multicolumn{3}{|l|}{ Apc 4} \\
\hline \multicolumn{3}{|l|}{ Apc5 } \\
\hline Cdc16 & & $\begin{array}{l}\text { TPR repeats, Cdk } \\
\text { phosphorylation }\end{array}$ \\
\hline \multicolumn{3}{|l|}{$\mathrm{Cdc} 26$} \\
\hline Cdc23 & & $\begin{array}{l}\text { TPR repeats, Cdk } \\
\text { phosphorylation }\end{array}$ \\
\hline Apc9 & & $\begin{array}{l}\text { Nonessential for } \\
\text { viability but } \\
\text { required for timely } \\
\text { anaphase entry }\end{array}$ \\
\hline Doc1 & & Doc domain \\
\hline Apc11 & Recognition of Ubcs & Ring-H2 finger \\
\hline $\mathrm{Cdc} 20$ & $\begin{array}{l}\text { APC activator/ } \\
\text { specificity factor }\end{array}$ & WD40 repeats \\
\hline Cdh1/Hct1 & $\begin{array}{l}\text { APC activator/ } \\
\text { specificity factor }\end{array}$ & $\begin{array}{l}\text { WD } 40 \text { repeats, Cdk } \\
\text { phosphorylation sites }\end{array}$ \\
\hline \multirow[t]{2}{*}{ Ama1 } & $\begin{array}{l}\text { Meiosis specific APC } \\
\text { activator }\end{array}$ & WD40 repeats \\
\hline & & TPR repeats \\
\hline
\end{tabular}


Most of the functional properties of the other core proteins of this essential complex remain unclear (Table 2). Nevertheless, a low-resolution structure was solved which showed that features of the APC/C are dominated by an outer protein wall, which is tunneled by the reaction chamber (Gieffers et al. 2001).

During the cell cycle the core composition of the APC/C does not change, but different activators are bound to it, thereby determining the substrate specificity of the ubiquitin ligase (for review see (Harper et al. 2002)). In Saccharomyces cerevisiae, three activating proteins have been found: Cdc20, Cdh1 (also Hct1) and Ama1 (Zachariae and Nasmyth 1999).

\subsubsection{Activators of the APC/C: Cdc20, Cdh1 (Hct1) and Ama1}

As the targets of APC/C-mediated proteolysis change with the cell cycle stage, $\mathrm{APC} / \mathrm{C}$ target recognition has to be coordinated with cell cycle progression. This is maintained on multiple levels including association with activator proteins, phosphorylations and influences of different checkpoints, which halt APC/C activity by different mechanisms.

$\mathrm{APC} / \mathrm{C}$ ubiquitination activity and substrate specificity are dependent on three activator proteins, Cdc20 and Cdh1 (Hct1) (for review see (Pfleger et al. 2001)) in mitosis and Amal during meiosis. To allow flexibility in APC/C function, the activator proteins bind directly to the target and recruit it to the ubiquitination machinery (Burton and Solomon 2001). All three known activators bear WD 40 repeats, which consist of repeated sequences of approximately 40 amino acids ending with tryptophan (W) and aspartate (D) (Li and Roberts 2001).

In mitosis $\mathrm{Cdh} 1$ ( $\underline{\mathrm{Cdc} 20}$ homologue) and $\mathrm{Cdc} 20$ bind to the $\mathrm{APC} / \mathrm{C}$ in a sequential manner (Figure 7), thereby targeting a distinct set of proteins for degradation at the 26S proteasome. However, proteins like $\mathrm{Clb} 2$ or the spindle-associated protein Ase1 are recognized by both activators. 


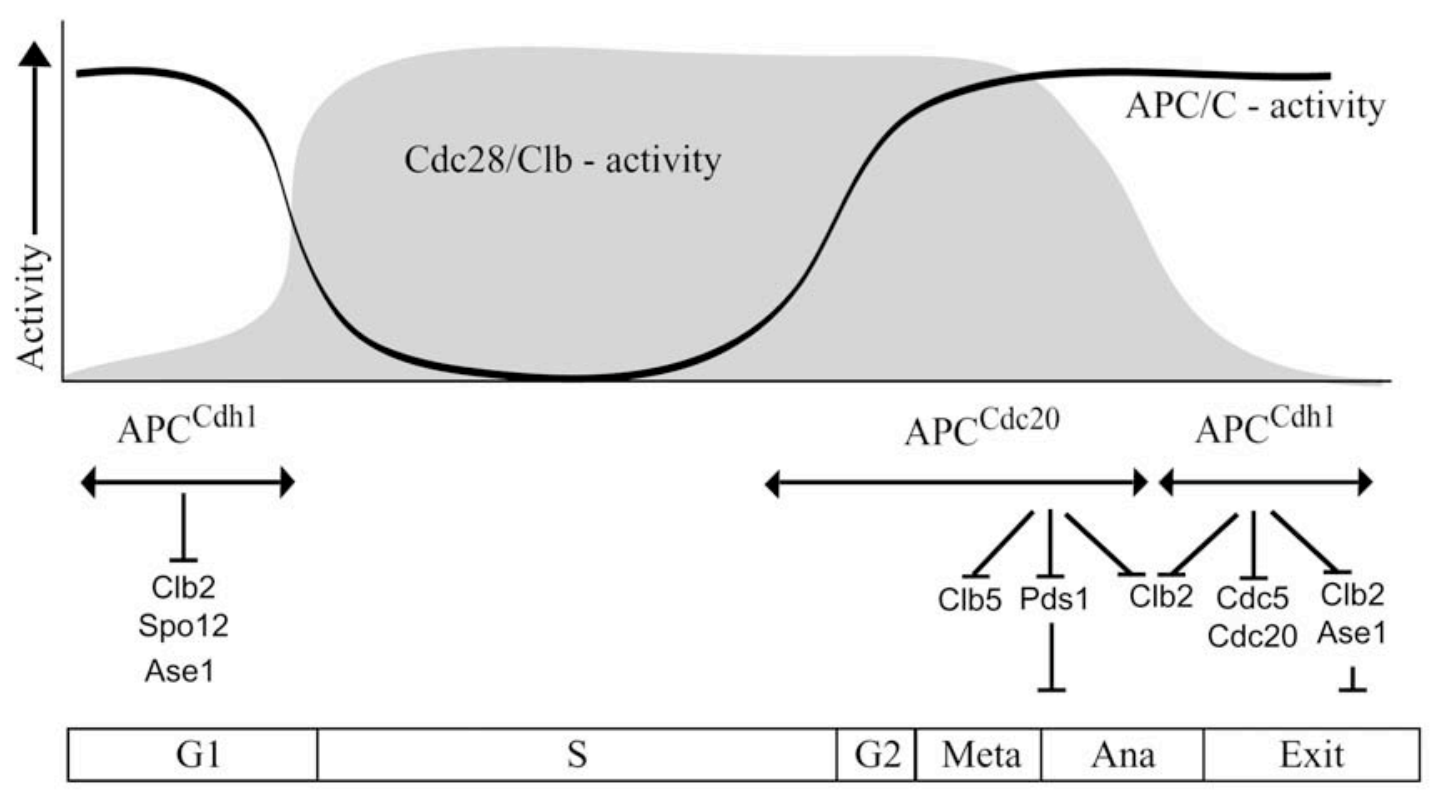

Figure 7: Cell Cycle Stage Dependent APC/C-triggered Proteolysis (modified from (Harper et al. 2002))

Cdh1 and $\mathrm{Cdc} 20$ bind the $\mathrm{APC} / \mathrm{C}$ in sequential manner thereby conferring cell cycle stage dependent target specificity. In S-phase, the $\mathrm{Clb}$ amount rises triggered by G1-cyclins. At the same time $\mathrm{Cdc} 28 / \mathrm{Clb}$ activity elevates to a maximum level until APC/Cdc20 is activated and heralds anaphase by marking Pds1 for destruction. First fraction of $\mathrm{Clb} 2$ is also destroyed leading to a reduced kinase activity, which allows the binding of $\mathrm{Cdh} 1$ to the $\mathrm{APC} / \mathrm{C}$. This complex triggers further $\mathrm{Clb} 2$ destruction leading to the mitotic exit and an again-rising kinase activity, which finally evokes the dissociation and inactivation of the APC/C-Cdh1 complex.

Assembly of $\mathrm{Cdc} 20$ with the APC/C is promoted by a high kinase activity whereas Cdh1 binding is inhibited (Jaspersen et al. 1999). Thus, high kinase activity leads to the binding of only Cdc20 to the APC/C. This complex triggers the destruction of the anaphase inhibitor Pds1, the S-phase cyclin Clb5 and the first fraction of the cyclin Clb2. Reduced cyclin levels in combination with elevated Cdc14 phosphatase activity lower Cdc28/Clb kinase activity and finally evoke the dephosphorylation of $\mathrm{Cdh} 1$, which displaces Cdc20 and triggers destruction of the residual APC/C substrates.

\subsubsection{The Double Oscillator Model of the Cell Cycle}

In early metazoan embryos, where the cell cycle stage shuttles only between S- and M-phase without interjecting growth phases, the essential elements of the cell cycle are obvious. 
They consist of an oscillating Cdk-activity driven by fluctuating cyclin levels. The cyclin levels rise as the cells approach mitosis leading to a maximum of Cdk-activity bringing the cell into metaphase. Subsequent cyclin destruction reduces Cdk-activity to approximately zero allowing mother and daughter cell to separate irreversibly and exit mitosis.

In this system, Cdk-activity is the activating element of this oscillator, whereas the $\mathrm{APC} / \mathrm{C}$ is its repressor. $\mathrm{Cdks}$ in association with cyclins phosphorylate the $\mathrm{APC} / \mathrm{C}$ activator $\mathrm{Cdc} 20$, thereby triggering APC/C-mediated degradation of cyclins finally leading to switching off of Cdk kinase activity. In somatic cells, the picture of a classic negatively regulated feedback inhibitor has to be modified, as these cells need a growth phase to maintain the size threshold.

Inclusion of the G1 growth phase is achieved by insertion of a second oscillator in which Cdk activity and its mitotic repressor $\mathrm{APC} / \mathrm{C}$ are influenced by a second activating protein: Cdh1. Whereas Cdc20 is activated by phosphorylation, Cdh1 can only bind and activate the $\mathrm{APC} / \mathrm{C}$ when it is dephosphorylated. In late mitosis, when Cdk activity is already lowered, the APC/C preferably binds unphosphorylated Cdh1 instead of $\mathrm{Cdc} 20$, which is no more active due to a lack of phosphorylation. In this way, destruction of mitotic cyclins persists also during G1 phase, which is terminated by rising G1-cyclin/Cdk activity.

In budding yeast it was proposed that $\mathrm{APC} / \mathrm{C}-\mathrm{Cdc} 20$ is required to drive cells to mitosis by triggering destruction of the anaphase inhibitor Pds1 (Schwab et al. 1997). However, cells lacking Pds1 and Cdc20 undergo anaphase but arrest in late mitosis with high Cdk-activity (Visintin et al. 1997) suggesting that another protein has to be destroyed by the second oscillator involving APC/C-Cdh1.

In a screen for genes whose deletion allows mitotic exit, Clb5 was identified as the essential target of APC/C-Cdh1 (Shirayama et al. 1999) supported by the fact that $c d c 20 \Delta p d s 1 \Delta$ clb5 $\Delta$ triple deletion mutants were able to survive. This was a surprise as the expected gene to be found was the major mitotic cyclin Clb2.

A model considering this surprising result was proposed: The decline in Clb5 levels was thought to activate APC/C-Cdh1, which in turn destroys residual $\mathrm{Clb} 2$. Additional factors of this system are the Cdk inhibitor Sic1, which is inhibited by direct phosphorylation and helps to turn off kinase activity at the G1/M border. The other player supporting the mitotic exit is the phosphatase Cdc14, which dephosphorylates and activates Cdh1 and Sic1. 
Further studies, however, raised doubts about this model, as stable destruction box mutants of Clb5 had no defect in mitotic exit (Wasch and Cross 2002). Even when the Cdk inhibitor Sic1 was absent, the cells succeeded to exit from mitosis. A first clue came from the finding that $C L B 2$ destruction box mutants unlike $C L B 5 \triangle D B$ mutants were unable to exit mitosis. Furthermore, the fact that $\mathrm{Clb} 2$ was identified as a target of the first oscillator driven by the APC/C-Cdc20 (Baumer et al. 2000a; Yeong et al. 2000) indicated that this could be necessary for mitotic exit. Furthermore, cells in which the second oscillator is sabotaged by a $\operatorname{sic} \Delta \operatorname{cdh} 1 \Delta$ deletion can exit from mitosis.

This is reminiscent of the simple metazoan architecture: The first oscillator implying action of APC/C-Cdc20 can drive the cell cycle independently. But on the other hand, also the second APC/C-Cdh1 Sic1 oscillator can power the mitotic exit when Clb5 and Pds1 are deleted (see Figure 8).

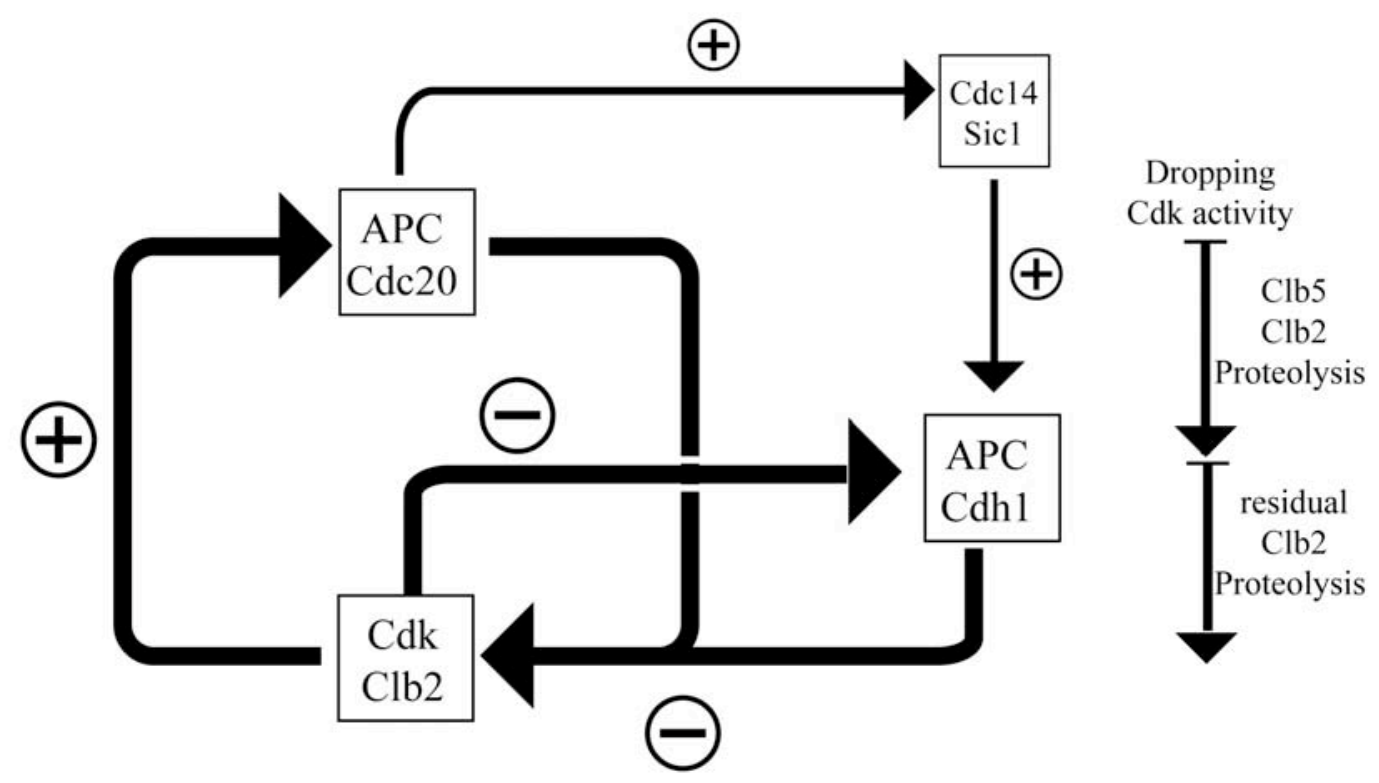

Figure 8: Schematic Presentation of Cell Cycle Regulation

The budding yeast cell cycle consists of two oscillating system influencing each other. The first oscillator is build up on the antagonizing $\mathrm{Cdk} / \mathrm{Clb} \mathrm{APC} / \mathrm{Cdc} 20$ pair; the second implies APC/C Cdh1 as $\mathrm{Cdk} / \mathrm{Clb} 2$ counterpart. Both oscillators are connected via $\mathrm{Cdc14}$ and Sic1, which are activated by dropping Cdk activity due to $\mathrm{Clb} 5$ and $\mathrm{Clb} 2$ proteolysis. Under special circumstances, each oscillator alone is sufficient to drive the cell out of mitosis. 
However, normal growth requires both oscillators as their interplay provides a protection system: By destroying Pds1, the APC/C-Cdc20 triggers DNA segregation. Further cyclin $\mathrm{Clb} 2$ and $\mathrm{Clb} 5$ proteolysis dampens $\mathrm{Cdk} / \mathrm{Clb}$ activity, leading in turn to the activation of the Cdk antagonizing proteins Cdc14 and Sic1, which then switch on the second oscillator triggering the mitotic exit. This system ensures that cells separate from each another only if the DNA was segregated.

\subsubsection{Coordination of DNA Replication With Cell Division}

To coordinate the DNA replication cycle with the cell division cycle, additional components in the yeast cell cycle monitor the accomplishment of crucial events and halt progression if errors are detected (Figure 9). These additional factors are called checkpoints.

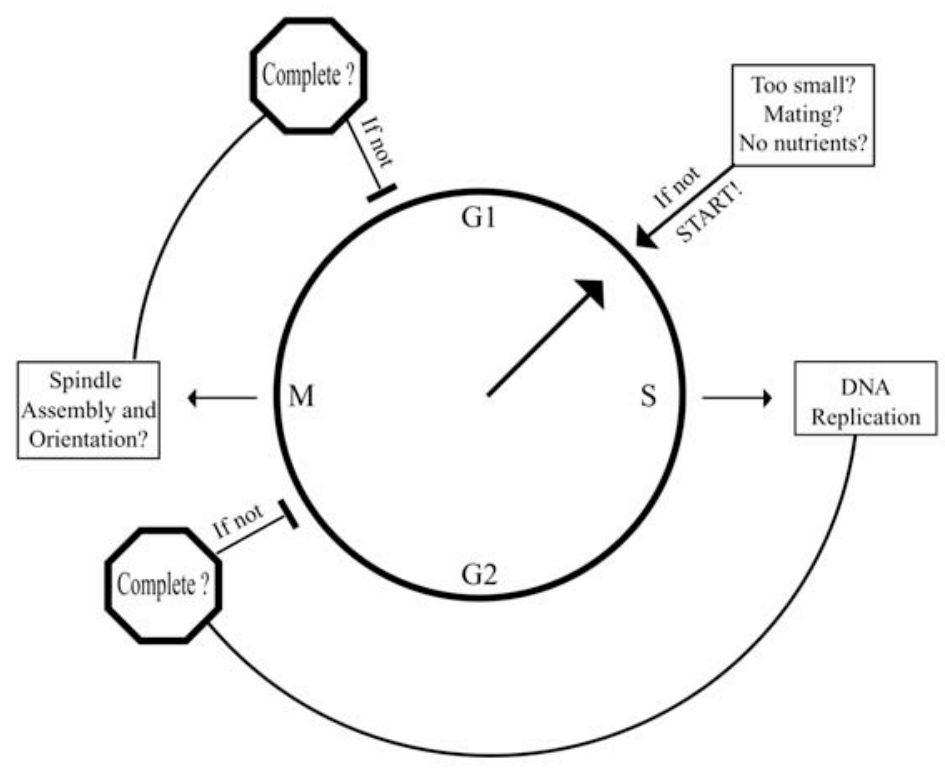

Figure 9: Checkpoint Monitoring of Crucial Cell Cycle Events

Checkpoints in the yeast cell cycle monitor the accomplishment of crucial events during the cell cycle and halt it if one key event is perturbed or environmental influences force the cell to exit from mitosis. In G1-phase, S-phase is only initiated if no mating pheromones are sensed, enough nutrients are present and the cell has grown to a certain size threshold. In S-phase the accurate replication and condition of DNA is monitored by the DNA damage and DNA replication checkpoint, which halts the cell cycle in case of its activation before anaphase onset. In mitosis correct orientation and assembly of all chromosomes to the spindle is sensed by the FEAR (1.3.11) and the MEN network (1.3.12). 
In G1-phase, S-phase is only initiated if no mating pheromones are sensed, enough nutrients are present and the cell has grown to a certain size threshold. In S-phase the accurate replication and condition of DNA is monitored by the DNA damage and DNA replication checkpoint, which halts the cell cycle in case of its activation before anaphase onset. In mitosis, assembly of all chromosomes to the spindle and its correct orientation is controlled by the spindle checkpoint.

In the following sections we focus on three checkpoints, which modulate $\mathrm{APC} / \mathrm{C}$ function during mitosis: The DNA damage checkpoint, the spindle assembly checkpoint and the spindle orientation checkpoint, which controls the completion of segregation of the DNA.

\subsubsection{The DNA Damage Checkpoint}

DNA replication is a crucial process, which is sensitive to genotoxic agents that cause damages such as strand breaks or base modifications. Even in the absence of toxic agents, replication forks may stall, and base misincorporation may interfere with the accurate copying of the genome (for review see (Longhese et al. 2003)).

In this case, the Mec1 kinase enters the scene, activating two independent downstream branches controlled either by kinases Chk1 or Rad53 (Agarwal et al. 2003). The downstream target of Rad53 is still unknown but it was shown that the Rad53 pathway inhibits Cdc20 assembly with the APC/C (Schwab et al. 2001). Chk1 targets the anaphase inhibitor protein Pds1 for phosphorylation (Wang et al. 2001), inhibiting its ubiquitination and proteolysis. Thus, both pathways inhibit APC/C-mediated Pds1 destruction either by directly inhibiting Pds1 ubiquitination or by hindering Cdc20 binding to the APC/C. Stable Pds1 (also called securin) inhibits the liberation of Esp1, which in turn is unable to cleave cohesins, thereby inhibiting sister chromatid segregation (Cohen-Fix et al. 1996; Tinker-Kulberg and Morgan 1999). Thus, both pathways are required to block DNA segregation if DNA is damaged or its duplication is not accomplished.

\subsubsection{The Spindle Assembly Checkpoint}

Chromosomes can only segregate if Pds1 destruction is triggered by the ubiquitin ligase $\mathrm{APC} / \mathrm{C}$ in association with Cdc20. Like the DNA damage checkpoint, the 
spindle assembly checkpoint also targets Cdc20 assembly with the APC/C to mediate the checkpoint control.

A single unattached chromosome is sufficient to induce the checkpoint signal, for which six gene products are essential: Mps1, Mad1-3, Bub1 and Bub3 (for review see (Wassmann and Benezra 2001)). The APC/C-Cdc20 directly binds to Mad2 (Li et al. 1997) which in turn is recruited to unattached kinetochores by Mad1 (Chen et al. 1998) thus preventing the degradation of Pds1 and Cdc14 phosphatase release. An unattached kinetochore seems to load Mad2-Cdc20-APC/C to transmit the stop signal. After the last kinetochore is attached to the spindle, the stop signal is ended (Wassmann and Benezra 2001) leading to APC/C-mediated Pds1 destruction.

This in turn releases Esp1 from the Pds1 block leading to the separation of sister chromatids (Uhlmann et al. 2000).

Furthermore, Esp1 is the first enzyme in a signaling cascade called FEAR (Cdc Fourteen Early Anaphase Release) network (for review see (Jensen et al. 2002)) that acts by an unknown mechanism on two FEAR downstream components Slk19 and Spo12 (Sullivan et al. 2001; Stegmeier et al. 2002). Finally, FEAR activation frees Cdc14 from the nucleolus allowing it to enter the nucleus and cytoplasm.

Another essential regulator of the Cdc14 release is $\mathrm{Cdc5}$, which connects the FEAR network with the mitotic exit network (MEN) (1.3.12)(Dumitrescu and Saunders 2002).

\subsubsection{Spindle Orientation Checkpoint}

In Saccharomyces cerevisiae transmission of one half of the separated sister chromatids to the daughter cell must be faithful to avoid ploidy. Thus, during mitosis, the cell must ensure that one end of the spindle, and hence one set of chromosomes, has traversed the bud neck and entered the daughter cell. Accordingly, the mitotic exit network (MEN) (Hoyt 2000) senses when a progeny spindle pole body enters the bud and then starts to trigger septation during cytokinesis.

The signal that activates the mitotic exit network is the entrance of the spindle pole body-associated Ras-like GTP/GDP binding protein Tem1 into the bud, where it meets the GTP exchange factor Lte1, which is localized only in the bud (Bardin et al. 2000). Once located together, Lte1 transfers GTP to Tem1, which in turn activates the protein kinases Cdc15 and Dfb2 (Stegmeier et al. 2002). This signal is essential to 
maintain the released state of Cdc14 out of the nucleolus, which was initiated in early anaphase by the FEAR network (1.3.11).

Cdc14 release in telophase and G1 dephosphorylates Cdh1 and Sic1 in the nucleus and Swi5 in the cytoplasm. Dephosphorylation of Cdh1 and Sic1 triggers termination of residual $\mathrm{Cdc} 28 / \mathrm{Clb}$ kinase activity whereas the transcriptional activator Swi5 enters the nucleus inducing the expression of G1 cyclins, which drive the cell through START into a new round of replication. 


\subsection{Meiosis}

The main mechanistic difference between mitosis, which produces somatic cells, and the germ-generating meiosis is that in meiosis one round of DNA replication is followed by two sequential rounds of chromosome generation. Given the fact that in the interval between DNA replication and cell division the cell bears four copies of each chromosome it is clear that such a meiotic program produces four spores each with the single set of chromosomes.

Meiotic nuclear division consists of two stages (

Figure 10), called meiosis I and meiosis II. The meiotic program starts also in G1 when a cell senses absence of nitrogen in presence of a non-fermentable carbon source. In contrast to mitosis, the alignment of chromosomes for prophase is different. Homologous chromosomes join into tetrades, and the tetrades line up in the metaphase plane. During prophase I (the prophase of meiosis I), various phenomena unique to meiosis may occur, such as crossing over.

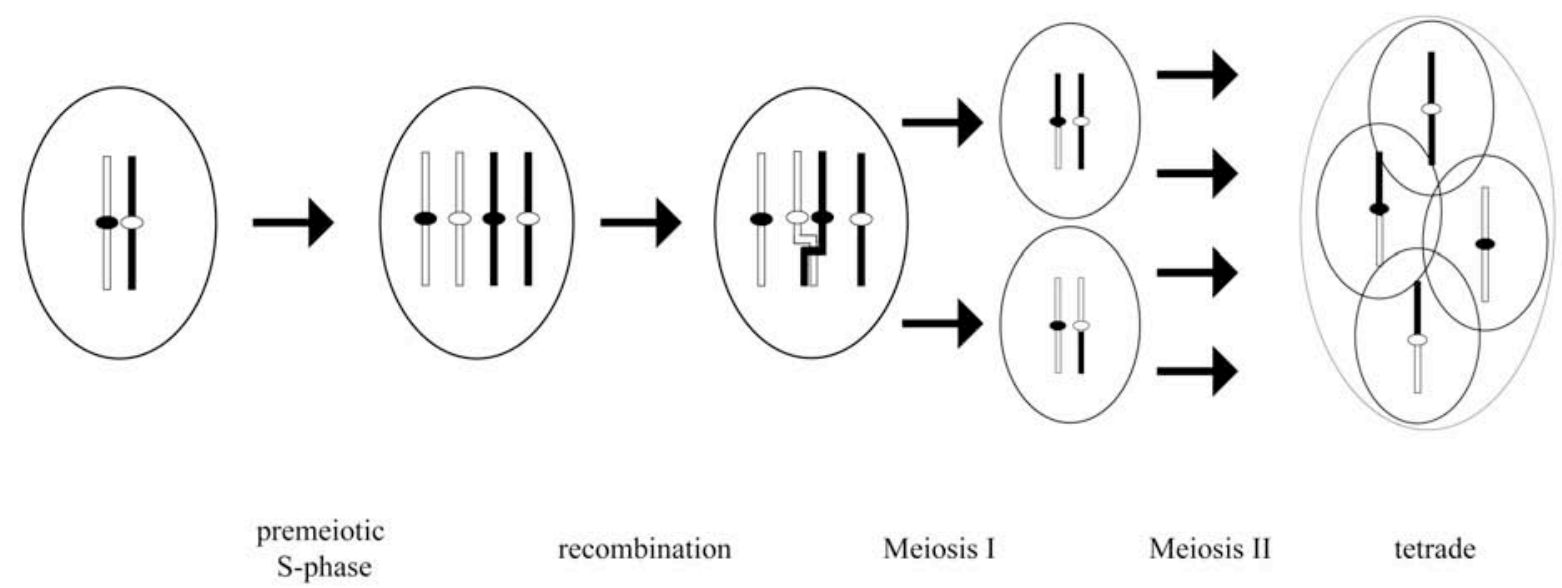

\section{Figure 10: Schematic Presentation of Meiosis}

Homologous chromosomes join into tetrades, and the tetrades line up in the metaphase plane. During prophase I (the prophase of meiosis I), various phenomena unique to meiosis may occur, such as crossing over. In Meiosis I, homologous chromosomes are pulled apart. Meiosis II is identical to mitosis. 
During metaphase I, the tetrades line up on the equatorial plate. During anaphase I, they are pulled apart into their constituent homologous chromosomes. Meiosis II is identical to mitosis. As a result four haploid ascospores are generated, which are kept together in a tetrade.

\subsubsection{Selected Features of Meiotic Regulation}

Meiosis can be considered a modified form of mitosis with the difference that one round of DNA replication is followed not only by one but two sequential rounds of chromosome segregation. This is achieved by fundamental differences between meiotic and mitotic chromosome segregation (for review see (Petronczki et al. 2003)). When meiosis is triggered by nitrogen starvation in the absence of a fermentable carbon source, the cell activates Ime1, which at the same time starts the meiotic program and inhibits mitosis by blocking $\mathrm{Cln} / \mathrm{Cdc} 28$ activity (Colomina et al. 1999). In the absence of $\mathrm{Cln} / \mathrm{Cdc} 28$ activity, essential functions such as initiation of DNA replication or spindle pole body formation are carried out by the meiosis specific kinase Ime2 (Dirick et al. 1998). As the core replication machinery seems to be identical, the pre-meiotic S-phase is prolonged compared to the pre-mitotic S-phase, allowing interhomologous interactions like recombination or the segregation of homologous chromosomes to happen (Cha et al. 2000).

During meiosis I, homologous chromosomes and not sister chromatids are segregated. This modified division requires three essential events: firstly, a physical linkage between homologous chromosomes to resist the pulling force of the spindle; secondly, the fixation of two sister chromatids has to be maintained beyond meiosis I to prevent premature sister chromatid separation; thirdly, sister chromatids have to be connected to microtubules coming from the same and not the opposite pole.

Yeast meiotic studies revealed (Galbraith et al. 1997) that the linkages between homologous chromosomes are established by manifestations of recombinatorial events, called chiasmata. To allow chiasmata, arm cohesion of chromosomes has to be cut by the meiosis specific cohesin subunit Rec8 (Buonomo et al. 2000), whereas the bond and the centrosome is protected by additional uncleaved Rec8, which is retained at centromeric regions until the onset of anaphase II (Watanabe and Nurse 1999). Rec8, like the mitotic homologue Scc1/Mcd1, is cleaved by separase Esp1 (Buonomo et al. 2000). Taken together the loss of arm cohesion in anaphase I allows 
chromosome segregation, whereas termination of centromeric cohesion allows chromatid separation in anaphase II. In agreement with this model, Pds1 is stable during meiosis I preventing premature chromatid separation by inhibiting the separase Esp1, which is liberated by APC/C-mediated Pds1 destruction in meiosis II (Shonn et al. 2000).

Co-orientation seems to be a result of association of Bub1, Slk19 and Mam1 with the kinetochores in close coordination with the linkage protection by Rec8 (Watanabe and Nurse 1999).

In meiosis, like in mitosis, the Cdc28 kinase in association with cyclins drives the cell from meiosis I to meiosis II (Dahmann and Futcher 1995). The meiosis-specific transcription factor Ndt80 regulates the expression of three cyclins, which are essential for meiosis: $\mathrm{Clb} 1, \mathrm{Clb} 3$ and $\mathrm{Clb} 4$. In contrast to mitosis, the most important cyclin gene $C L B 2$ does not play a role in meiosis as it does not contain a Ndt80 binding site and is therefore not expressed during meiosis (Grandin and Reed 1993). The APC/C is essential for meiosis but its role still remains to be characterized.

\subsubsection{The Meiotic Protein Kinase Ime2}

Starvation of an essential nutrient (e.g. carbon, nitrogen, methionine, sulfur) leads to arrest in G1-phase. Here, the diploid cell can switch either to pseudohyphal growth if the lacking nutrient is nitrogen and glucose is present, or to sporulation if no fermentable carbon source (e.g. glucose) is present (Freese et al. 1982). The molecular switch between both processes is the transcription factor Ime1, which is responsible for expression of early meiotic genes including the essential meiosis specific kinase Ime2 (for review (Mitchell 1994)).

Both genes are trancriptionally regulated by two signaling cascades sensing the present nutritional conditions. IME1 possesses a large promoter region consisting of four upstream control regions, which are sensitive to different stimuli, e.g. glucose represses one IME1 transcription site, whereas another one can be activated by acetate (Honigberg and Purnapatre 2003). The residual two control regions bear sites recognizing the diploid state of the cell by transmitted "a" and " $\alpha$ " signal (Covitz and Mitchell 1993).

$I M E 1$ triggers the expression of IME2, whose repression by glucose is also mediated by several additional signal transduction pathways (Carlson 1999) and activated by a 
non-fermentable carbon source and starvation conditions. Transcription of both, IME1 and $I M E 2$, is required for normal meiotic initiation.

IME2 codes for a Ser/Thr protein kinase sharing homology with several amino acid motifs common among kinases and responsible for nucleotide binding and catalyzing the phosphate-substrate transfer via K97 (Hui et al. 2002). Ime2 seems to be regulated by stability as its C-terminal domain has been proposed to destabilize the protein in interaction with negatively regulating factors (Guttmann-Raviv et al. 2002).

Ime2 is required not only in the initial stage of meiosis where it is responsible for the induction of meiotic DNA replication and induction of S-phase by lowering levels of the Cdk inhibitor Sic1 leading to elevated Cdc28/Clb5-6 kinase activity (Foiani et al. 1996). Later, Ime2 also inhibits re-replication of DNA (Stuart and Wittenberg 1998) and negatively regulates Ime1 by triggering its degradation through phosphorylation (Guttmann-Raviv et al. 2002).

Furthermore, Ime2 triggers the expression of early (SPO11, SPO13) and middle (NDT80) mitotic genes, among them the B-type cyclins CLB1, CLB3 and CLB4 (Hepworth et al. 1998). In late meiosis, Ime2 is also required for M-phase where it stimulates and stabilizes the key meiotic transcription factor Ndt80, which is in turn needed for high Cdk activity (Benjamin et al. 2003).

A screen for genes inhibiting APC/C-mediated $\mathrm{Clb} 2$ proteolysis identified Ime2 as a negative regulator (Bolte et al. 2002). IME2 expression in G1 results in phosphorylation of $\mathrm{Cdh} 1$ and inhibited beside $\mathrm{Clb} 2$ proteolysis, bud formation and caused a cell cycle arrest in mitosis. Furthermore, it was found that Ime 2 is itself an unstable protein being degraded by an unknown, APC/C and SCF independent pathway. 


\section{Aim of this Work}

The yeast Saccharomyces cerevisiae is a well-established model organism in which many processes are conserved up to humans. Especially cell cycle regulation, whose mechanisms are highly conserved, has turned out to be crucial for human diseases like cancer. Accordingly, the investigation and understanding of the molecular cell cycle regulation is a prerequisite to develop attractive drug targets.

Ubiquitin-dependent proteolysis is essential for sister chromatid segregation and the exit from mitosis. This process depends on the ubiquitin-triggered proteolysis of two proteins: The anaphase inhibitor Pds1 and the mitotic cyclin Clb2. Both processes involve the anaphase-promoting complex or cyclosome (APC/C) acting as E3ubiquitin ligase but require in addition two different APC/C-associated activators: The WD40 repeat protein for Pds1 degradation at the G2/M border and Cdh1 for Clb2 proteolysis at the end of mitosis.

This work aims to contribute to the characterization of the complex interplay between kinases, APC/C-regulating and regulated factors and ubiquitination. Furthermore, the undefined interaction between the antagonizing partners $\mathrm{APC} / \mathrm{C}$ and the meiosis specific kinase Ime2 is investigated.

The first part of this thesis analyzes the role of SUMOylation for APC/C mediated proteolysis. Prior studies reported that in mutant strains, bearing a temperature sensitive allele of the SUMO-conjugating enzyme $u b c 9$, ubiquitin-mediated proteolysis is altered (Seufert et al. 1995). Furthermore, the identification of SUMO in a screen for mutants defective in chromosome segregation suggested an interfering role with the APC/C (Biggins et al. 2001). In this part SUMO's role during mitosis should be characterized by analyzing protein degradation of the anaphase inhibitor Pds1 and its consequences on chromosome segregation and cell cycle progression.

In the second part, $\mathrm{APC} / \mathrm{C}$-dependant and independent proteolysis of the S-phase cyclin Clb5 is investigated. Degradation of this cyclin was thought to be essential (Shirayama et al. 1999) for the exit from mitosis before Wäsch (Wasch and Cross 2002) reported conflicting results considering $\mathrm{Clb} 2$ as the essential APC/C target. Our results contribute to the re-definition of the mechanisms necessary for the exit from mitosis.

Thirdly, the meiosis specific and highly unstable protein kinase Ime2 is characterized. Previous work identified a C-terminal region of Ime2 as essential element for rapid 
degradation. Up to now, it is unknown, if Ime 2 might be regulated in meiosis by proteolysis. The truncated stable Ime2 protein allows us to investigate whether Ime2 instability is important for meiosis and to determine the effects of a stabilization on the meiotic cell cycle. Furthermore, the functionality of the truncated protein is analyzed. 


\section{Materials \& Methods}

\subsection{Materials}

Chemicals used for the production of gels, solutions, buffers and culture media were sourced from MERCK (Darmstadt, D), ROCHE GMBH (Mannheim, D), Carl ROTH GMBH \& CO KG (Karlsruhe, D), INVITROGEN GMBH (Karlsruhe, D), FLUKA (Neu-Ulm, D) und SIGMA-ALDRICH GMBH (Steinheim, D). Restriction enzymes were provided by MBI FERMENTAS (Vilnius, Lit). KOD HIFI DNA Polymerase is fabricated by NOVAGEN (Darmstadt, D). DNA size standard "GENE RULER $1 \mathrm{~kb}$ DNA ladder Plus" is produced by MBI FERMENTAS (Vilnius, Lit). The preparation of plasmid DNA from E.coli and DNA gel elution was carried out using kits from QIAGEN (Hilden, D).

DNA sequencing chemicals were provided by APPLIED BIOSYSTEMS GMBH (Weiterstadt, D); synthetic oligonucleotides were produced by INVITROGEN. Bradford solution for the determination of protein contents was provided by BIORAD Industries GMBH (München, D).

"See Blue Pre-Stained" ( NOVEX, San Diego CA, USA) was also used as marker for determination of protein weight as "Rainbow marker RPN 756" from AMERSHAM LIFE SCIENCE (Uppsala, S). SDS-Protein Gels were blotted on membrane obtained from SCHLEICHER \& SCHUELL (Dassel, D). Antibodies were produced by MOLECULAR PROBES (Eugene, OR, USA) and SANTA CRUZ BIOTECH INC. (Santa Cruz, CA, USA) and detected on Hyperfilm ${ }^{\mathrm{TM}}-\mathrm{ECL}^{\mathrm{TM}}$ (AMERSHAM PHARMACIA BIOTECH, Buckinghamshire, GB).

\subsection{Yeast Strains and Plasmids}

All strains used in this study are derivatives of the Saccharomyces cerevisiae W303 or SK1 strains and are listed in Table 3.

Initially, a $u b c 9$ deletion strain $(u b c 9 \Delta)$ strain was constructed by transformation of a deletion cassette containing the TRPI gene inserted between a $500 \mathrm{bp}$ fragment containing sequences immediately upstream of the UBC9 ORF start codon and a 280 bp fragment containing sequences of the $3^{\prime}$ region. The temperature-sensitive $u b c 9-2$ allele was created by PCR mutagenesis of the $U B C 9$ gene. Plasmids from colonies 
growing at $25^{\circ} \mathrm{C}$, but not at $37^{\circ} \mathrm{C}$ were isolated and cloned into the integrative plasmid YIplac128 (containing the LEU2 marker).

$u b c 9$ deletions strains kept alive by the $G A L-U B C 9$ gene fusion were created by transformation of an $U B C 9 / u b c 9 \Delta$ heterozygous diploid with a centromeric plasmid containing $G A L-U B C 9$ and $U R A 3$ as selection marker. $u b c 9 \triangle G A L-U B C 9$ segregants were obtained by sporulation and tetrade dissection. The $G A L-U B C 9$ construct was isolated from a GAL-cDNA library (Liu et al. 1992) during a genetic screening. It contains the entire $U B C 9$ ORF fused 24 base pairs upstream of the ATG start codon to the GAL1-10 promoter.

The GAL-ubcI plasmid was isolated from a Aspergillus nidulans cDNA library expressed from the yeast GAL1-10 promoter (Krappmann et al. 1999), by transformation of an $u b c 9-2$ mutant, followed by a selection for transformants able to grow at $37^{\circ} \mathrm{C}$ on galactose medium. $u b c 9 \Delta G A L-u b c I$ segregants were obtained by sporulation and tetrade dissection of a plasmid carrying $U B C 9 / u b c 9 \Delta$ heterozygous diploid. The GAL-HA3-SMT3 strain, containing a replacement of the endogenous $S M T 3$ promoter by the GAL1-10 promoter, and the smt3-331 mutant strain, were received from Sue Biggins and were previously described (Biggins et al. 2001).

Table 3: Yeast Strains Used in this Study.

\begin{tabular}{|c|c|}
\hline $\begin{array}{l}\text { S.cerevisie } \\
\text { Strains }\end{array}$ & Relevant Genotype \\
\hline S001 & $\begin{array}{l}\text { W303-1A wildtype strain } \\
\text { MATa, ade2-1, trp1-1, can1-100, leu2-3, 112, his3-11, 15, ura3, GAL }\end{array}$ \\
\hline S016 & MATa, GAL, psi+, clB2::LEU2, containing GAL-CLB2 ::TRP1 \\
\hline S054 & MATa, $c d c 23, U R A 3: \because G A L-C L B 5 H A H i s(1 x)$ \\
\hline S056 & MATa, GAL-CLB3-HA3/URA3, bar1::HisG \\
\hline S057 & MATa, GAL-CLB2-HA3/URA3, bar1::HisG \\
\hline S088 & MATa, GAL-CDC5-HA3 /URA3, bar1::HisG \\
\hline S090 & MATa, $c d c 34-2$ \\
\hline S099 & MAT $\alpha, u b c 9:: T R P 1, u b c 9-2 / L E U 2$ \\
\hline S122 & 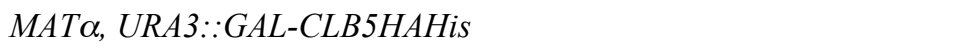 \\
\hline $\mathrm{S} 123$ & MAT $\alpha$, URA3::GAL-CLB5HAHis-destruction box deletion \\
\hline
\end{tabular}




\begin{tabular}{|c|c|}
\hline $\mathrm{S} 185$ & MATa, PDS1-HA3/URA3 \\
\hline S206 & MATa, GAL-PDS1-HA/URA3, bar1::HisG \\
\hline S234 & MATa, CDC16-MYC6/URA3 \\
\hline $\mathrm{S} 265$ & MATa, $c d c 23-1$ \\
\hline S365 & MATa, ubc9::TRP1, ubc9-2/LEU2, GAL-PDS1-HA3/URA3, barl::HisG \\
\hline S379 & 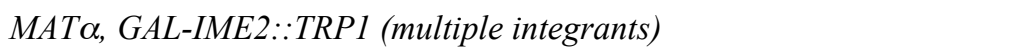 \\
\hline $\mathrm{S} 390$ & MATa, ubc9::TRP1, ubc9-2/LEU2, Gal-CLB3-HA3/URA3, bar1::HisG \\
\hline S396 & MATa, GAL-IME2-HA3/TRP1 \\
\hline S403 & MAT $\alpha, c d c 34-2$, URA3::GAL-CLB5HAHis \\
\hline S406 & MATa, ubc9::TRP1, ubc9-2/LEU2, PDS1-HA3/URA3 \\
\hline S425 & MATa, $u b c 9:: T R P 1, p R S 316-G A L-U B C 9 / U R A 3$ \\
\hline S432 & Mata, cdc34-2, cdc23-1, URA3::GAL-CLB5HAHi \\
\hline S437 & MATa, GALL-HA3-HCT1::TRP1, pep4::LEU2, bar1::HisG \\
\hline S457 & MATa, GALL-HA3-HCT1::TRP1, GAL-IME2::URA3 \\
\hline S481 & MATa, MYC18-CDC20/TRP1 \\
\hline S483 & MATa, ubc9::TRP1, pRS316-GAL-UBC9/URA3, pds1::LEU2 \\
\hline S487 & MATa, ubc9::TRP1, ubc9-2/LEU2, GAL-CDC5-HA3/URA3, bar1::HisG \\
\hline S497 & SK-1 diploid wildtype \\
\hline S504 & SK1 diploid IME2-myc9/IME2-myc 9 \\
\hline S527 & MATa, $u b c 9:: T R P 1, u b c 9-2 / L E U 2, M Y C 18-C D C 20 / T R P 1$ \\
\hline S528 & MATa, ubc9::TRP1, ubc9-2/LEU2, CDC16-MYC6/URA3 \\
\hline S533 & MATa, GAL-HA3-SMT3/HIS3 \\
\hline S534 & MATa, ubc9::TRP1, ubc9-2/LEU2, GAL-IME2-HA3/TRP1 \\
\hline S535 & MATa, smt3-331, GAL-PDS1-HA3/URA3, bar1::HisG \\
\hline S537 & MATa, PDS1-MYC18/LEU2 \\
\hline S542 & 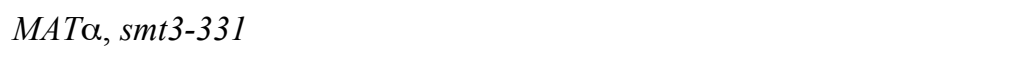 \\
\hline S543 & MATa, smt3-331, GAL-CLB2-HA3/URA3, bar1::HisG \\
\hline S544 & MATa, smt3-331, GAL-CLB3-HA3/URA3, bar1::HisG \\
\hline
\end{tabular}




\begin{tabular}{|c|c|}
\hline S545 & MATa, smt3-331, PDS1-MYC18/LEU2 \\
\hline S546 & MATa, ubc9::TRP1, ubc9-2/LEU2, PDS1-MYC18/LEU2 \\
\hline S547 & MATa, smt3-331, MYC18-CDC20/TRP1 \\
\hline S548 & MATa, smt3-331, CDC16-MYC6/URA3 \\
\hline S550 & $M A T \alpha, G A L-H A 3-S M T 3 / H I S 3, P D S 1-M Y C 18 / L E U 2$ \\
\hline S552 & MATa, ubc9::TRP1, pRS316- GAL-UBC9/URA3, PDS1-MYC18/LEU2 \\
\hline S566 & MATa, GAL-HA3-SMT3/HIS3, mad2::URA3, PDS1-MYC18/LEU2 \\
\hline S568 & MATa, ubc9::TRP1, ubc9-2/LEU2, mad2::URA3, PDS1-MYC18/LEU2 \\
\hline S589 & $\begin{array}{l}\text { SK1 diploid, IME2 } \triangle \text { C-term (405-645aa)-HA-KanMX6/IME2 } \triangle C \text {-term (405-645aa)-HA- } \\
\text { KanMX6 }\end{array}$ \\
\hline S591 & SK1 diploid, IME2 $\triangle$ C-term (405-645aa)-HA-KanMX6/IME2 \\
\hline S596 & MATa, GALL-HA3-HCT1::TRP1, URA3::GAL-CLB5HAHis \\
\hline S597 & MATa, GALL-HA3-HCT1::TRP1, URA3::GAL-CLB5HAHis- $\triangle D B$ \\
\hline S598 & MATa, GALL-HA3-HCT1::TRP1, Clb5-DB-deletion \\
\hline
\end{tabular}

Table 4: Plasmids Used in this Study

\begin{tabular}{|c|c|}
\hline Plasmid & Description \\
\hline pME2710 & $U R A, G A L-U B C 9, A M P^{R}$ (bla), lacZ, ori \\
\hline pME2711 & $U R A, G A L-G C N 4-M Y C 9, A M P^{R}$ (bla), lacZ, ori \\
\hline pME2116 & TRP1, GAL-IME2-HA3 (2x), AMP ${ }^{R}$ (bla), lacZ, ori \\
\hline pME2595 & TRP1, GAL-IME2 $4405-645(2 x)-H A 3, A M P^{R}$ (bla), lacZ, ori \\
\hline pME2712 & TRP1, GAL-IME2 $4405-645(2 x), A M P^{R}$ (bla), lacZ, ori \\
\hline pME2713 & URA, GAL-STREP-SMT3, AMP $P^{R}$ (bla), lacZ, ori \\
\hline pME2714 & $U R A, G A L-u b c I, A M P^{R}$ (bla), lacZ, ori \\
\hline
\end{tabular}




\subsection{Growth Conditions}

\subsubsection{Cultivation of Yeast and Cell Cycle Arrests}

Cells were grown in YEP medium (2\% bactopeptone, 1\% yeast extract, $0,005 \%$ adenine sulfate) supplemented either with $2 \%$ glucose (YEPD) or $2 \%$ raffinose. Plasmid carrying strains were grown in appropriate synthetic minimal medium containing $0.8 \%$ yeast nitrogen base, supplemented with amino acids and adenine. The GAL1-10 promoter was induced by the addition of galactose ( $2 \%$ final concentration). Before gene expression from the GAL1-10 promoter was induced, cells were grown in raffinose medium. To turn off the GAL1-10 promoter, cells were filtered and re-suspended in medium containing $2 \%$ glucose. To arrest cells in G1 with $\alpha$-factor pheromone, cultures were incubated for $2.5 \mathrm{~h}$ in the presence of $5 \mu \mathrm{g} / \mathrm{ml}$ $\alpha$-factor. For investigations during S-phase, cells were arrested by presence of $2,5 \mathrm{mg} / \mathrm{ml}$ Hydroxyurea for $2 \mathrm{~h}$. Nocodazol in a final concentration of $1,5 \mu / \mathrm{ml}$ for $2 \mathrm{~h}$ arrested cells in M-phase.

\subsubsection{Cultivation of E.coli}

Bacterial strains were grown at $37^{\circ} \mathrm{C}$ in Luria-Bertani-Medium (LB, $1 \%$ tryptone, $0,5 \%$ yeast extract, $1 \% \mathrm{NaCl})$. For selective media Ampicillin $(100 \mu \mathrm{g} / \mathrm{ml})$ or chloramphenicol $(25 \mu \mathrm{g} / \mathrm{ml})$ was added. Media for zeocin selection $(50 \mu \mathrm{g} / \mathrm{ml})$ contained beside $0,5 \%$ yeast extract, $1 \%$ tryptone only $0,5 \% \mathrm{NaCl}$. Solid medium contained $2 \%$ agar. SOB medium ( $2 \%$ tryptone, $0,5 \%$ yeast extract, $10 \mathrm{mM} \mathrm{NaCl}$, $2,5 \mathrm{mM} \mathrm{KCl}, 10 \mathrm{mM} \mathrm{MgCl}_{2}, 10 \mathrm{mM} \mathrm{MgSO}_{4}$ ) was used for the preparation of competent E.coli cells (Inoue et al. 1990).

\subsection{Protein and DNA Detection Methods}

\subsubsection{Northern Hybridization}

RNA isolation and Northern hybridization were performed as described (Cross and Tinkelenberg 1991). Polymerase chain reaction-generated fragments were radio labeled using a labeling kit (Stratagene) and used as hybridization probes. 


\subsubsection{Preparation of Cell Extracts (Surana et al. 1993)}

At the desired time point, $15 \mathrm{~mL}$ of culture were harvested at $2500 \mathrm{rpm}$ for 3 minutes and then washed with $2 \mathrm{ml}$ of $10 \mathrm{mM}$ Tris $\mathrm{pH}$ 7.5. The yielded pellet can be frozen in liquid nitrogen and stored at $-80^{\circ} \mathrm{C}$ in the freezer for further use. Breaking up off cells was achieved by adding $200 \mu 1$ of glass beads $(\varnothing 0,25 \mathrm{~mm})$ and $200 \mu 1$ of freshly prepared "Breaking Buffer" (50mM Tris/HCL, 1mM EDTA, 50mM DTT, $1 \mathrm{mM}$ PMSF, 0,5mM TPCK, 0,025mM TLCK and $2 \mu \mathrm{g} / \mathrm{ml}$ Epstein). This mixture was vortexted at $4^{\circ} \mathrm{C}$ for ten minutes to break up cells. $10 \mu 1$ of the obtained suspension were pipetted to an extra tube and centrifuged for $10 \mathrm{~min}$ at maximum speed. The rest of the suspension was mixed with $100 \mu \mathrm{L}$ SDS-buffer $(0,25 \mathrm{M}$ TrisHCl $\mathrm{pH} 6,8,15 \%$ mercaptoethanol, 30\% glycerol, 7\% SDS and 0,3\% brominephenolblue) and incubated for $10 \mathrm{~min}$ at $95^{\circ} \mathrm{C}$. Finally, the denatured protein samples were centrifuged $10 \mathrm{~min}$ at maximum speed and stored at $-80^{\circ} \mathrm{C}$ for further use.

\subsubsection{Detection of Protein Content (Bradford 1976)}

$10 \mu 1$ of the crude cell extracts were centrifuged at maximum speed for 10 minutes. $3 \mu l$ of the supernatant were mixed in a cuvette with $1 \mathrm{ml}$ of 1:5 diluted Bradford solution (BIO-RAD, München, D). After incubation for 10 minutes, extinction at 595 $\mathrm{nm}$ was measured in an UV/Vis photometer using 1:5 diluted Bradford solution as blank.

\subsubsection{SDS-Polyacrylamide Gel Electrophoresis (Laemmli 1970)}

Electrophoretic separation of protein mixtures was carried out in $12 \%$ SDS vertical gels build up on two different gel types (running gel: $3,5 \mathrm{ml}$ water, 2,5 $\mathrm{ml}$ "WUG"buffer (1,5M Tris Base pH 9, 0,4\% SDS), $4 \mathrm{ml} 30 \%$ acryl amide, $50 \mu 1 \quad 10 \%$ ammoniumperoxodisulfate, $10 \mu \mathrm{l} \mathrm{N}^{\prime}, \mathrm{N}^{\prime}, \mathrm{N}, \mathrm{N}$-tetra-ethylen-methylen-diamide) stacking gel: 1,8 ml water, 2,5ml "WOG"-buffer (0,25M Tris Base $\mathrm{pH}$ 6,8, 0,2\% SDS), $650 \mu 130 \%$ acryl amide, $25 \mu 1$ 10\% ammoniumperoxodisulfate, $5 \mu 1$ $\mathrm{N}^{\prime}, \mathrm{N}^{\prime}, \mathrm{N}, \mathrm{N}$-tetra-ethylen-methylen-diamide). The two Gels were casted and polymerized successively on each other. Depending on the observed protein, 10 to 60 $\mu \mathrm{g}$ of whole protein was loaded on the gel. Running of the gel was carried out for 60 
minutes at $200 \mathrm{~V}$ in electrophoresis buffer $(25 \mathrm{mM}$ Tris Base, $192 \mathrm{mM}$ glycine, 0,1\% SDS).

\subsubsection{Immunoblotting (Towbin et al. 1979)}

Preparation of yeast cell extracts and protein immunoblot analysis were performed as described. Transfer of electrophoretically separated protein bands to a nitrocellulose membrane ("Protan", SCHLEICHER \& SCHUELL) was carried out in a "MiniTrans-Blot-Electrophoretic-Cell” (BIO-RAD, München, D) in transfer buffer containing $25 \mathrm{mM}$ Tris Base, $192 \mathrm{mM}$ glycine and 20\% methanol overnight at $35 \mathrm{~V}$.

After accomplished protein transfer, free binding sites on the nitrocellulose membrane were blocked by treatment with $3 \%$ milk powder in PBS buffer $(80 \mathrm{mM} \mathrm{Na} 2 \mathrm{HPO} 4$, $25 \mathrm{mM} \mathrm{NaH} 2 \mathrm{PO} 4,100 \mathrm{mM} \mathrm{NaCl}$, Tween 20, $\mathrm{pH}$ 7,5) for 45 minutes. Then, the first antibody diluted in PBS milk powder was applied for 60 minutes. Residual antibody was washed away by shaking the membrane 10 minutes once in PBS milk powder and twice in PBS containing Tween 20. The secondary peroxidase-labeled antibody was incubated with the membrane for 60 minutes and washed away analogously to the first.

Detection of proteins on the membrane was carried out using the "Enhanced Chemiluminiscence System" (ECL, (Tesfaigzi et al. 1994)) involving two solutions

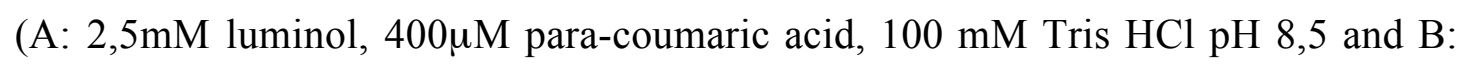
$6 \mathrm{mM} \mathrm{H} 2 \mathrm{O} 2,100 \mathrm{mM}$ Tris $\mathrm{HCl} \mathrm{pH} 8,5)$, which were put on the membrane for two minutes. Finally, luminescence was detected on Hyperfilm ${ }^{\mathrm{TM}}-\mathrm{ECL}^{\mathrm{TM}}$ (AMERSHAM $^{\mathrm{T}}$ PHARMACIA BIOTECH, Buckinghamshire, GB).

Antibodies were used in 1:1000 (Clb2), 1:2000 (Cdc28), 1:100 (HA, 12CA5) and 1:100 (MYC) dilutions, respectively.

\subsubsection{Immunofluorescence Analysis (Pringle et al. 1991)}

For indirect immunofluorescence, cells were fixed in 3.7\% formaldehyde for at least 40 minutes, washed three times in phosphate-buffer $\left(0,3 \mathrm{mM} \mathrm{K}_{2} \mathrm{HPO}_{4}, 0,1 \mathrm{mM}\right.$ $\left.\mathrm{KH}_{2} \mathrm{PO}_{4}\right)$ and once in SCE-buffer (1 $\mathrm{M}$ sorbitol, 0,1M sodium citrate, 0,06M EDTA $\mathrm{pH} 7)$. 
Then the cells were spheroblasted in $200 \mu$ l SCE-buffer mixed with $2 \mu 1$ zymoylase (TEIKAGU CORPORATION, Tokyo JPN) and 20 $\mu 1$ glusulase (PERKIN ELMER MA, USA) for 1 hour at $30^{\circ} \mathrm{C}$. Careful centrifugation (2000rpm, $3 \mathrm{~min}$ ) was followed by washing with SPC-buffer (1,2M sorbitol, $0,3 \mathrm{mM} \mathrm{K}_{2} \mathrm{HPO}_{4}, 0,1 \mathrm{mM} \mathrm{K \textrm {H } _ { 2 }} \mathrm{PO}_{4}$ and $0,1 \mathrm{M}$ sodium citrate). To fix spheroblasts on glass eight-well slides (ICN BIOMEDICALS INC, OHIO, USA), the slides were treated with $10 \mu 1$ polylysine for one minute. Polylysine was washed away by water and $12 \mu 1$ of the spheroblasts suspension was put on the air-dried slide, which was the put into a $-20^{\circ} \mathrm{C}$ methanol bath followed by $30 \mathrm{sec}$ incubation in $-20^{\circ} \mathrm{C}$ acetone. After fixation, the first antibody diluted in $1 \%$ bovine-serum albumin in PBS was applied and incubated in darkness for one hour. Intermediate washing was carried out using 1\% bovine-serum albumin in PBS for three times. The second antibody diluted in 1\% bovine-serum albumin in PBS carrying the light-stimulable alexa domain was incubated on the slide again for one hour. After the last three washing steps with $1 \%$ bovine-serum albumin in PBS. Staining with 4,6-diamidino-2-phenylindole (DAPI) and anti-tubulin antibodies were used for visualization of nuclei and spindles, respectively.

\subsubsection{FACS Analysis}

Cells were fixed in 70\% ethanol overnight, centrifuged (13.000 rpm 1 minute) and washed twice with $50 \mathrm{mM}$ Tris $\mathrm{pH} 7,8.800 \mu 1$ of $50 \mathrm{mM}$ Tris $\mathrm{pH} 7,8$ was used to resuspend the cells before $20 \mu 1 \mathrm{RNase}(10 \mathrm{mg} / \mathrm{ml})$ were added and incubated for at least $6 \mathrm{~h}$ at $37^{\circ} \mathrm{C}$. Then, $0,5 \mathrm{~mL}$ pepsin $(5 \mathrm{mg} / \mathrm{ml}$ in $55 \mathrm{mM} \mathrm{HCl})$ were added and incubated for 30 minutes on a shaker at $37^{\circ} \mathrm{C}$. Two times washing with $1 \mathrm{ml} 200 \mathrm{mM}$ Tris $\mathrm{pH} 7,5,200 \mathrm{mM} \mathrm{NaCl}$ and $78 \mathrm{mM} \mathrm{MgCl}_{2}$ and collection in the same buffer preceded staining of DNA by addition of $55 \mu 1$ propidiumiodide $(0,5 \mathrm{mg} / \mathrm{ml})$. Shortly before FACS measurement, cells were sonificated. $50 \mu 1$ of cell-suspension diluted in $1 \mathrm{ml} \mathrm{50mM}$ Tris $\mathrm{pH} 7,8$ were used for the analysis.

\subsubsection{Single-Step Purification of Proteins}

Protein Extracts were prepared as described in 3.4.2. All following procedures were carried out at $4^{\circ} \mathrm{C}$. STREP-Tactin $®$-Superflow-Columns were equilibrated using $3 \mathrm{ml}$ buffer $\mathrm{W}(100 \mathrm{mM}$ Tris-HCl, $150 \mathrm{mM} \mathrm{NaCl}$ and $1 \mathrm{mM}$ EDTA). Then, $4 \mathrm{ml}$ of the 
crude protein extract containing the recombinant STREP-tag fusion protein or the untagged control was applied to one column and ran through by gravity flow. Unspecific flow-through was collected. To wash residual unspecifically bound protein off the column, $5 \mathrm{ml}$ of buffer $\mathrm{W}$ was applied. Afterwards, the fusion proteins were eluted by adding three times $1 \mathrm{ml}$ of buffer $\mathrm{E}(100 \mathrm{mM}$ Tris- $\mathrm{HCl}, 150 \mathrm{mM} \mathrm{NaCl}$ and 1 $\mathrm{mM}$ EDTA, 2,5mM desthiobiotin) and collected in three fractions of $1 \mathrm{ml}$. After the elution step, the column was regenerated using buffer R (100 mM Tris-HCl, $150 \mathrm{mM}$ $\mathrm{NaCl}$ and $1 \mathrm{mM}$ EDTA, 1mM HABA). The obtained purified protein was used for Western Blot, 2D gel-electrophoresis or silver staining.

\subsection{DNA Manipulation}

\subsubsection{Isolation of Plasmid DNA from E.coli (STET PREP) (Holmes and Quigley 1981)}

E.coli overnight cultures were harvested by centrifugation (13.000 rpm 1 minute) and resuspended in $400 \mu \mathrm{l}$ STET-buffer (8\% sucrose, $0,5 \%$ triton X-100, 50mJM EDTA, $50 \mathrm{mM}$ Tris- $\mathrm{HCl} \mathrm{pH} 8,0)$. Lysis was triggered by addition of $25 \mu$ lysozyme $(12 \mathrm{mg} / \mathrm{ml})$ for 5 minutes and followed by 40 seconds incubation in a boiling water bath. Cell fragments were pelleted by centrifugation (13.000 rpm, 15 minutes) at $4^{\circ} \mathrm{C}$. the sticky pellet was removed by a wooden toothpick. Plasmid DNA was precipitated by addition of $50 \mu 13 \mathrm{M}$ sodium acetate $(\mathrm{pH} 4,8)$ and $500 \mu 1$ isopropanol. After centrifugation (13.000 rpm, 15 minutes, $4^{\circ} \mathrm{C}$ ), the DNA pellet was washed with $70 \%$ ethanol and air dried until it was solved in $50 \mu$ l elution buffer (QIAGEN).

\subsubsection{QIAGEN Spin-Plasmid DNA Mini-Preparation (QIAGEN, Hilden D)}

E.coli overnight cultures were harvested by centrifugation (13.000 rpm 1 minute) and treated as described.

\subsubsection{Polymerase Chain Reaction (PCR) (Saiki et al. 1985)}

PCR reactions were carried out using the thermo-stable Taq-, Pfu- or KODPolymerase. In general, oligonucleotides were used in a concentration of $5 \mu \mathrm{M}$, DNA 
in 10ng plasmid DNA in $50 \mu 1$ reaction mixtures. The following temperature profile was applied after a starting denaturation lasting 3 minutes at $94^{\circ} \mathrm{C}$ : 1 minute $94^{\circ} \mathrm{C}, 1$ minute $50^{\circ} \mathrm{C}$ and finally the DNA amplification, which lasted according to template size and the used DNA Polymerase.

\subsubsection{DNA Restriction}

Analytical restrictions required $0,5 \mu \mathrm{g}$ DNA digested at $37^{\circ} \mathrm{C}$ for $2 \mathrm{~h}$ by $1-2$ units of restriction enzymes (MBI FERMENTAS, Lit.). Preparative restrictions required, depending on the strategy, more DNA.

\subsubsection{Agarose Gel-Electrophoresis}

DNA solutions were mixed with 0,2 volumes DNA sample buffer (30\% glycerol, $0,25 \%$ brominephenolblue, $0,25 \%$ Xylenecyanol) and put on a $1 \%$ horizontal Agarose gel in TAE-buffer (40mM Tris, 20mM sodium acetate, $2 \mathrm{mM}$ EDTA pH 8,3) in presence of $0,5 \mu \mathrm{g} / \mathrm{ml}$ ethidiumbromide and run at $80 \mathrm{mV}$. DNA bands were detected on a UV-transilluminator at a wavelength of $\lambda=254 \mathrm{~nm}$. Size determination of fragments was done using "GENE RULER 1kb DNA ladder" (MBI FERMENTAS, Lit) as comparison.

\subsubsection{Isolation of DNA Fragments (QIAGEN, Hilden D)}

The desired band was cut out of the Agarose gel and treated as described (Quiaquick Gel extraction kit). DNA fragments were solved in distilled water and stored at -20 until they were used.

\subsubsection{Ligation of DNA Fragments}

Linear DNA fragments (ca. $5 \mu \mathrm{g}$ ) were incubated overnight at $16^{\circ} \mathrm{C}$ or for two hours at room temperature in $20 \mu 1$ of a mixture consisting of 5 units T4-DNA-ligase (MBI FERMENTAS, Lit.) and the appropriate buffer. Molar proportions between vector and insert were chosen about 1:5 to 1:10. After ligation, the DNA could directly be transformed into the desired host. 


\subsubsection{Quick DNA Preparation from Yeast (Hoffman and Winston 1987)}

A $10 \mathrm{ml}$ overnight culture was harvested $(13.000 \mathrm{rpm}, 1$ minute) by repeated centrifugation in a $2 \mathrm{ml}$ eppendorf tube. The supernatant was removed and the cells were washed in $0,5 \mathrm{ml}$ distilled water and centrifuged again (13.000 rpm, 1 minute). The supernatant was discarded and the cell resuspended in the residual liquid. Then, $0,2 \mathrm{ml}$ lysis buffer (2\% triton X-100,1\% SDS, $100 \mathrm{mM} \mathrm{NaCl}, 10 \mathrm{mM}$ Tris, $1 \mathrm{mM}$ EDTA $\mathrm{pH} 8,0$ ) together with $0,2 \mathrm{ml}$ Phenol/ $\mathrm{MeCl}_{2} /$ Tris-EDTA and $200 \mu \mathrm{l}$ of glass beads was added and vortexed at $4^{\circ} \mathrm{C}$. The crude extracts were spinned at maximum speed in a microfuge and the upper aqueous layer was transferred to a fresh tube. To precipitate DNA, $1 \mathrm{ml}$ ethanol was added and the tube content was mixed by inversion. 5 minutes of centrifugation at maximum microfuge speed pelleted the DNA, which was solved in $0,4 \mathrm{ml}$ Tris-EDTA and $\mu 1 \mathrm{RNase}(10 \mathrm{mg} / \mathrm{ml})$. After ten minutes of incubation, again ethanol was added together with the caotrophic salt ammonium sulfate (10 $\mu 1$ of $4 \mathrm{M}$ solution). Mixing and a following centrifugation resulted in a transparent pellet, which was finally solved in $50 \mu 1$ Tris-EDTA.

\subsubsection{Silver Staining of Protein Gels (Copeland et al. 1982)}

Fixation of SDS gels was carried out by two 40 minutes incubation-steps in Fixationsolution 1 (30\% ethanol, 10\% pure acetic acid) and Fixation-solution 2 ( 30\% ethanol, 0,5M sodium acetate, 0,5\% glutaric-acid-di-aldehyde, 0,2\% sodium thiosulfate). Subsequent washing (3 times) in distilled water removed all traces of thiosulfate before silver nitrate solution $3(0,1 \%$ silver nitrate, $0,02 \%$ formic aldehyde) was applied to the gel. Residual silver was removed in a washing step with distilled water. The gel was stained by solution $4\left(2,5 \% \mathrm{Na}_{2} \mathrm{CO}_{3}, 0,01 \%\right.$ formic aldehyde) and stopped by stop-solution 5 (0,05M EDTA) when the appropriate degree of staining was achieved.

\subsection{Transformation Methods}

\subsubsection{Preparation of Competent E.coli (Mandel and Higa 1970)}

$250 \mathrm{ml}$ SOB medium were inoculated with E.coli (DH5 $\alpha$ or XL1 blue) in a 2L Erlenmeyer flask and shaken at $18^{\circ} \mathrm{C}$ at $200 \mathrm{U} / \mathrm{min}$ for at least $24 \mathrm{~h}$ until an $\mathrm{OD}_{600}$ of 
0,6 was achieved. The cells were chilled on ice for 10 minutes until they were harvested by centrifugation $\left(5000 \mathrm{x} \mathrm{g}, 10 \mathrm{~min}, 4^{\circ} \mathrm{C}\right)$. The bacterial pellet was resuspended in $80 \mathrm{ml}$ of ice-cold transformation buffer (10mM pipes, $15 \mathrm{mM} \mathrm{CaCl}_{2}$, $250 \mathrm{mM} \mathrm{KCl}, 55 \mathrm{mM} \mathrm{MnCl}_{2} \mathrm{pH} \mathrm{6,7)}$ and centrifuged (5000 x g, $10 \mathrm{~min}, 4^{\circ} \mathrm{C}$ ) again. Then, the cells were carefully resuspended in $20 \mathrm{ml}$ transformation buffer until Dimethylsulfoxide was added at a final concentration of $7 \%$. Careful mixing was followed by another chilling step on ice before the cells were frozen in $200 \mu$ aliquots in liquid nitrogen and stored at $-80^{\circ} \mathrm{C}$ until they were used.

\subsubsection{Transformation of E.coli (Mandel and Higa 1970)}

Frozen, competent E.coli were defrosted on ice and incubated for $30 \mathrm{~min}$ on ice with 1 $\mu 1$ of DNA to be transformed. After a heat shock $\left(45 \mathrm{~s}\right.$ at $\left.42^{\circ} \mathrm{C}\right), 800 \mu \mathrm{l}$ of LB medium were added and the mixture was kept at $37^{\circ} \mathrm{C}$ for $1 \mathrm{~h}$. Cells were finally plated out on appropriate selective media.

\subsubsection{One-Step Transformation of Saccharomyces cerevisiae}

15 to $20 \mathrm{ml}$ of an overnight culture in YP medium containing glucose were harvested at an $\mathrm{OD}_{600}$ of 0,8 to 1 . The pellet was resuspended in $1 \mathrm{ml}$ „One-Step-Buffer“ $(0,2 \mathrm{M}$ lithium acetate, 40\% poly-ethylene-glycol and 100mM DTT). To $100 \mu 1$ of this mixture, $50 \mathrm{ng}$ to $1 \mu \mathrm{g}$ of plasmid DNA were added together with $6 \mu \mathrm{l}$ of salmon sperm DNA (10 mg/ml), which served as carrier. The suspension was vortexed and heat shocked $\left(30 \mathrm{~min} 45^{\circ} \mathrm{C}\right.$, for ts-strains $15 \mathrm{~min}$ at $30^{\circ} \mathrm{C}$ !) until $100 \mu \mathrm{l}$ of medium were added to ease plating on appropriate solid media.

\subsubsection{Transformation of Linearized DNA Fragments for Integration in Saccharomyces cerevisiae}

$0,5 \mathrm{ml}$ of a saturated overnight culture was harvested by centrifugation (13.000 rpm 1 $\mathrm{min}$ ) and resuspended in a buffer containing $40 \%$ poly-ethylene-glycol, 0,1 M lithium acetate, $10 \mathrm{mM}$ Tris, $1 \mathrm{mM}$ EDTA, 0,1 M DTT pH 7,5. Then $100 \mu \mathrm{g}$ of salmon sperm carrier DNA and appropriate amount of DNA to be transformed was added and incubated overnight at room temperature. A heat shock $\left(42^{\circ} \mathrm{C}, 15 \mathrm{~min}\right)$, which was 
omitted using ts-strains, was followed by addition of $800 \mu \mathrm{l} \mathrm{YP}$ medium. After one hour of incubation at $30^{\circ} \mathrm{C}\left(25^{\circ} \mathrm{C}\right.$ using ts-strains $)$, the cells were plated out on appropriate selective media.

\subsection{Other Saccharomyces cerevisiae Methods}

\subsubsection{Sporulation of Saccharomyces cerevisiae (Cao et al. 1990)}

A YP pre-culture was inoculated with a single colony and grown for $36 \mathrm{~h}$ at $30^{\circ} \mathrm{C}$ until stationary phase. Afterwards, $200 \mathrm{ml}$ of YP acetate medium was inoculated by addition of $4 \mathrm{ml}$ pre-culture in a 11 Erlenmeyer flask. For better aeration, several holes were picked into the aluminium foil cover of the flask. This culture was shaken (230 $\mathrm{U} / \mathrm{min}$ ) for $13,5 \mathrm{~h}$ at $30^{\circ} \mathrm{C}$ until the cells were harvested by centrifugation (1800 $\mathrm{U} / \mathrm{min}, 5 \mathrm{~min}$ ) and washed once with water. Then, cells were shifted to $400 \mathrm{ml}$ SPOmedium in a 21 Erlenmeyer flask and shaken at $30^{\circ} \mathrm{C}, 230 \mathrm{U} / \mathrm{min}$. The flask remained uncovered for optimal aeration. To observe the course of sporulation, samples were taken during the following $10 \mathrm{~h}$ and treated for immunofluorescence microscopy or Western Blot.

\subsubsection{Crossing of Yeast Strains and Tetrade Dissection}

Small portions of two haploid yeast strains of the opposite mating type were suspended in a drop of sterile water on a YPD plate and incubated at $30^{\circ} \mathrm{C}$ or $25^{\circ} \mathrm{C}$ in case of $t s$-strains. After $6 \mathrm{~h}$, zygotes were dissected under the micro manipulator or grown on selective media.

For sporulation, zygotes were grown overnight on YPD plates and shifted to SPO medium plates. After two or three days of incubation, tetrades could be dissected. For this purpose, the cells were treated with $50 \mu 11 \mathrm{M}$ Sorbitol and 2,5 $\mu 1$ Zymolyase $(10 \mathrm{mg} / \mathrm{ml})$ for $10 \mathrm{~min}$ at $30^{\circ} \mathrm{C}$. The cells were carefully resuspended in $200 \mu 1$ sterile water. $25 \mu 1$ of this suspension were pipetted to the border of a YPD plate. Finally, spores could be dissected from the dried suspension, dissected under the micro manipulator and grown either on YPD or selective plates. 


\section{Results}

\subsection{Smt3/SUMO and Ubc9 are Required for Efficient Securin Degradation in Budding Yeast}

Ubiquitin-mediated proteolysis triggered by the anaphase-promoting complex/cyclosome (APC/C) is essential for sister chromatid separation and the mitotic exit. Like ubiquitylation, protein modification with the small ubiquitin-related modifier SUMO appears to be important during mitosis, because yeast cells impaired in the SUMO-conjugating enzyme Ubc9 were found to be blocked in mitosis and defective in cyclin degradation. Here, we analyzed the role of SUMOylation in the metaphase/anaphase transition and in APC/C-mediated proteolysis in Saccharomyces cerevisiae. We show that cells depleted of Ubc9 or Smt3, the yeast SUMO protein, mostly arrested with undivided nuclei and with high levels of securin Pds1. This metaphase block was partially relieved by a deletion of $P D S 1$. The absence of Ubc9 or Smt3 also resulted in defects in chromosome segregation. Temperature-sensitive ubc9-2 mutants were delayed in proteolysis of Pds1 and of cyclin Clb2 during mitosis. The requirement of SUMOylation for APC/C-mediated degradation was tested more directly in G1-arrested cells. Both $u b c 9-2$ and smt3-331 mutants were defective in efficient degradation of Pds1 and mitotic cyclins, whereas proteolysis of unstable proteins that are not APC/C substrates was unaffected. We conclude that SUMOylation is needed for efficient proteolysis mediated by $\mathrm{APC} / \mathrm{C}$ in budding yeast.

\subsubsection{Yeast Cells Depleted of Ubc9 and Smt3 Arrest With Short Spindles and} High Levels of Pds 1

It was reported previously that yeast $u b c 9$ cells, which were kept alive by $U B C 9$ expressed from the galactose-inducible GAL1-10 promoter, arrested in mitosis upon promoter shut-off in glucose medium (Seufert et al. 1995). Despite this cell cycle defect, we found that most cells of an $u b c 9$ GAL-UBC9 strain were viable and able to form colonies on plates containing glucose (data not shown). These findings prompted us to reinvestigate the requirement of $U B C 9$ for viability, by analyzing cells completely depleted of Ubc9. Haploid segregants containing the $u b c 9$ allele were 
obtained from a sporulating heterozygous diploid $U B C 9 / u b c 9$ strain. The analysis of about 30 haploid $u b c 9$ segregants revealed that cells lacking $U B C 9$ were able to produce micro colonies (Figure 12), mostly consisting of 30-50 cells, before cells ceased cell division and finally lysed.

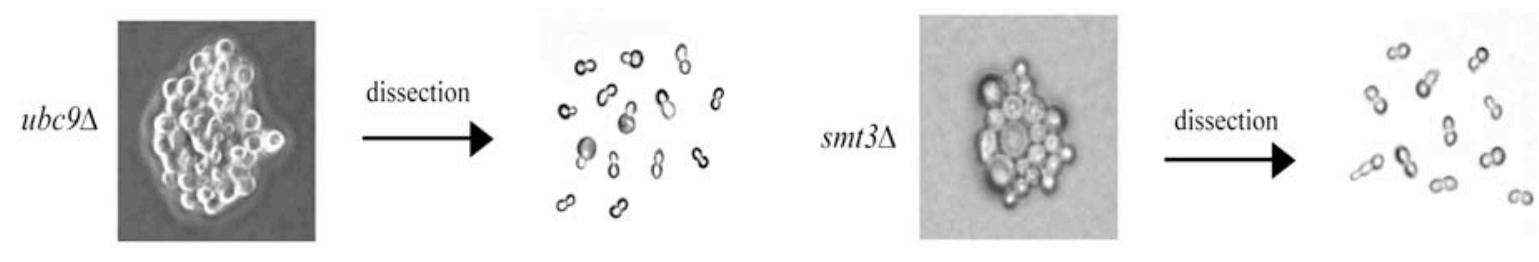

Figure 11: $u b c 9 \Delta$ and smt3 $\Delta$ Cells Divide a Few Times but Fail to Form Colonies

Diploid $U B C 9 / u b c 9$ and diploid SMT3/smt3 yeast strains were sporulated, and tetrades were dissected. Spores were grown on YEPD plates at $30^{\circ} \mathrm{C}$. Representative segregants containing the $u b c 9$ and $s m t 3$ alleles were photographed after $36 \mathrm{~h}$. Micro colonies from segregants containing the deletion alleles were dissected with a micromanipulator to determine the phenotype of individual cells.

Thus, $u b c 9$ segregants were able to divide on average four to six times, implying that Ubc9 protein inherited from the parental diploid strain is sufficient for $u b c 9$ cells to undergo several cell divisions. A depletion of the SUMO protein Smt3 resulted in a similar phenotype. $s m t 3$ segregants obtained from a $S M T 3 / s m t 3$ diploid strain were able to undergo three to five cell divisions on average. Thus, low amounts of Ubc9 and Smt3 are sufficient for viability. The dissection of $u b c 9$ and $\operatorname{sit} 3$ cell micro colonies showed that at least $80 \%$ of these cells were large budded, suggesting that they terminally arrested in $\mathrm{G} 2 / \mathrm{M}$ phase. These findings underline the essential role of Ubc9 and Smt3 in G2/M phase.

To characterize further the mitotic arrest of cells defective in SUMOylation, we introduced a Myc-tagged version of Pds1 into a strain in which the SMT3 gene was replaced by a GAL-SMT3 construct (Biggins et al. 2001) and into an $u b c 9$ GAL-UBC9 strain. These strains were pre-grown in galactose medium and then transferred to glucose medium. After a $15 \mathrm{~h}$ incubation period, most of the cells were large budded. Nuclei, spindles and Pds1-Myc were analyzed by indirect immunofluorescence. About $70-80 \%$ of these large-budded cells had a single nucleus and a short mitotic 
spindle, and virtually all these cells contained Pds1-Myc (Figure 12A and B). In contrast, $20-30 \%$ of large-budded cells had elongated anaphase spindles, and Pds1Myc signals were only rarely detectable. Only a few cells had clearly separated masses of DNA. Instead, the DAPI signal was often dispersed, and chromosomes appeared to be lagging along the spindles (Figure 12B, arrow), indicating that these cells failed to segregate chromosomes to opposite poles properly. We then asked whether the metaphase arrest of Smt3-depleted cells and the failure to degrade Pds1 might be caused by the activation of the spindle checkpoint (Wassmann and Benezra 2001). To test this, we constructed a GAL-SMT3 strain lacking MAD2, a gene required for the checkpoint arrest (Li and Murray 1991). Upon a shift to glucose medium, the GAL-SMT3 mad2 strain arrested similarly to the GAL-SMT3 strain (Figure 12A and B). The percentage of cells containing short spindles and the Pds1-Myc signal was not reduced, implying that the metaphase block of Smt3-depleted cells is independent of $\operatorname{Mad} 2$.

These results show that SUMOylation is needed for Pds1 degradation and the onset of anaphase, independently of the spindle checkpoint.

\subsubsection{Deletion of PDS1 Alleviates Anaphase Onset in Ubc9-Depleted Cells}

We next addressed the question whether the metaphase arrest of cells defective in SUMOylation may be caused by a failure to degrade Pds1. We argued that a deletion of the PDS1 gene would then allow these cells to elongate their spindles and segregate their chromosomes, as shown previously for other mutants defective in metaphase, such as apc or $c d c 20$ mutants (Yamamoto et al. 1996; Lim et al. 1998). To test this, we crossed $p d s 1$ mutants with an $u b c 9 G A L-U B C 9$ strain and received an $u b c 9 G A L-$ $U B C 9 \mathrm{pds} 1$ strain that was reasonably viable at $25^{\circ} \mathrm{C}$. This strain and an $u b c 9 G A L-$ $U B C 9$ control strain were pre-grown at $25^{\circ} \mathrm{C}$ in galactose medium and then transferred to glucose medium. A large fraction of $u b c 9 G A L-U B C 9 p d s 1 \Delta$ cells were large budded after incubation in glucose medium, and these were analyzed by immunofluorescence microscopy (Figure 12A and B). In contrast to $u b c 9$ GAL-UBC9 cells containing the PDS1 gene, about $50 \%$ of $p d s 1 \Delta$ cells had elongated spindles and separated or dispersed DNA masses. DNA masses were only poorly segregating in many cells containing elongated spindles, indicating defects in chromosome segregation. Thus, a deletion of PDS1 partially suppresses the metaphase arrest of 
Ubc9-depleted cells, implying that the metaphase block of cells defective in SUMOylation is caused, at least in part, by a failure to degrade Pds1.

A

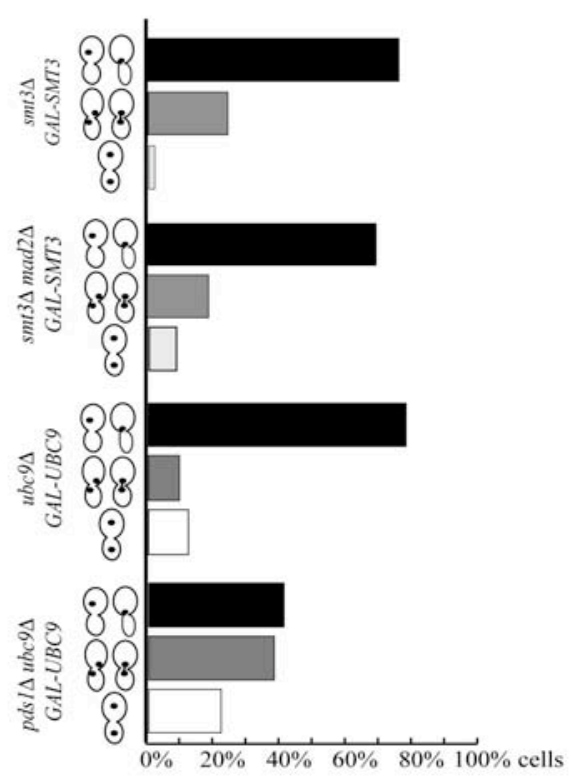

B
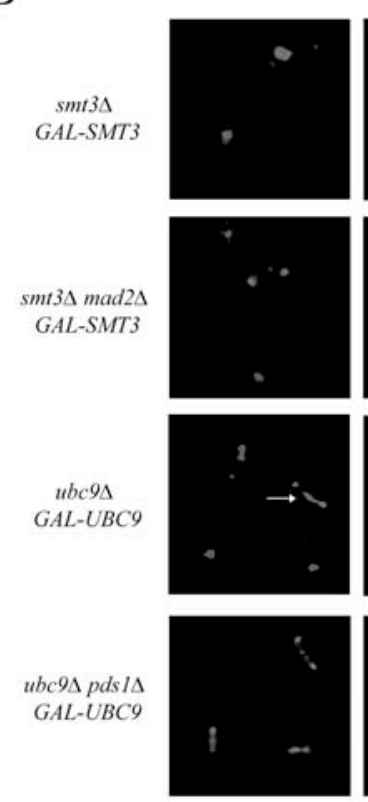

anti-Myc
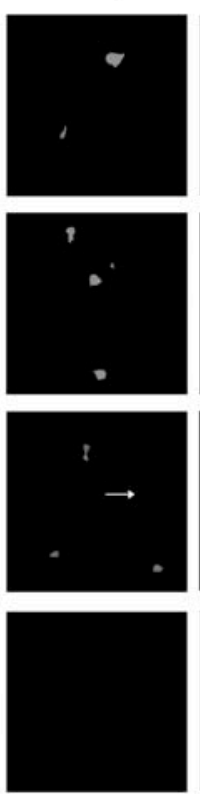

anti-Tubulin
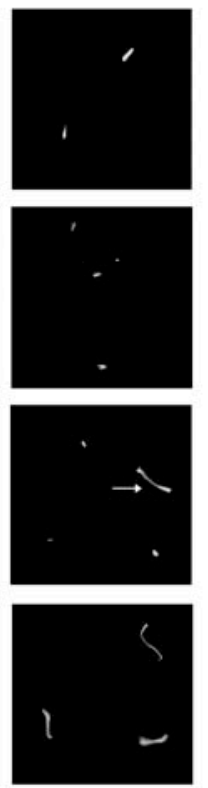

Figure 12: Yeast Cells Depleted of Ubc9 and Smt3 Mostly Arrest in Metaphase With High Pds1 Levels, But This Arrest Can Be Bypassed by a Deletion of PDS1.

The following yeast strains were used for these experiments: (i) a strain containing SMT3 expressed from the GAL1-10 promoter instead of the wildtype SMT3 gene (smt3 GAL-SMT3, S550); (ii) a strain containing in addition a deletion of the MAD2 gene (smt3 mad2A, GAL-SMT3, S566); (iii) a strain with a deletion of the $U B C 9$ gene, but kept alive by the $U B C 9$ gene from the $G A L 1-10$ promoter ( $u b c 9 G A L$ $U B C 9, \mathrm{~S} 552$ ); and (iv) a strain containing in addition a deletion of the PDS1 gene (ubc 9 GAL-UBC9 $p d s 1 \Delta$, S483). Strains (i)-(iii) also contained a Myc18-tagged version of Pds1. These strains were pregrown in YEP medium containing 2\% raffinose and 2\% galactose. Cells were then transferred to YEP medium containing 2\% glucose (YEPD) and incubated for $15 \mathrm{~h}$. Subsequently, cells were collected for indirect immunofluorescence microscopy. Large-budded cells were analyzed using DAPI, anti-tubulin antibodies and anti-Myc antibodies to visualize nuclei, spindles and Pds1-Myc respectively. A. Analysis of large-budded cells. Black columns, percentage of cells with short spindles and a single nucleus; gray columns, percentage of cells with elongated spindles and dispersed or barely separated nuclei; white columns, percentage of cells with elongated spindles and distinctly separated nuclei. At least 200 cells from each strain were analyzed. B. DAPI, anti-tubulin and anti-Myc staining of representative cells the arrow marks a cell containing a dispersed nucleus and an elongated spindle.

\subsection{3. ubc9-2 ts-Mutants Are Delayed in Degradation of Securin Pds1 and}

\section{Cyclin Clb2 During Mitosis}

To characterize further the role of Ubc9 in mitosis, we used a temperature-sensitive $u b c 9-2$ mutant. The cell cycle arrest of this mutant at the restrictive temperature was less distinct than for Ubc9-depleted cells. After a shift for to $37^{\circ} \mathrm{C} 4 \mathrm{~h}$, both large- 
budded and unbudded cells accumulated, but the number of small-budded cells was reduced compared with wildtype cultures (data not shown). A similar phenotype was described previously for a smt3-331 temperature-sensitive mutant, which only moderately accumulated G2/M cells at the non-permissive temperature (Biggins et al. 2001). By analyzing large-budded cells of $u b c 9-2$ mutants containing a Myc-tagged version of Pds1 by immunofluorescence microscopy, we found that about $70 \%$ of these cells contained short spindles, whereas about $30 \%$ of cells had elongated spindles (Figure 13A). Virtually every cell with a short spindle contained a Pds1-Myc signal (data not shown). $u b c 9-2$ mutants containing long spindles frequently failed to segregate chromosomes to opposite poles properly. In an $u b c 9-2$ mad $2 \Delta$ mutant strain, cells arrested with short spindles and similarly accumulated Pds1-Myc, as in $u b c 9-2$ mutants, implying that the observed mitotic delay occurs independently of the spindle checkpoint. This phenotype of $u b c 9-2$ mutants was similar to that described previously for smt3-331 mutants (Biggins et al. 2001). Thus, both $u b c 9-2$ and smt3331 mutants are characterized by the accumulation of cells with undivided nuclei and by obstructions in chromosome segregation.

we next monitored the levels of Pds1 and cyclin Clb2 in synchronized wildtype and $u b c 9-2$ cultures. For this purpose, cultures were pre-grown at $25^{\circ} \mathrm{C}$ and then arrested in G1 phase with $\alpha$-factor. Subsequently, cells were shifted to $36^{\circ} \mathrm{C}$ and released from the pheromone arrest. Both wildtype and $u b c 9-2$ strains synchronously entered the cell cycle, as monitored by the appearance of small buds. The $u b c 9-2$ mutation affected neither budding nor the initiation of DNA replication (data not shown). Immunoblot analysis revealed that haemagglutinin (HA)-tagged Pds1 and Clb2 accumulated with similar kinetics in wildtype cells and $u b c 9-2$ mutants (Figure 13B and $\mathrm{C}$ ). However, $u b c 9-2$ cells were delayed in the degradation of Pds1 and Clb2. At the 75 min time point, Pds1 levels were decreased in wildtype cells, but remained at high levels in the mutant strain, before they dropped with a 15 min delay (Figure 13B and $\mathrm{C}$ ). The $\mathrm{Clb} 2$ protein levels decreased in the wildtype culture after $90 \mathrm{~min}$, whereas only a slow decrease occurred in $u b c 9-2$ mutants at later time points.

These results show that proteolysis of the two APC/C substrates Pds1 and $\mathrm{Clb} 2$ is delayed in $u b c 9-2$ mutants, suggesting that proper proteolysis of these substrates during mitosis requires a functional $\mathrm{Ubc} 9$ protein. 
A

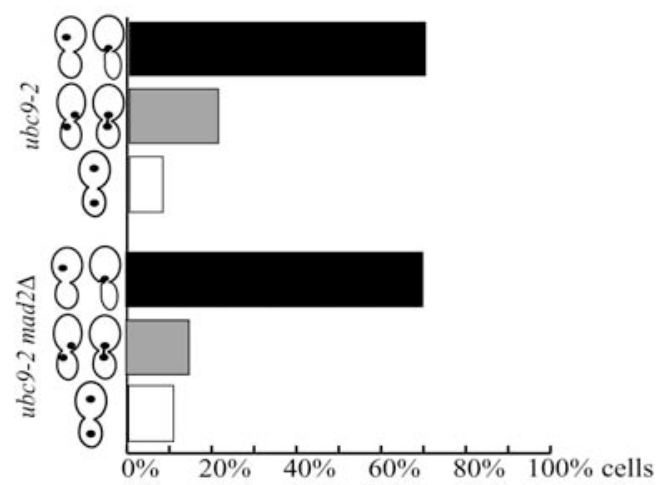

$\mathrm{B}$

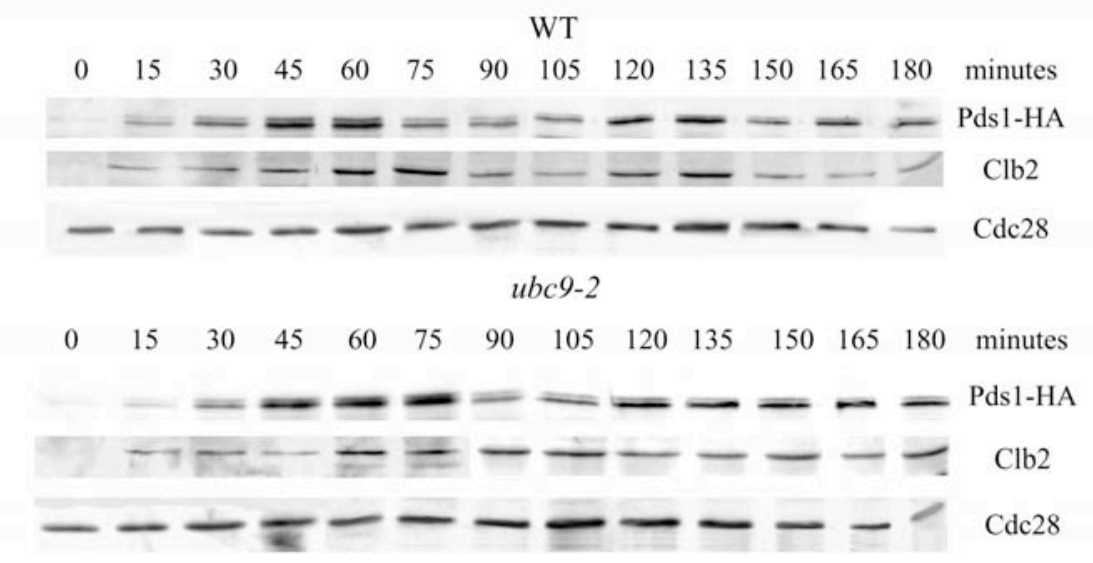

C
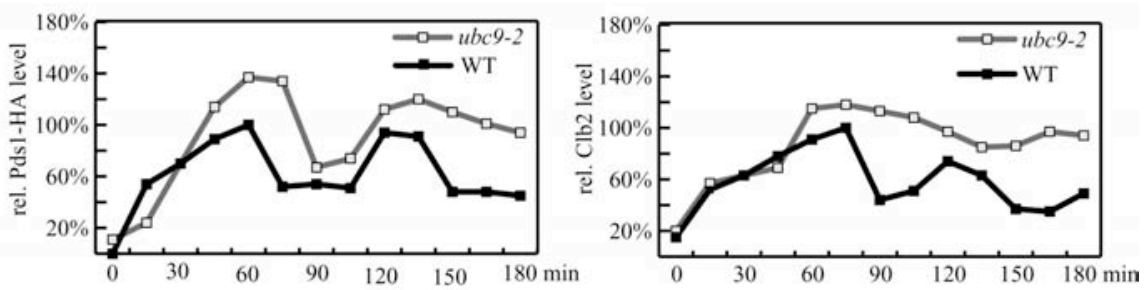

Figure 13: Temperature-Sensitive $u b c 9-2$ Mutants are Delayed in Degradation of Pds1 and Clb2. A. $u b c 9-2$ (S546) and $u b c 9-2$ mad2 $\Delta$ (S568) mutants, both containing an Myc18-tagged version of $\mathrm{Pds} 1$, were pre-grown at $25^{\circ} \mathrm{C}$ and then shifted to $37^{\circ} \mathrm{C}$ for $4 \mathrm{~h}$. Then, cells were collected for indirect immunofluorescence microscopy. Large-budded cells were analyzed by DAPI, anti-tubulin antibodies and anti-Myc antibodies to visualize nuclei, spindles and Pds1-Myc respectively. Black columns, percentage of cells with short spindles and a single nucleus; gray columns, percentage of cells with elongated spindles and dispersed or barely separated nuclei; white columns, percentage of cells with elongated spindles and distinctly separated nuclei. At least 200 cells from each strain were analyzed. B and C. Log-phase cultures of a wildtype strain (S185) and a $u b c 9-2$ mutant strain (S406), both containing PDS1-HA, were pre-grown in YEPD medium at $25^{\circ} \mathrm{C}$ and then treated with the pheromone $\alpha$-factor for $2.5 \mathrm{~h}$. Then, cultures were shifted to a restrictive temperature, $36^{\circ} \mathrm{C}$, and incubated for an additional $30 \mathrm{~min}$ in the presence of $\alpha$-factor. To remove the pheromone, cells were filtered, washed and transferred to fresh YEPD medium. Synchronized cultures were incubated further at $36^{\circ} \mathrm{C}$. At the indicated time points after the release, samples were collected and analyzed by immunoblotting, using the HA antibody to detect Pds1-HA and Clb2 antibodies to visualize $\mathrm{Clb} 2(\mathrm{~B})$. Cdc28 was used as a loading control. Pds1-HA and $\mathrm{Clb} 2$ protein levels were quantified using a densitometer (C). 


\subsubsection{Proteolysis of Securin Pds1 Depends on UBC9 and SMT3}

To test more directly whether Ubc9 and Smt3 are required for Pds1 proteolysis, we tested its stability in $\alpha$-factor-arrested G1 cells. In these G1 cells, APC/C is fully active, and Pds1 is highly unstable (Amon et al. 1994; Cohen-Fix et al. 1996). The stability of Pds1 in cells arrested in G1 phase was determined by promoter shut-off experiments. Wildtype cells, $u b c 9-2$ and smt3-331 mutants were arrested with $\alpha-$ factor at $25^{\circ} \mathrm{C}$, and then $P D S 1-H A$ was transiently expressed by galactose addition. After a temperature shift to $36^{\circ} \mathrm{C}, P D S 1-H A$ expression was turned off by transferring cells to glucose medium. In wildtype cells, Pds1 was rapidly degraded under these conditions (Figure 14).

A

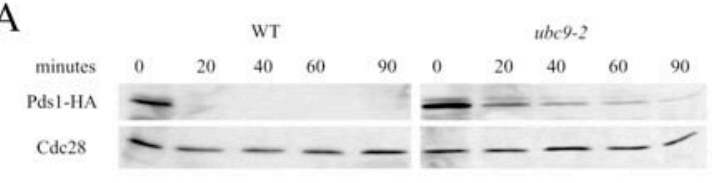

B

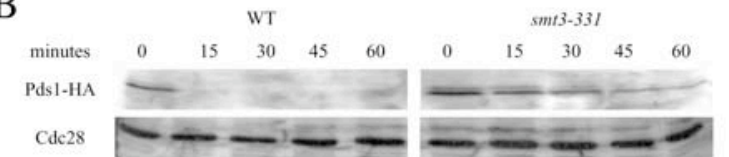

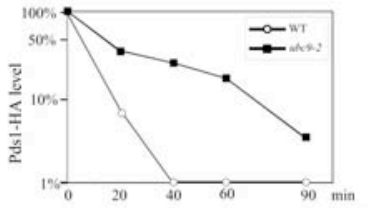

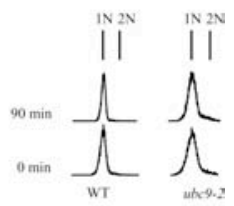

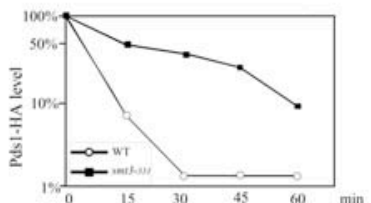

Figure 14: Proteolysis of Securin Pds1 is Impaired in Yeast $u b c$ 9-2 and smt3-331 Mutants. A. A wildtype strain (S206) and an $u b c 9-2$ (S365) mutant strain, both containing barl deletions and GAL-PDS1-HA constructs, were pre-grown in YEP + raffinose medium at $25^{\circ} \mathrm{C}$ to $\log$ phase. $\alpha$-factor was added to arrest cells in G1 phase. After $2.5 \mathrm{~h}$ incubation with $\alpha$-factor, galactose (2\%) was added to induce PDSI-HA expression. After $30 \mathrm{~min}$, cultures were shifted to the restrictive temperature, $36^{\circ} \mathrm{C}$, and incubated for another $30 \mathrm{~min}$. To turn off the GAL1-10 promoter, the cultures were filtered, transferred to YEPD medium containing $\alpha$-factor and incubated at $36^{\circ} \mathrm{C}$. Samples were collected at the indicated time points and analyzed by immunoblotting. The HA antibody was used to detect Pds1-HA. Cdc28 served as a loading control. Pds1-HA protein levels were quantified using a densitometer. Samples at 0 and 90 min time points were collected for determining the DNA content by FACS analysis to confirm the G1 arrest (right). Microscopic analysis showed that more than $90 \%$ of cells were unbudded and displayed a shmoo-like phenotype. B. A wildtype strain (S206) and a smt3-331 (S535) mutant strain, both containing barl deletions and GAL-PDS1-HA constructs, were treated as described in (A). Samples at the 0 and 60 min time points were analyzed by FACS (right). Microscopic analysis confirmed that more than $90 \%$ of cells were unbudded. Proteolysis of cyclin and non-cyclin APC/C substrates is impaired in $u b c 9-2$ and $s m t 3-331$ mutants 
In $u b c 9-2$ and smt3-331 mutants, Pds1 proteolysis was inefficient, and its half-life increased to more than $10 \mathrm{~min}$, compared with less than $5 \mathrm{~min}$ in wildtype cells. The analysis of the DNA content by fluorescence-activated cell sorting (FACS) analysis confirmed that cultures remained arrested in G1 phase during the course of the experiment. Thus, proteolysis of Pds1 is impaired in the absence of functional Ubc9 and Smt3 proteins, suggesting that SUMOylation is required for efficient securin degradation during G1 phase.

Previous results described a role for Ubc9 in the degradation of cyclins $\mathrm{Clb} 2$ and $\mathrm{Clb} 5$ (Seufert et al. 1995). These and our results indicate that SUMOylation may generally be required for proteolysis mediated by APC/C. To address these assumptions, we tested whether $u b c 9-2$ and smt3-331 mutants are defective in degradation of cyclin and non-cyclin substrates. Consistent with the defects observed previously with $u b c 9$ 1 mutants (Seufert et al. 1995), Clb2 was partially stabilized in smt3-331 mutants (Figure 15A). To test whether a further mitotic cyclin, $\mathrm{Clb} 3$, is stabilized in $u b c 9-2$ and smt3-331 mutants, we performed promoter shut-off experiments. We found that proteolysis of $\mathrm{Clb} 3$ was delayed in $s m t 3-331$ and $u b c 9-2$ mutants (Figure 15B and C). The stabilization of $\mathrm{Clb} 2$ and $\mathrm{Clb} 3$ in G1-arrested cells suggests that $\mathrm{Ubc} 9$ and $\mathrm{Smt} 3$ are required for efficient proteolysis of mitotic cyclins.

To test the requirement of Ubc9 for degradation of another non-cyclin APC/C substrate, we analyzed the accumulation of the polo-like kinase Cdc5 in G1-arrested cells. Upon expression of CDC5-HA from the GAL1-10 promoter, Cdc5 accumulates only to low levels in wildtype G1 cells, because of its instability (Shirayama et al. 1998). We found that Cdc5 accumulates to higher levels in $u b c 9-2$ mutants than in wildtype cells at the restrictive temperature, indicating that its rapid degradation is impaired (Figure 15D).

In summary, these results indicate that Ubc9 and Smt3 are required for efficient proteolysis of various APC/C substrates, implying that SUMOylation is generally important for the proper function of this ubiquitin ligase.

To elucidate further the involvement of Ubc9 in APC/C-mediated proteolysis, we tested whether the $u b c 9-2$ mutation displays genetic interactions with mutations in the APC/C subunit genes $C D C 16$ and $A P C 10$. Double mutants containing the $u b c 9-2$ mutation in combination with either the $c d c 16-123$ or apc10-22 mutations were constructed. Both $u b c 9-2$ apc10-22 and $u b c 9-2$ cdc16-123 were non-viable at $30^{\circ} \mathrm{C}$, whereas each of the single mutants was viable (data not shown). These synthetic 
phenotypes reveal at least moderate genetic interactions between $U B C 9$ and genes encoding APC/C subunits.

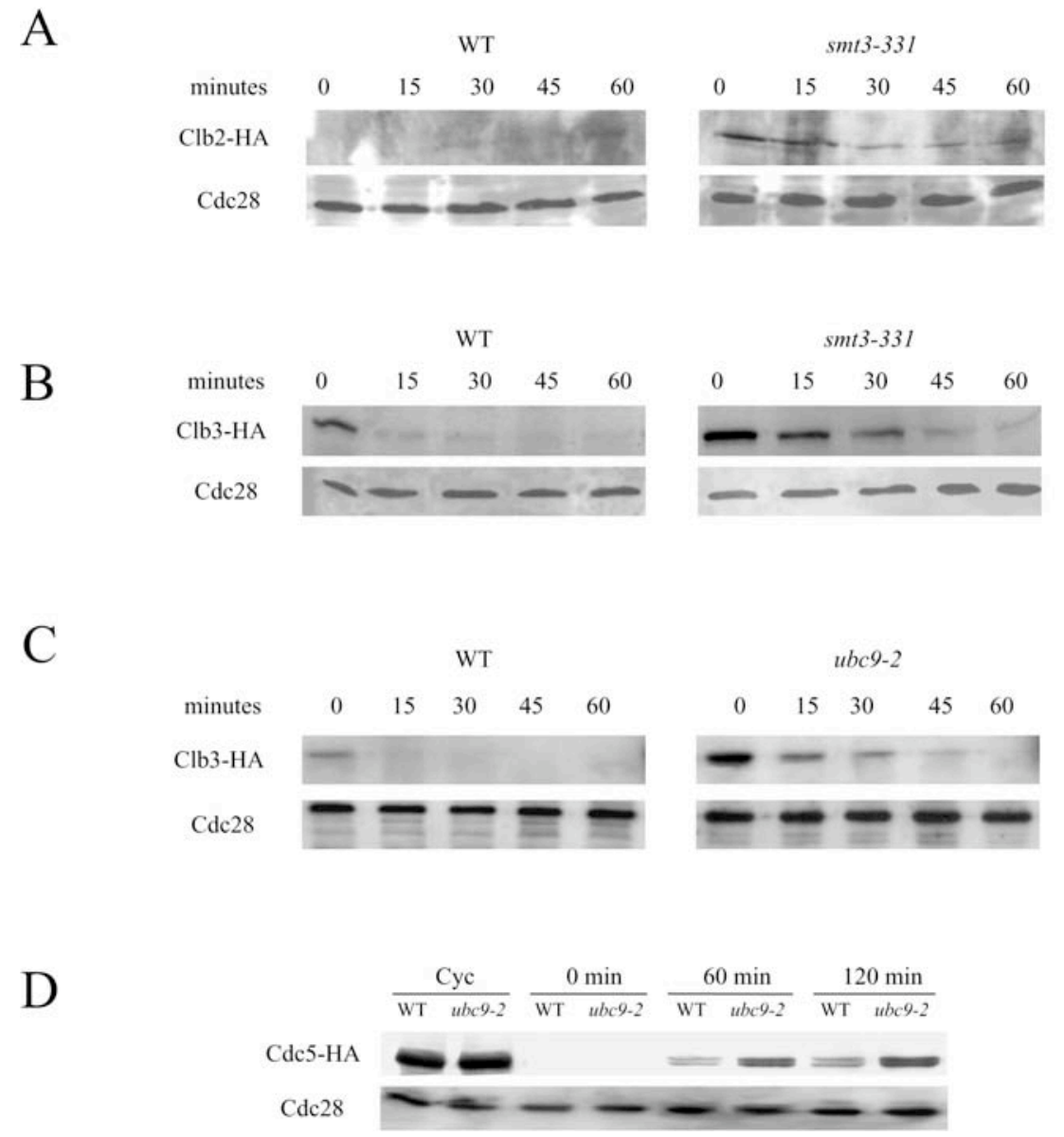

Figure 15: Efficient Proteolysis of APC/C Substrates is Impaired in $u b c 9-2$ and smt3-331 Mutants.

A. A wildtype strain (S057) and a smt3-331 mutant strain (S543), both containing barl deletions and the $G A L-C L B 2-H A$ construct, were pre-grown in YEP medium containing $2 \%$ raffinose at $25^{\circ} \mathrm{C}$. $\alpha$ factor was added to arrest cells in G1 phase. After $3 \mathrm{~h}$ incubation with $\alpha$-factor, galactose (2\%) was added to induce CLB2-HA expression, and then cultures were incubated for $30 \mathrm{~min}$. Then, they were shifted to the restrictive temperature, $36^{\circ} \mathrm{C}$, for another $30 \mathrm{~min}$. To turn off the GAL1-10 promoter, the cultures were filtered, transferred to YEPD medium containing $\alpha$-factor and incubated at $36^{\circ} \mathrm{C}$. Microscopic analysis confirmed that at least $90 \%$ of cells were unbudded and displayed a shmoo-like phenotype, implying that these cells were arrested in G1 phase (not shown). Samples were collected at the indicated time points and analyzed by immunoblotting. The HA antibody was used to detect Clb2HA. Cdc28 served as a loading control. B. A wildtype strain (S056) and a smt3-331 mutant strain (S544), both containing barl deletions and GAL-CLB3-HA constructs, were treated as described in (A). The HA antibody was used to detect Clb3-HA. C. A wildtype strain (S056) and an $u b c 9-2$ mutant strain (S390), both containing barl deletions and GAL-CLB3-HA constructs, were treated as described in (A). The HA antibody was used to detect Clb3-HA. D. A wildtype strain (S088) and a $u b c 9-2$ mutant strain (S487), both containing barl deletions and GAL-CDC5-HA constructs, were pre-grown at $25^{\circ} \mathrm{C}$ overnight in YEP + Raff medium. $\alpha$-factor was added to arrest cells in G1 phase. After $2.5 \mathrm{~h}$, galactose (2\%) was added to induce $C D C 5-H A$ expression. At the same time, cells were shifted to $36^{\circ} \mathrm{C}$ and incubated for $120 \mathrm{~min}$ in the presence of $\alpha$-factor. Microscopic analysis confirmed that at least $90 \%$ of cells were unbudded. Samples were collected at 0,60 and $120 \mathrm{~min}$ and analyzed by immunoblotting. Cyc, sample of cycling cultures at the $120 \mathrm{~min}$ time point. Cdc5-HA levels were analyzed by immunoblotting using the HA antibody. 


\subsubsection{Other Unstable Proteins Are Normally Degraded in ubc9-2 and smt3-}

\section{Mutant Strains}

It may be possible that SUMOylation does not specifically affect APC/C-mediated proteolysis, but may instead be needed for proteolysis in general, for example for the proper function of the $26 \mathrm{~S}$ proteasome. We therefore tested whether $u b c 9-2$ and smt3331 mutants are generally impaired in the rapid degradation of unstable proteins. To test this possibility, we compared the stability of the transcription activator Gen4 in wildtype cells and in $u b c 9-2$ and smt3-331 mutants. Gcn4 proteolysis is not dependent on $\mathrm{APC} / \mathrm{C}$, but is instead a substrate of the SCFCdc4 ubiquitin ligase (Meimoun et al. 2000). Wildtype and mutant strains were transformed with a centromeric plasmid containing a $G A L-G C N 4-M Y C$ construct. GCN4-MYC was transiently expressed by galactose addition. The temperature was shifted to $36^{\circ} \mathrm{C}$, and $\mathrm{Gcn} 4$ stability was determined by transferring cells to glucose medium. We found that Gcn 4 degradation occurred with a similar efficiency in wildtype cells and in $u b c 9-2$ and smt3-331 mutants (Figure 16A). Ime2 is a further unstable protein, the proteolysis of which appears to be independent of the SCF and APC/C ubiquitin ligases (Bolte et al. 2002). To test whether Ime2 is stabilized in $u b c 9-2$ mutants, IME2-HA was transiently expressed in wildtype and mutant cells. We found that Ime 2 is similarly degraded in both strains at the restrictive temperature (Figure 16B).

The undisturbed degradation of Gen 4 and Ime 2 in these mutants suggests that Ubc9 and Smt3 are not generally required for proteolysis of unstable proteins. 
A
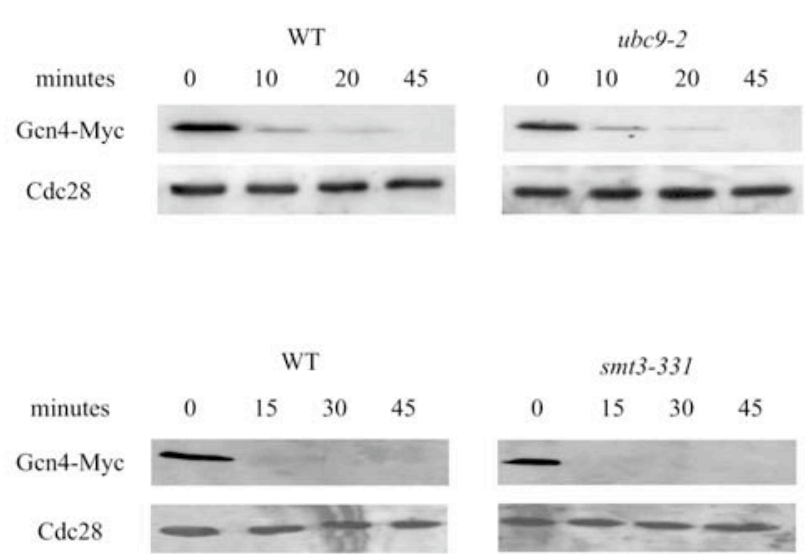

$\mathrm{B}$

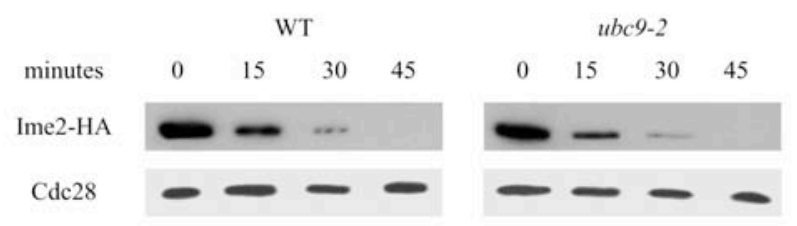

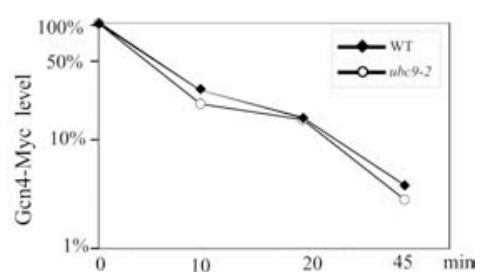
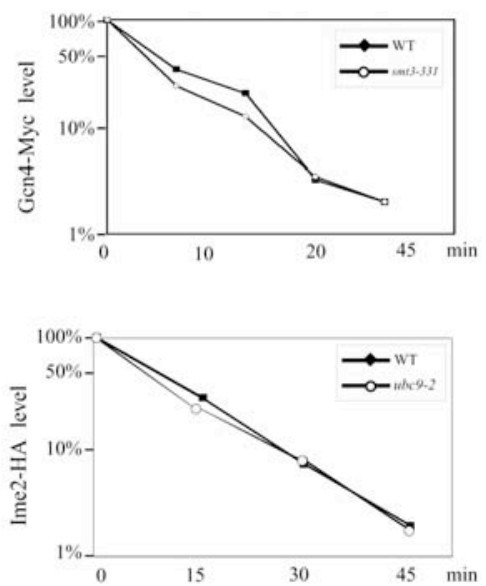

Figure 16: $u b c$ 9-2 and smt3-331 Mutants Are Not Generally Defective in Proteolysis of Unstable Proteins. A. A wildtype yeast strain (S001) and ubc9-2 (S099) and smt3-331 (S542) mutant strains were transformed with a centromeric plasmid containing GAL-GCN4-MYC. Transformants were pregrown at $25^{\circ} \mathrm{C}$ in minimal medium lacking uracil and containing $2 \%$ raffinose. Galactose was added to induce GCN4-MYC expression, and cells were incubated for $30 \mathrm{~min}$. Then, cultures were shifted to a restrictive temperature, $36^{\circ} \mathrm{C}$, and incubated for another $30 \mathrm{~min}$. To turn off the GAL1-10 promoter, cultures were filtered, transferred to minimal medium containing $2 \%$ glucose and incubated at $36^{\circ} \mathrm{C}$. Samples were collected at the indicated time points and analyzed by immunoblotting, using the MYC antibody to detect Gcn4-Myc. Cdc28 served as a loading control. Protein levels were quantified using a densitometer. B. A wildtype yeast strain (S396) and a $u b c 9-2$ mutant strain (S534), both containing a GAL-IME2-HA construct, were pre-grown in YEP medium containing $2 \%$ raffinose at $25^{\circ} \mathrm{C}$. Galactose (2\%) was added to induce $I M E 2-H A$ expression. After $30 \mathrm{~min}$, cultures were shifted to $36^{\circ} \mathrm{C}$ and incubated for another $30 \mathrm{~min}$. To turn off the GAL1-10 promoter, the cultures were filtered, transferred to YEPD medium and incubated at $36^{\circ} \mathrm{C}$. Samples were collected at the indicated time points and analyzed by immunoblotting. The HA antibody was used to detect Ime2-HA. Cdc28 served as a loading control. Protein levels were quantified using a densitometer.

\subsubsection{APC/C and Pds1 are Localized to the Nucleus in ubc9-2 and smt3-331}

\section{Mutant Strains}

Previous findings have implicated SUMO modification in the subcellular localization of proteins (Wilson and Rangasamy 2001a; Kim et al. 2002). APC/C is mainly localized to the nucleus (Tugendreich et al. 1995) and, most probably, this ubiquitin ligase is highly active predominantly in this cellular compartment. We asked whether impaired APC/C-mediated proteolysis in mutants defective in SUMOylation might 
primarily be caused by the mislocalization of the APC/C core complex, regulatory proteins or substrates.

To test this, we analyzed the subcellular localization of the core subunit Cdc16, the regulatory protein $\mathrm{Cdc} 20$ and of Pds1 in $u b c 9-2$ and smt3-331 mutants. Cells were shifted to the restrictive temperature and, after $4 \mathrm{~h}$, samples were collected for indirect immunofluorescence. We found that tagged versions of Cdc16, Cdc20 and Pds1 were localized mainly in the nucleus in $u b c 9-2$ and smt3-331 mutants, as found for wildtype cells (Figure 17). Similar data were obtained with Clb2 (data not shown). Thus, $u b c 9-2$ and smt3-331 mutants apparently do not affect the nuclear localization of either of these proteins.

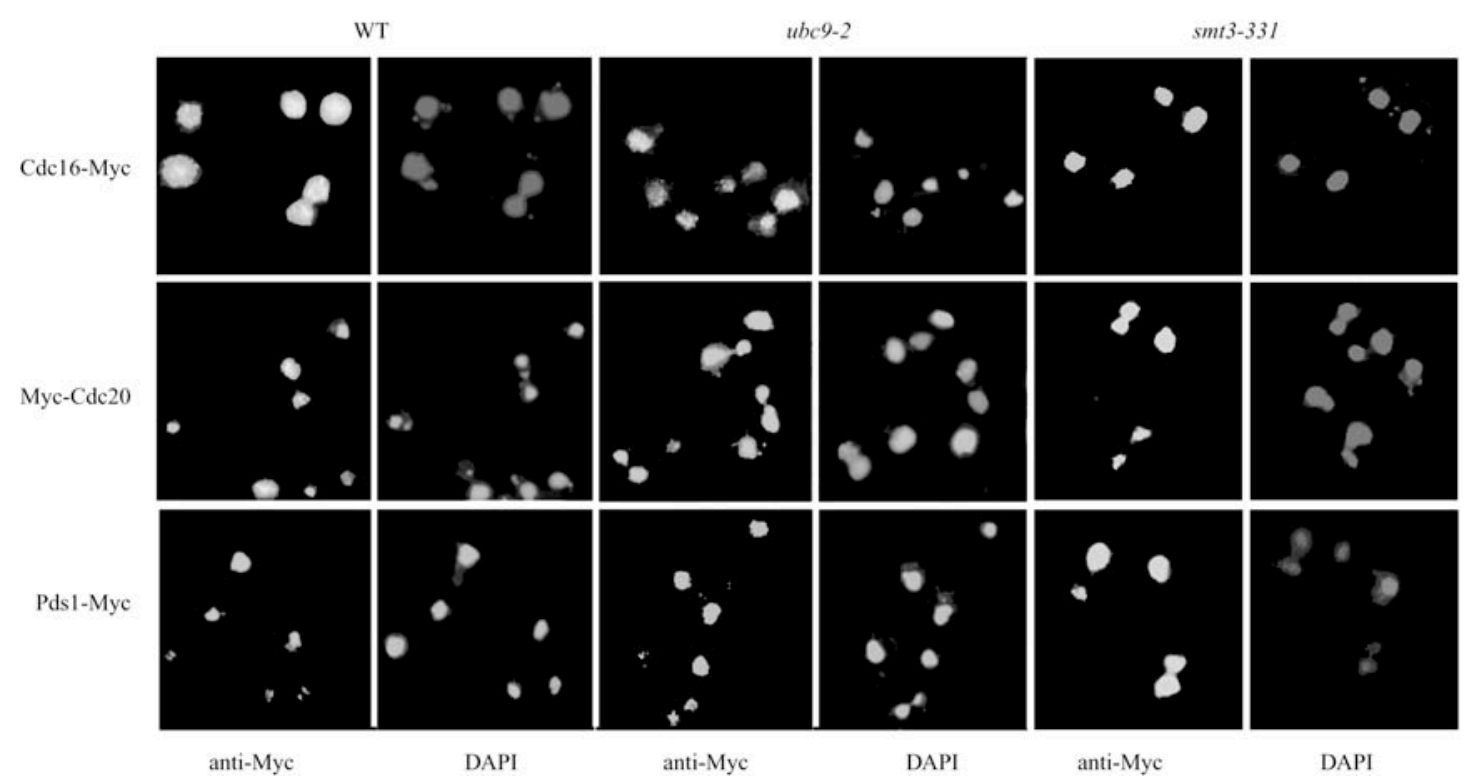

Figure 17: The Localization of $\mathrm{APC} / \mathrm{C}$ and Its Substrates is Similar in Wildtype Cells and $u b c 9-2$ and smt3-331 Mutants. A wildtype strain and $u b c 9-2$ and smt3-331 mutant strains containing MYCtagged versions of the APC/C subunit $\mathrm{Cdc} 16$ (Cdc16-Myc), the activator protein $\mathrm{Cdc} 20$ (Myc-Cdc20) or securin Pds1 (Pds1-Myc) were pre-grown in YEPD medium at $25^{\circ} \mathrm{C}$. Cultures were shifted to $36^{\circ} \mathrm{C}$ for $4 \mathrm{~h}$. Then, cells were fixed, spheroplasted and analyzed by indirect immunofluorescence using the MYC antibody. DAPI was used to visualize nuclei. 


\subsection{Two Different Mechanisms of Cyclin Clb5 Proteolysis}

Decreasing Cdc28/Clb kinase activity heralds the end of mitosis (Yeong et al. 2000). Once, the drop in B-type cyclin levels is initiated in anaphase, the $\mathrm{Cdc} 28$ antagonists Cdc14 and Sic1 become activated and subsequently trigger inactivation of the kinase. But, when Cdk activity is decreased to low levels, the next wave of kinase activity is already prepared by Swi5-mediated transcriptional activation of the G1 cyclin genes CLN1 and CLN2 (Moll et al. 1993). These cyclins initiate budding and the transcription of the S-phase cyclins Clb6 and its major partner Clb5, which in turn activates the DNA replication machinery (Toone et al. 1997). During G2- and Mphase a high Cdk activity, maintained basically by the $\mathrm{Clb} 2 / \mathrm{Cdc} 28$ kinase, prevents the re-initiation of DNA replication, budding and promotes simultaneously M-phase functions like spindle formation on the other (Amon et al. 1993). High Cdk activity leads in late $\mathrm{G} 2$ to the phosphorylation of $\mathrm{Cdc} 20$, which then recruits proteolytic target proteins to the APC/C ( $\mathrm{Lim}$ et al. 1998). Among them are the anaphase inhibitor Pds1, S-phase and M-phase cyclins (Peters 2002). This proteolytic activity provides a first drop in $\mathrm{Clb} / \mathrm{Cdc} 28$ activity that is necessary to activate the mitotic exit network (Hoyt 2000) finally leading to activation of the kinase antagonists Cdc14 and Sic1. In $\mathrm{G} 1$, lowered $\mathrm{Clb} / \mathrm{Cdc} 28$ activity allows binding of dephosphorylated $\mathrm{Cdh} 1$ to the APC/C (Jaspersen et al. 1999) so that this complex abolishes residual $\mathrm{Cdc} 28 / \mathrm{Clb}$ kinase activity.

Presently the necessity of Clb5 degradation for the mitotic exit is in the center of an ongoing debate. Irniger and Nasmyth observed that Clb5, in contrast to Clb2, is not completely stabilized during G1-phase in $c d c 16$ APC/C mutants (Irniger and Nasmyth 1997) indicating an alternative degradation pathway to APC/C-mediated Clb5 proteolysis.

Later, a screen for genes whose deletion would allow $c d c 20 \Delta p d s 1 \Delta$ cells to survive, (Shirayama et al. 1999) identified surprisingly CLB5, a gene previously known to initiate DNA replication. The ability of $c d c 20 \Delta p d s 1 \Delta$ clb5 $\Delta$ cells to survive led to the widespread believe that $\mathrm{Cdc} 20$ dependent $\mathrm{Clb} 5$ destruction is a necessary pre-requisite for the exit from mitosis. Clb5 degradation was finally accepted to drop Cdk activity leading to the activation of APC/C-Cdh1, which in turn abolishes Clb2.

Three years after the Shirayama report, Wäsch and Cross observed that CLB5 $D D B$ mutants had no defect in mitotic exit (Wasch and Cross 2002), raising doubts about 
the assumed model. Construction of a $C L B 2 \triangle D B$ strain revealed that these strains are not viable in contrast to Clb5 mutants lacking the destruction box. This idea was supported by the observation, that Clb2 destruction is not only triggered by the APC/C-Cdh1 complex but also by the APC/C-Cdc20 ubiquitin ligase (Baumer et al. 2000a; Yeong et al. 2000). Taken together, these results ascribed the essential drop in $\mathrm{Cdk}$ activity in anaphase due to proteolysis of a first fraction of $\mathrm{Clb} 2$.

The conflicting reports can be explained as Clb5 might be identified as essential APC/C-Cdc20 target under artificial conditions in $p d s 1 \Delta c d c 20 \Delta$ mutants, where Clb5 dependant inactivation of Cdh1 becomes unphysiologically important. Thus, it is clear, that as well $\mathrm{Clb} 2$ as Clb5 proteolysis lower Cdk activity, but only APC/C$\mathrm{Cdc} 20$ mediated $\mathrm{Clb} 2$ destruction is essential under physiological conditions. APC/Cindependent proteolysis of Clb5 may be sufficient to control the activity of this cyclin. This prompted us to characterize Clb5 degradation more in detail. We show, that $\mathrm{Clb} 5$ is degraded by a mechanism uncoupled from SCF and APC/C mediated proteolysis and is therefore not dependent on an intact destruction box.

The observed APC/C- and SCF-independent proteolysis is sufficient to down-regulate Clb5/Cdk activity in G1 and could make therefore Clb5 ubiquitination obsolete. Only under artificial conditions like CLB5 overexpression, sicl deletion or lack of APC/CCdc20 mediated Clb2 proteolysis, Clb5 ubiquitin-triggered degradation becomes essential as observed by Sihrayama (Shirayama et al. 1999).

\subsubsection{APC/C - Independent Clb5 Degradation}

We investigated Clb5 proteolysis in wildtype and $c d c 23-1$ strains cultivated as Sphase arrested or cycling cells. cdc23-1 cells are defective in APC/C-mediated ubiquitination. The S-phase arrest is achieved by incubating the cultures for two hours in presence of the DNA polymerase-inhibiting drug Hydroxyurea, which abolishes DNA synthesis and arrests cells in S-phase.

For this purpose, YP-raffinose log-phase cultures of strains carrying a temperature sensitive $c d c 23-1$ mutation in combination with an inducible GAL-CLB5 construct were arrested in S-phase in addition to a wildtype strain by treatment with Hydroxyurea and compared to unarrested cycling cells (Figure 18). In all cultures, $C L B 5$ expression was induced by addition of $2 \%$ galactose before the ts-mutation was induced by a shift to the restrictive temperature $\left(37^{\circ} \mathrm{C}\right) 45$ minutes later. Finally, the 
cells were filtered and shifted to glucose to turn off the GAL1-10 promoter. Samples were taken at the start and 15, 30, 45 and 60 minutes later. Western Blot detection of fading $\mathrm{Clb} 5$ bands revealed that the $\mathrm{APC} / \mathrm{C}$ mutation did not stabilize $\mathrm{Clb} 5$ neither in cycling nor in Hydroxyurea-arrested cells. These results suggest that an APC/C independent pathway for $\mathrm{Clb5}$ degradation is active throughout the cell cycle.

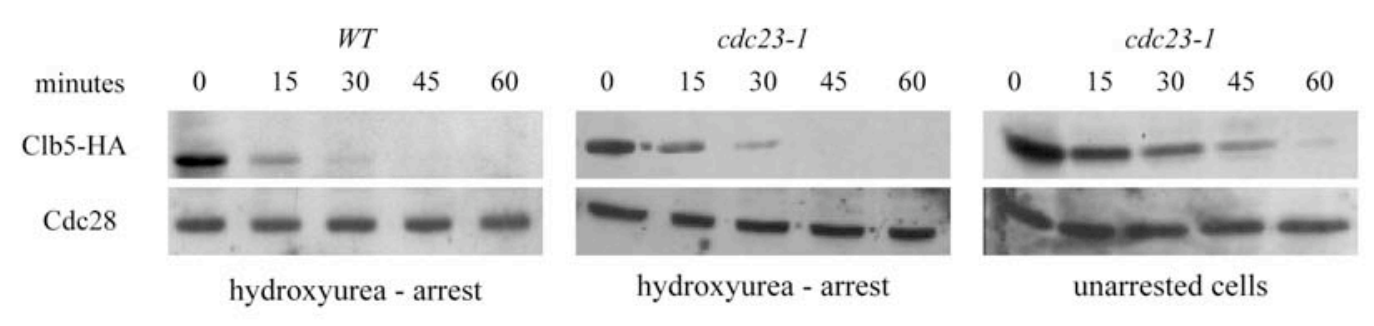

Figure 18: Clb5 is Degraded by a Pathway Independent of APC/C-mediated Proteolysis.

A wildtype (S122) and a $c d c 23-1$ (S54) mutant strain both containing a GAL-CLB5-HA construct were pre-grown at $30^{\circ} \mathrm{C}$ in YP-raffinose to log-phase. Cultures were arrested as indicated in S-phase by addition of Hydroxyurea or cultivated as unarrested cells. After $2 \mathrm{~h}$ incubation, galactose (2\%) was added to induce CLB5-HA expression. After 45 minutes, the cultures were shifted to the restrictive temperature $\left(37^{\circ} \mathrm{C}\right)$ for another 45 minutes whereupon the cells were filtered and put into YP-glucose medium (containing Hydroxyurea in case of the arrested cells) to turn off the GAL1-10 promoter. Samples were collected at the indicated time points and analyzed by immunoblotting using HAantibody to detect Clb5-HA levels. Cdc28 served as loading control.

\subsection{2. $S C F / C d c 34$ Do Not Contribute to APC/C Independent Clb5 Degradation}

Similar to the G2/M transition, which depends on proteolysis mediated by the APC/C, the $\mathrm{G} 1 / \mathrm{S}$ transition is regulated by stage-specific degradation triggered by the second large ubiquitin ligase, the SCF. This complex is required to degrade proteins like G1 cyclins or the Cdc28 kinase antagonist Sic1. As CLB5 is expressed in early S-phase and in contrast to $\mathrm{Clb} 2$ unstable throughout S- and M-phase it could be a target of SCF-mediated degradation.

To find out if this APC/C independent instability is due to ubiquitination by the SCFcomplex, we observed Clb5 stability in temperature sensitive $c d c 34-2$ (E2-enzyme of the SCF-complex) mutants in S- (Figure 19A) and M-phase (Figure 19B). Wildtype 
and $c d c 34-2$ single mutants were pre-grown in YP-raffinose to log-phase and arrested as mentioned by the spindle-depolymerizing drug Nocodazol in M-phase or in Sphase by addition of Hydroxyurea. After $2 \mathrm{~h}$ incubation, galactose (2\%) was added to induce the GAL1-10 promoter followed by a shift to the restrictive temperature $\left(37^{\circ} \mathrm{C}\right)$. After promoter shut-off by filtration and incubation in YP-glucose medium (containing the indicated drug), Clb5 protein levels were analyzed at the indicated time points by Western Blot.

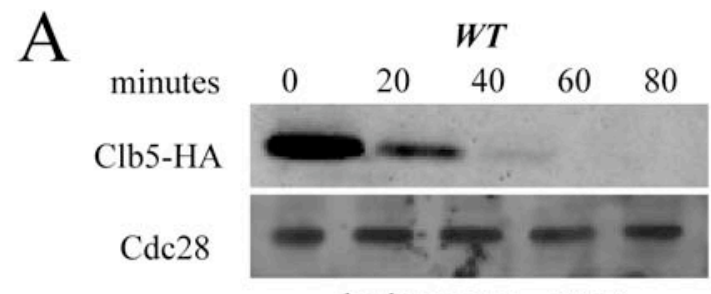

hydroxyurea - arrest
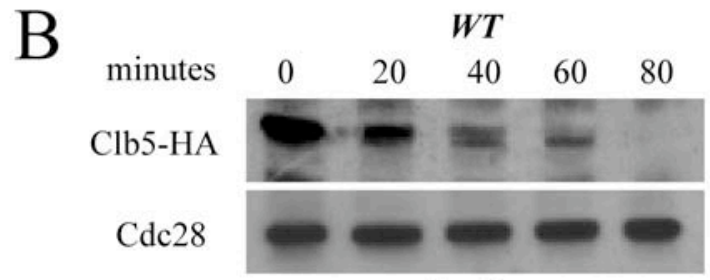

nocodazol - arrest cdc34-2

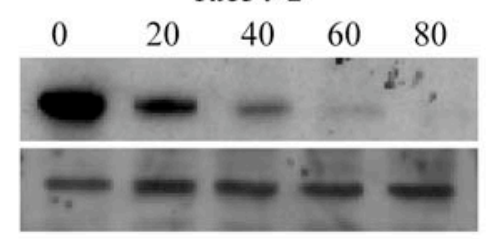

hydroxyurea - arrest

cdc34-2

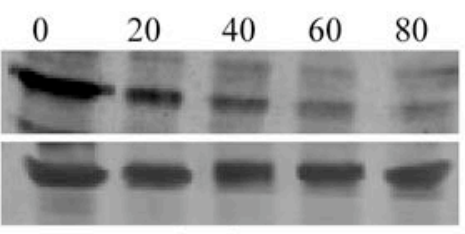

nocodazol - arrest

Figure 19: SCF-mediated Proteolysis Does Not Contribute Significantly to Clb5 Degradation in S- and M-phase.

A. WT (S122) and $c d c 34-2$ (S403) mutants, both containing a GAL-CLB5-HA construct, were pregrown at $30^{\circ} \mathrm{C}$ in YP-raffinose to log-phase and arrested in S-phase by addition of Hydroxyurea. After 2h incubation with Hydroxyurea, galactose (2\%) was added to induce CLB5-HA expression. After 45 minutes, the cultures were shifted to the restrictive temperature $\left(37^{\circ} \mathrm{C}\right)$ for another 45 minutes whereupon the cells were filtered and put into Hydroxyurea-containing glucose medium to turn off the GAL1-10 promoter. Samples were collected at the indicated time points and analyzed by immunoblotting using HA-antibody to detect Clb5-HA levels. Cdc28 served as loading control.

B. WT (S122) and $c d c 34-2$ (S403) mutants, both containing a GAL-CLB5-HA construct, were pregrown at $30^{\circ} \mathrm{C}$ in YP-raffinose to log-phase, arrested in M-phase by addition of Nocodazol. After $2 \mathrm{~h}$ incubation with Nocodazol, galactose (2\%) was added to induce CLB5-HA expression. After 45 minutes, the cultures were shifted to the restrictive temperature $\left(37^{\circ} \mathrm{C}\right)$ for another 45 minutes whereupon the cells were filtered and put into containing-containing glucose medium to turn off the GAL1-10 promoter. Samples were collected and treated as described in (A). 
As a result, Clb5 was not significantly stabilized in $c d c 34-2$ mutants neither in S- nor in M-phase, indicating that the SCF-ubiquitin ligase is not involved in Clb5 proteolysis (Figure 19A and Figure 19B). These results suggest that the observed $\mathrm{APC} / \mathrm{C}$ independent degradation mechanism is not coupled to SCF-complex activity.

Furthermore, we investigated in a similar experiment to the previous Clb5 proteolysis in $c d c 23-1$ cdc34-2 double mutant strains defective in both SCF- and APC/C mediated ubiquitination (Figure 20) as we aimed to find out whether Clb5 is still unstable in cells defective in both ubiquitin ligases with roles in the cell cycle. These strains were constructed by crossing a $c d c 23-1$ and a $c d c 34-2$ single $c d c$ mutant followed by a tetrade analysis to identify strains carrying the desired $c d c$ double mutation. In cycling as well as in S-phase arrested cdc34-2 cdc23-1 mutants, we found $\mathrm{Clb5}$ to be instable indicating that this alternative degradation pathway is uncoupled from action of the SCF and the APC/C.

cdc34-2 cdc23-1

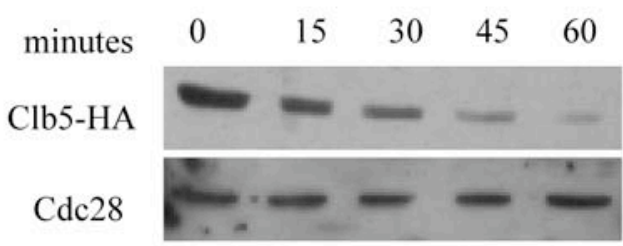

hydroxyurea - arrest cdc34-2 cdc23-1

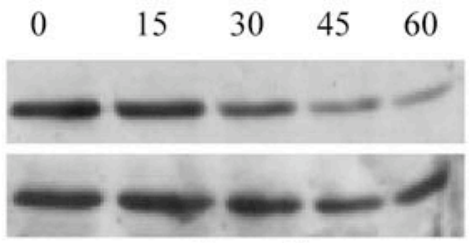

cycling cells

\section{Figure 20: Clb5 is Unstable in cdc34-2 cdc23-1 Double Mutants}

$c d c 23-1$ cdc34-2 (S432) double mutants, both containing a GAL-CLB5-HA construct, were pre-grown at $30^{\circ} \mathrm{C}$ in YP-raffinose to log-phase. The culture was split and in one part the cells were arrested by Hydroxyurea. After $2 \mathrm{~h}$, in both cultures galactose (2\%) was added to induce CLB5-HA expression. After 45 minutes, the cultures were shifted to the restrictive temperature $\left(37^{\circ} \mathrm{C}\right)$ for another 45 minutes whereupon the cells where filtered and put into glucose medium (containing in one case Hydroxyurea) to turn off the GAL1-10 promoter. Samples were collected and treated as described in Figure 19. 


\subsection{3. $A P C / C$ and $S C F / C d c 34$ Uncoupled Clb5 Degradation Does Not Depend on a Functional Destruction Box}

When Wäsch and Cross (Wasch and Cross 2002) investigated destruction box mutants in the CLB2 and CLB5 gene, they found that $C L B 5 \triangle D B$ mutants are viable and in contrast a $C L B 2 \triangle D B$ mutation is lethal.

A

\section{Hydroxyurea}

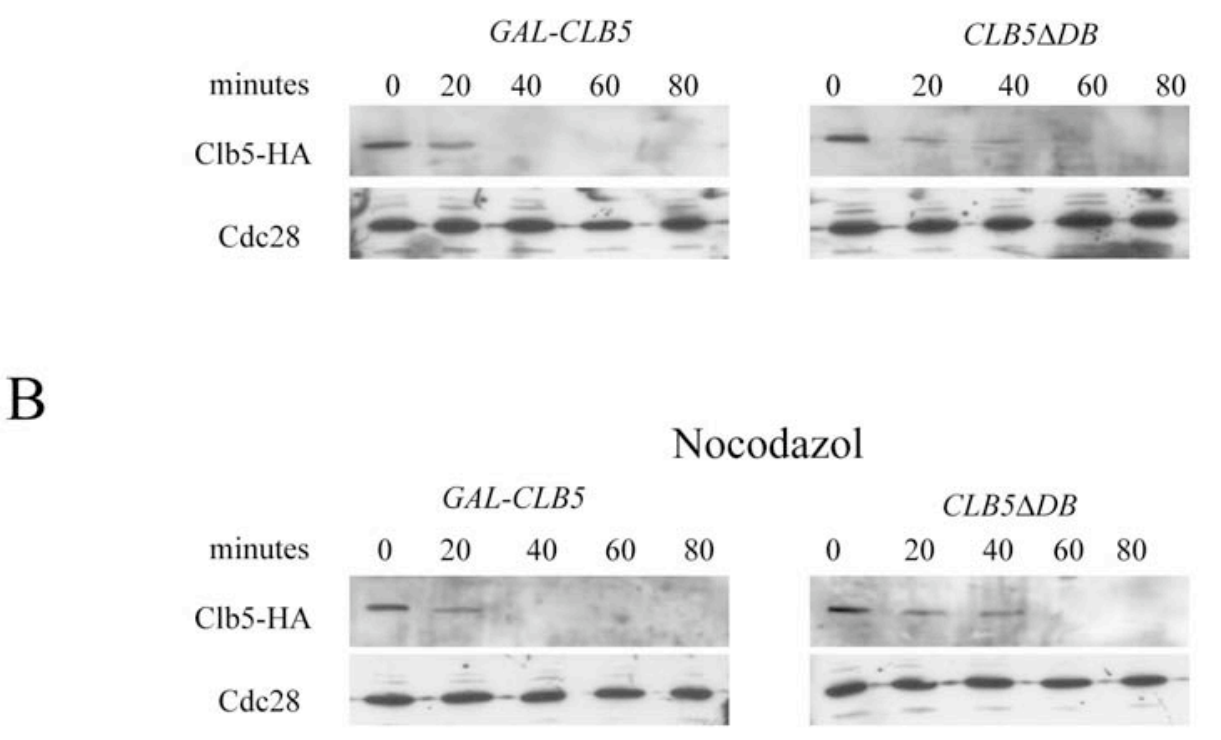

\section{Figure 21: Clb5 $\Delta \mathrm{DB}$ is Unstable in S- and M-phase}

A. S.cerevisiae Strains either containing a GAL-CLB5-HA construct (S116) or carrying a destruction box mutation $G A L-C L B 5 \triangle D B-H A$ (S117), were pre-grown at $30^{\circ} \mathrm{C}$ in YP-raffinose to log-phase, arrested in S-phase by addition of Hydroxyurea. After $2 \mathrm{~h}$ incubation with Hydroxyurea, galactose (2\%) was added to induce the GAL1-10 promoter. After 60 minutes, the cells where filtered and put into Hydroxyurea-containing glucose medium to turn off the GAL1-10 promoter. Samples were collected at the indicated time points and analyzed by immunoblotting using HA-antibody to detect Clb5-HA or Clb5 $\triangle$ DB-HA levels. Cdc28 served as loading control.

B. Strains either containing a $G A L-C L B 5-H A$ construct (S116) or carrying a destruction box mutation GAL-CLB5 $\triangle D B$ - $H A$ (S117), were pre-grown at $30^{\circ} \mathrm{C}$ in YP-raffinose to log-phase, arrested in M-phase by addition of Nocodazol. After $2 \mathrm{~h}$ incubation with Nocodazol, galactose $(2 \%)$ was added to induce the GAL1-10 promoter. After 60 minutes, the cells where filtered and put into Nocodazol-containing glucose medium to turn off the GAL1-10 promoter. Samples were collected and treated as described in (A). 
Thus, we tested whether the observed APC/C- and SCF-independent Clb5 degradation requires a functional destruction box.

For this purpose, log-phase YP-raffinose cultures were arrested in S- or M-phase by addition of Hydroxyurea (Figure 21A) or Nocodazol (Figure 21B), respectively. After 60 minutes incubation in galactose, the GAL1-10 promoter was shut off by transferring the cells to YP-glucose medium containing either Hydroxyurea or Nocodazol. Samples were taken directly, 20, 40, 60 and 80 minutes after the shut off and analyzed by Western Blot. This investigation revealed, that a destruction box mutation in CLB5 slightly elongated the half-life of Clb5 but did not stabilize the protein. As the APC/C is inactive during S-phase, these findings strengthen the hypothesis that $\mathrm{Clb5}$ is degraded by an APC/C-and destruction box-independent pathway.

\subsubsection{APC/C-mediated Degradation of Clb5 is Essential, When CLB5}

\section{Expression is Elevated}

In $c d c 20 \Delta p d s 1 \Delta$ cells, deletion of CLB5 was found to allow the exit from mitosis (Shirayama et al. 1999) indicating an essential role for APC/C-Cdc20 mediated proteolysis under these conditions. We addressed the question whether the misleading report by Shirayama could be founded on the unphysiological importance of Cdc20 mediated Clb5 proteolysis under artificial conditions. Furthermore, results of Wäsch and Cross showed that in wildtype cells APC/C-independent $\mathrm{Clb5}$ degradation is sufficient for viability (Wasch and Cross 2002). To get more insights into the importance of APC/C-dependent and APC/C-independent mechanisms, We analyzed yeast cells in which CLB5 is expressed at elevated levels (Figure 22). On glucose, when Clb5 is expressed at the physiological level, neither of the mutations in APC/C(cdc23) or SCF-mediated $(c d c 34)$ degradation is lethal when grown at $25^{\circ} \mathrm{C}$. On galactose plates, wildtype cells and strains overexpressing GAL-CLB5 displayed unhindered growth. Similarly, single $c d c 23$ and $c d c 34$ mutants showed unperturbed proliferation. In contrast, GAL-CLB5 $\triangle D B$ and $c d c 23$ GAL-CLB5 strains in which APC/C-mediated proteolysis was defective due to the $c d c$ or the destruction box mutation were unable to grow on galactose plates. This dramatic result could not be achieved in SCF-mutants overexpressing a GAL-CLB5 construct as they showed unaltered proliferation similar to wildtype cells. 
These results indicate that under unphysiological conditions like $C L B 5 \triangle D B$ or $C L B 5$ overexpression in $c d c 23$ mutants, APC/C-mediated ubiquitination becomes essential. In conclusion: As soon as CLB5 is expressed to higher levels, the APC/C-independent mechanism of $\mathrm{Clb5}$ degradation is not anymore sufficient for restricting the activity of this cyclin during the cell cycle.

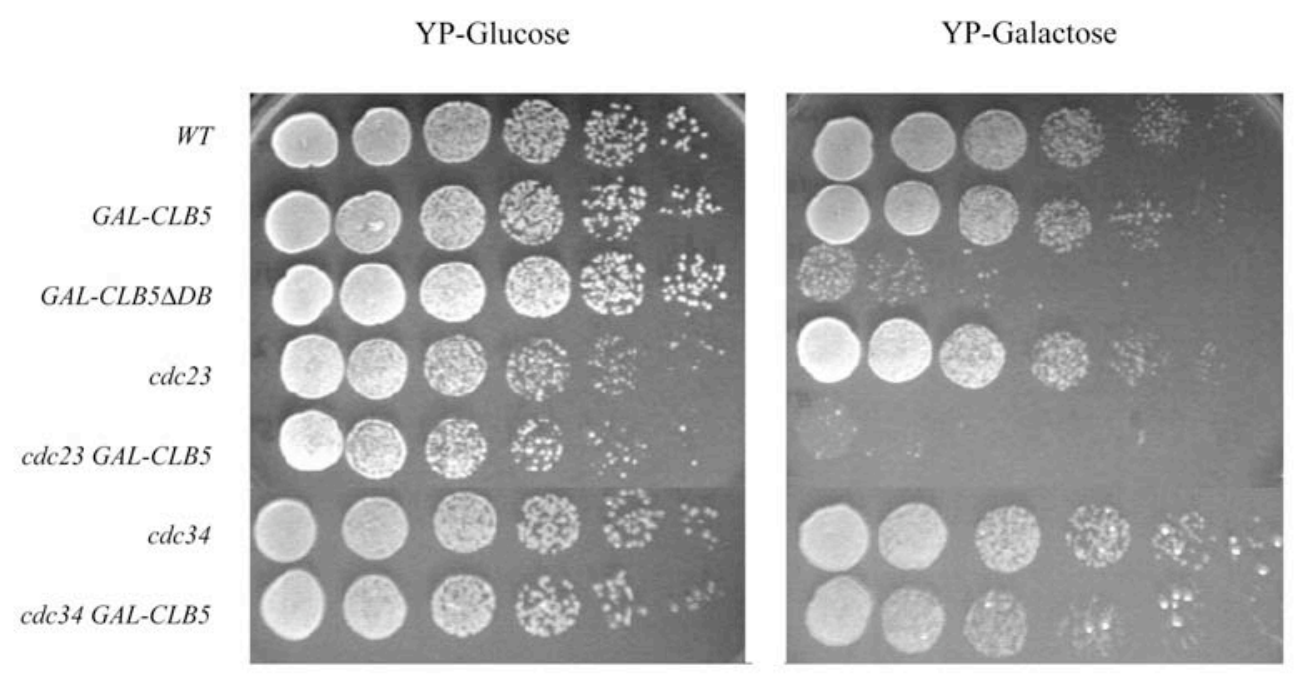

\section{Figure 22: Overexpression of $C L B 5 \triangle D B$ is Lethal in $c d c 23$ S.cerevisiae strains}

Serial dilutions (1:5) of a wildtype yeast strain (S1), a strain overexpressing GAL-CLB5 from the GAL1-10 promoter (S122), a strain carrying a $G A L-C L B 5 \triangle D B$ (S123) allele, single $c d c 34-2$ (S90), $c d c 23-1$ (S265) mutants and strains overexpressing GAL-CLB5 in combination with a either a $c d c 23-1$ (S265) or a $c d c 34-2$ (403) mutation were spotted on YP-plates containing either 2\% glucose or $2 \%$ galactose. Plates were incubated for two days at $25^{\circ} \mathrm{C}$.

\subsubsection{Abnormal CLB5 Expression Renders APC/C Essential for $\alpha$-Factor Induced G1 Arrest}

The appearance of B-type cyclins in G1 is known to initiate abnormal DNA replication (Irniger and Nasmyth 1997) in yeast. In particular Clb5 is intrinsically specialized for induction of DNA replication (Jacobson et al. 2000). We wanted to know if the APC/C proteolysis of Clb5 is essential to maintain an $\alpha$-factor induced G1 arrest.

For this purpose, we tested the effect of a strong overexpression of stable CLB5 $\triangle D B$ on premature DNA replication in G1 arrested cells by measuring DNA contents of GAL-CLB5 and GAL-CLB5 $\triangle D B$ strains (Figure 23). FACS analysis of log-phase cultures pre-grown in YP-raffinose revealed that despite a two-hour overexpression of 
GAL-CLB5, the activity of the cyclin is restricted, most likely by proteolytic degradation (APC/C and alternative mechanism). Incubation of GAL-CLB5 $D D B$ cells in YP-galactose medium however induced DNA replication in most cells after two hours. Destruction box-deleted Clb5 $\Delta$ DB protein thus triggered DNA replication efficiently as its activity is not restricted by APC/C-mediated proteolysis. This result illustrates that under these conditions, the APC/C-independent $\mathrm{Clb} 5$ degradation is not sufficient to lower Clb5 levels sufficiently. Taken together, these results prove that $\mathrm{APC} / \mathrm{C}$-mediated proteolysis is pivotal for maintaining a $\mathrm{G} 1$ arrest when $\mathrm{Clb5}$ is abnormally expressed.

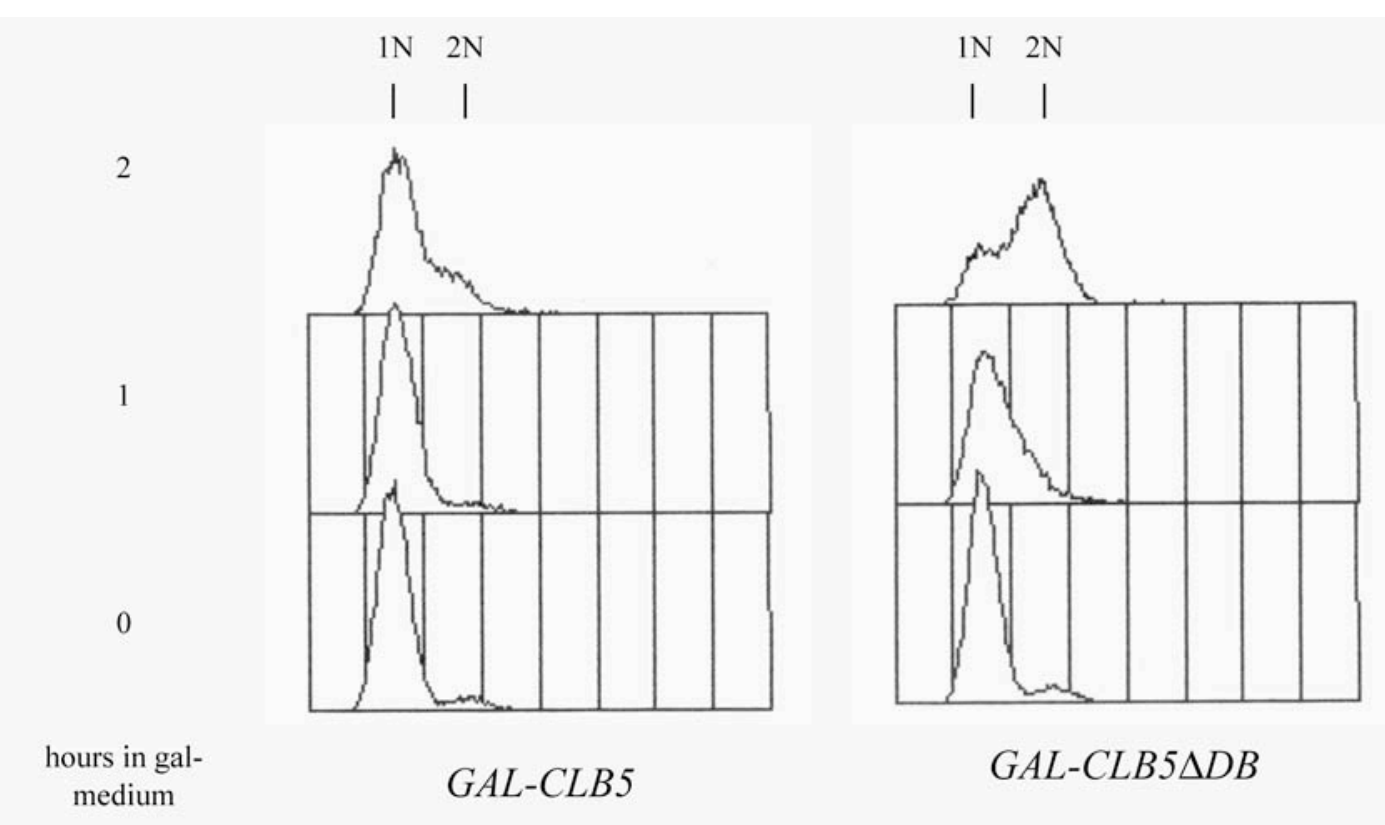

Figure 23: Abnormal CLB5 Expression Renders APC/C Essential for $\alpha$-Factor Induced G1 Arrest

GAL-CLB5 (S122) and GAL-CLB5 $D D B$ (S123) cells were pre-grown in YP-raffinose to log phase and arrested in G1 phase by $\alpha$-factor addition. A shift to YP-galactose (2\%) medium induced respectively $G A L-C L B 5$ or $G A L-C L B 5 \triangle D B$ expression. Samples were taken at the indicated time points and prepared for FACS analysis.

We observed that high levels of Clb5 activity forced cells to leave G1 phase and proceed to S-phase. A necessary precursor for G1/S transition is the inactivation of the APC/C achieved by phosphorylation of its activator $\mathrm{Cdh} 1$. As the $\mathrm{APC} / \mathrm{C}$ is highly active in G1, Cdh1 is physiologically unphosphorylated. We wanted to know to which extend expression of different $C L B 5$ or $C L B 5 \triangle D B$ constructs leads to Cdh1 phosphorylation. For this purpose, Western Blot analysis of strains moderately 
expressing a $G A L L-H A-C D H 1$ construct should reveal whether slower migrating bands appear indicating an elevated protein mass due to phosphorylation. Thus we pre-grew GALL-HA-CDH1 strains co-expressing either GAL-CLB5, GAL-CLB5 $D D B$ or $C L B 5 \triangle D B$ at $30^{\circ} \mathrm{C}$ in YP-raffinose to log-phase, arrested them with $\alpha$-factor and added galactose (2\%) after two hours to induce expression of the different CLB5 constructs.

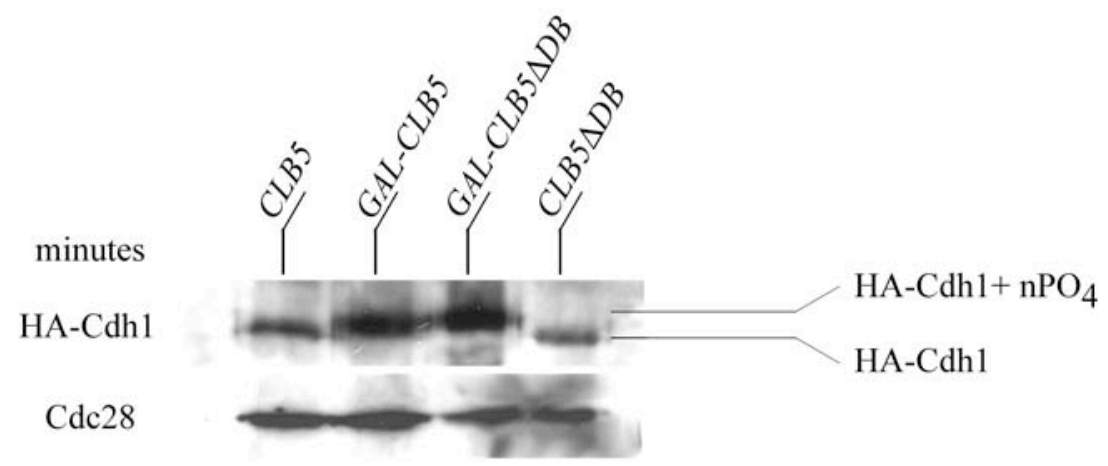

Figure 24: $C L B 5 \triangle D B$ Overexpression Triggers Cdh1 Phosphorylation in G1

WT (S437), GAL-CLB5 (S596), GAL-CLB5 $D B$ (S597) and CLB5 $D B$ (S598) S.cerevisiae strains, all containing a $G A L L-H A-C D H 1$ construct, were pre-grown at $30^{\circ} \mathrm{C}$ in YP-raffinose to log-phase and arrested with $\alpha$-factor in G1-phase. After $2 \mathrm{~h}$ incubation with $\alpha$-factor, galactose (2\%) was added to induce as well moderate $H A-C D H 1$ as $C L B 5$ constructs expression. Samples were collected at the indicated time points and analyzed by immunoblotting using HA-antibody to detect HA-Cdh1 levels. Cdc28 served as loading control.

Western Blot detection of HA-Cdh1 in strains with different CLB5 background revealed that a $G A L-C L B 5$ overexpression is only partially able to induce abnormal Cdh1 phosphorylation. In contrast, overexpression of GAL-CLB5 $D D B$ leads to high $\mathrm{Clb5} / \mathrm{Cdc} 28$ kinase activity that triggers unphysiological Cdh1 phosphorylation in G1phase. These findings are consistent with FACS data and prove that APC/C mediated proteolysis of Clb5 is important for preventing Cdh1 phosphorylation in G1 arrested cells and that alternative degradation is not sufficient when $C L B 5 \triangle D B$ is expressed to high levels. However, low levels of Clb5 $\Delta \mathrm{DB}$ are not sufficient to trigger Cdh1 phosphorylation (Figure 24 lane4) as in this case APC/C-independent proteolysis reduces $\mathrm{Clb} 5$ levels sufficiently. 


\subsection{Analysis of Ime2, a meiosis-specific $\mathrm{APC} / \mathrm{C}$ regulator}

In previous experiments, a genetic screen for factors involved in the regulation of APC/C-mediated cyclin proteolysis identified the meiotic protein kinase Ime 2 as an inhibitor (Bolte et al. 2002). It was shown that overexpression of IME2 prevents proteolysis of the mitotic cyclin $\mathrm{Clb} 2$ and that Ime2 inhibits APC/C activation in G1 by phosphorylating the activator protein $\mathrm{Cdh} 1$. Thus, Ime 2 negatively regulates the $\mathrm{APC} / \mathrm{C}$ in the same manner as the cyclin dependent kinase Cdc28. Expression of IME2 in cycling cells caused an arrest in mitosis and inhibited bud formation.

These data suggested that Ime 2 acts as a regulator of the $\mathrm{APC} / \mathrm{C}$. Since Ime 2 is expressed only in the meiotic cell cycle, it was proposed that Ime 2 represents a meiosis-specific regulator of the $\mathrm{APC} / \mathrm{C}$. In this study, we were interested to get insights how Ime2 itself may be regulated during meiosis. A clue for such a mechanism was presented by Bolte (Bolte et al. 2002). Unlike Cdc28, Ime2 is itself an unstable protein whose degradation occurs by an unknown, APC/C- and SCFindependent mechanism. Further investigations (Meyer 2003) showed that the Nterminal region of Ime2 is necessary for kinase activity (Figure 25) whereas the Cterminus regulates protein stability. Construction and investigation of systematic deletions in the Ime2 protein failed to identify a specific domain responsible for Ime2's instability. However, a deletion of a large 242 amino acid C-terminal region (Figure 25) resulted in a truncated protein, which resists proteolysis. This stabilizing effect does not occur due to the lack of the PEST-rich region, a common degradation motif among various proteins (Rechsteiner and Rogers 1996), because a version of Ime2 with a deleted PEST region does not show an enhanced half-life (Bolte 2004). Since the 242 amino acid deletion stabilized Ime2, but smaller deletions did not, it appears that this C-terminal region contains two or more degradation signals with redundant functions. 


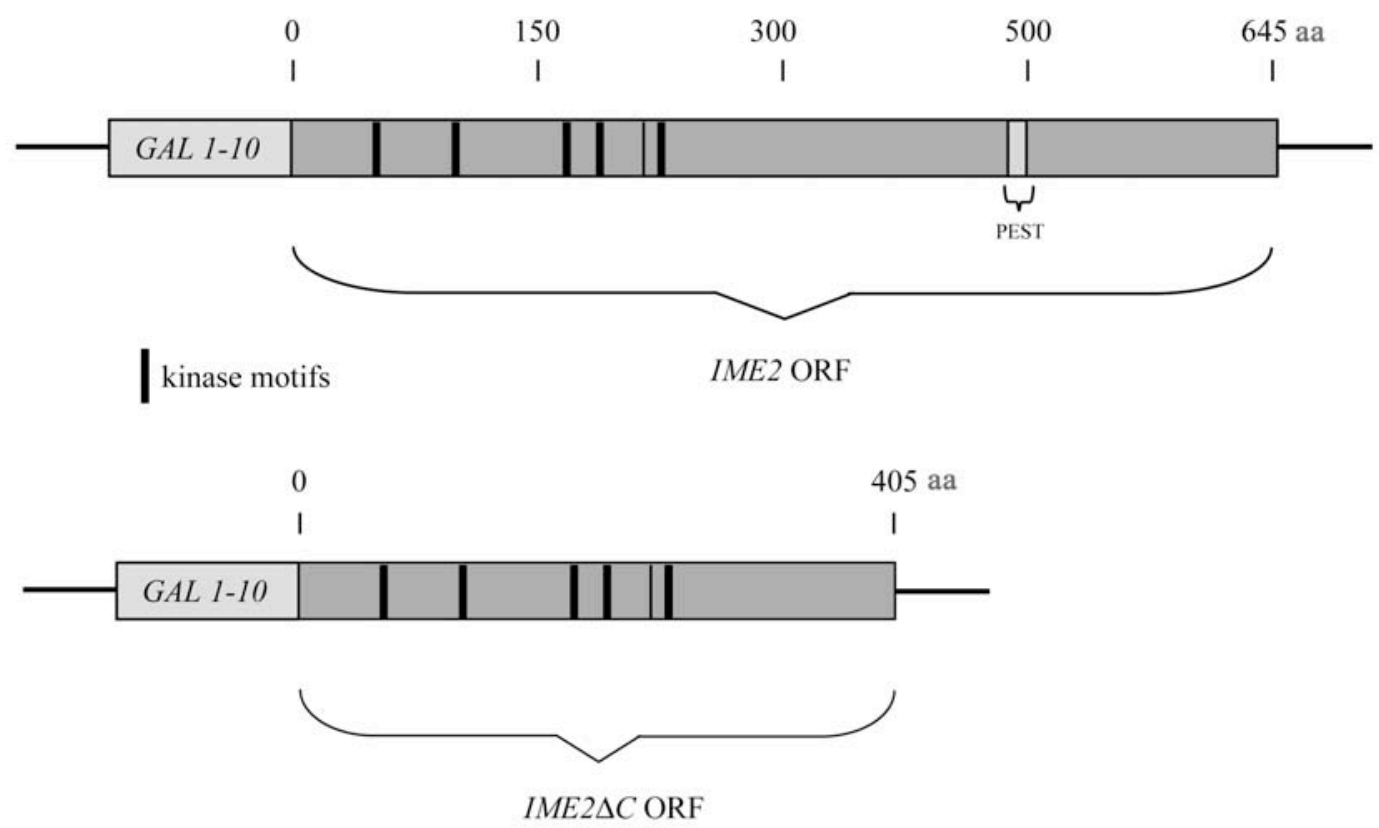

Figure 25: Map of the Wildtype and the Truncated IME2 ORF (Meyer 2003)

The stable, truncated version was one construct among several in a systematic deletion set produced by Meyer (Meyer 2003). A plasmid (pME2116) containing the IME2 ORF between a GAL1-10 promoter and a triple $H A$ tag was amplified using primers amplifying the $G A L$-promoter, the IME2 ORF up to amino acid 405 and the $H A$-tag. The obtained PCR products were cloned in a $C E N$-plasmid YCplac22 (Gietz and Sugino 1988) carrying the TRP1 marker.

Preliminary data obtained with the truncated by 242 amino acids Ime 2 protein (which is indicated as Ime $2 \Delta \mathrm{C}$ to in the following) suggests that this protein may still be functional despite the large truncation (Meyer 2003). In this case it would be possible to test the influence of a stabilized functional Ime $2 \Delta \mathrm{C}$ on the meiotic cell cycle and observe whether Ime 2 instability is indeed an important process to control the activity of this kinase during meiosis.

We show that the shortened Ime $2 \Delta \mathrm{C}$ is still a functional kinase being able to induce a mitotic cell cycle arrest when overexpressed. Furthermore, Ime $2 \Delta \mathrm{C}$ still carries out its inhibitory function on the APC/C by phosphorylating Cdh1. Western Blots of the efficiently sporulating strain SK1 show that in synchronously sporulating cultures, Ime $2 \Delta \mathrm{C}$ is stable throughout the whole meiotic process. This stabilization might contribute to the delayed sporulation and the failure in meiosis II that we observed in sporulating strains homozygous for the $I M E 2 \triangle C$ allele. 


\subsubsection{Overexpression of Truncated Ime2 $\Delta C$ Causes an Arrest in Mitosis}

If the truncated Ime $2 \Delta \mathrm{C}$ protein was still a functional kinase, it should still be able to induce the cell cycle effect observed in strains overexpressing native IME2 during mitosis (Bolte et al. 2002). To investigate Ime $2 \Delta C^{\prime}$ 's functionality as a kinase, we compared the efficiency of the cell cycle arrest induced by overexpression of native $I M E 2$ or truncated $I M E 2 \triangle C$. For this purpose, strains containing either a GAL-IME2 or a $G A L-I M E 2 \triangle C$ construct were pre-grown in YP-raffinose to log-phase, diluted to an $\mathrm{OD}_{600}$ of 0.2 and finally shifted to galactose. Every hour, $2 \mathrm{ml}$ of the cell cultures were harvested and centrifuged. Buds were scored under the light microscope. To determine the stage of the cell cycle in which the cells arrest, the samples were treated for immunofluorescence by staining the spindle with tubulin antibodies and the DNA with DAPI.

Consisting with earlier observations (Bolte 2004), 90\% of haploid yeast cells overexpressing IME2 arrested without buds and with undivided nuclei. Also the truncated $I M E 2 \Delta C$ is able to induce a cell cycle arrest similar to the full-length Ime2 when overexpressed from the GAL1-10 promoter. In both strains, unbudded cells accumulated upon galactose addition in a similar manner (Figure 26A and B). However, after $4 \mathrm{~h}$ no further drop occurred in the GAL-IME2 $\triangle C$ strain. Up to now, we cannot explain this differences occurring after long galactose incubation. DAPI and Tubulin staining revealed that most of the unbudded cells contained short spindles and undivided nuclei (Figure 26C and D).

It was earlier shown that this metaphase arrest is due to the activation of the morphogenesis checkpoint (Bolte et al. 2002). To test whether the truncated Ime $2 \Delta \mathrm{C}$ can also activate the checkpoint, we transformed the truncated GAL-IME2 $\triangle C$ construct into strains with a swe $1 \Delta$ deletion background. These cells are deficient in the morphogenesis checkpoint, which delays progression through the cell cycle in response to stimuli that prevent bud formation (Theesfeld et al. 2003). These mutants arrest like wildtype cells unbudded when overexpressing a GAL-IME2 or GAL$I M E 2 \triangle C$ construct. However, DAPI and tubulin staining of DNA or spindles respectively revealed that a large portion of these cells are in contrast to the wildtype able to separate their nuclei and arrest with long spindles (Figure 26D). 


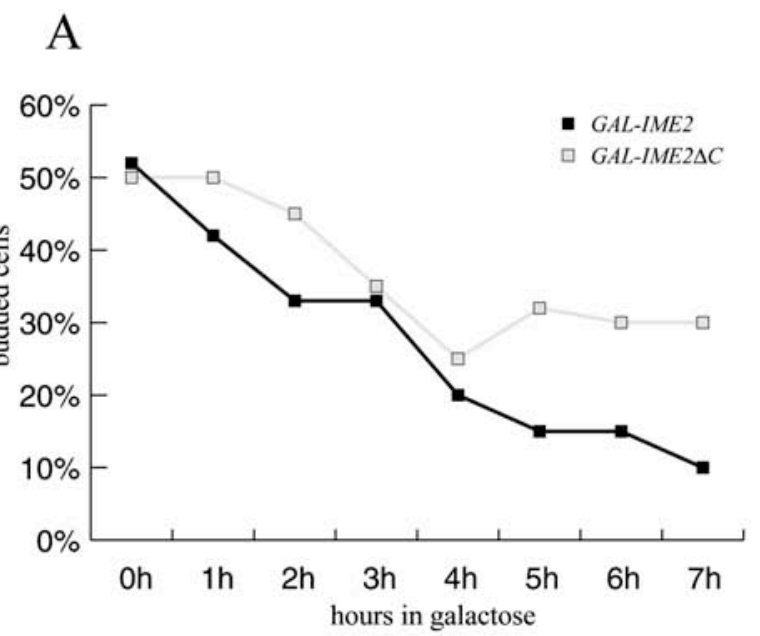

\section{B}

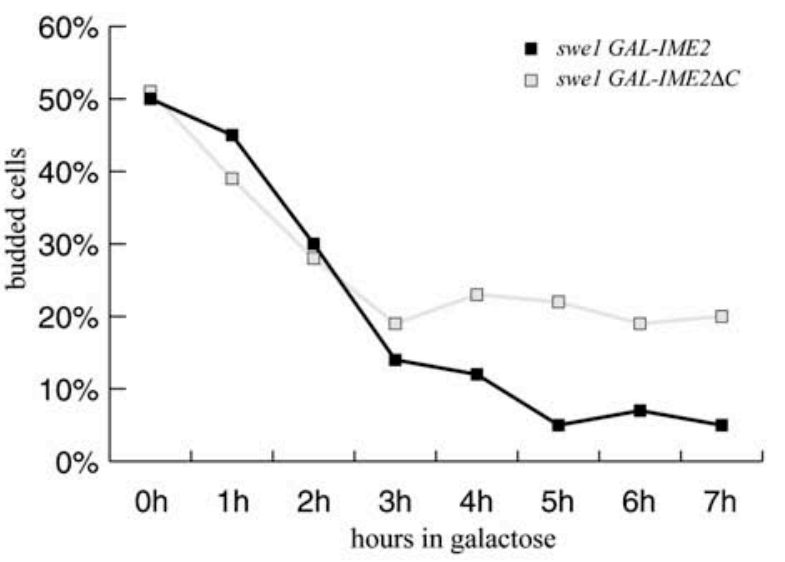

$\mathrm{C}$

D

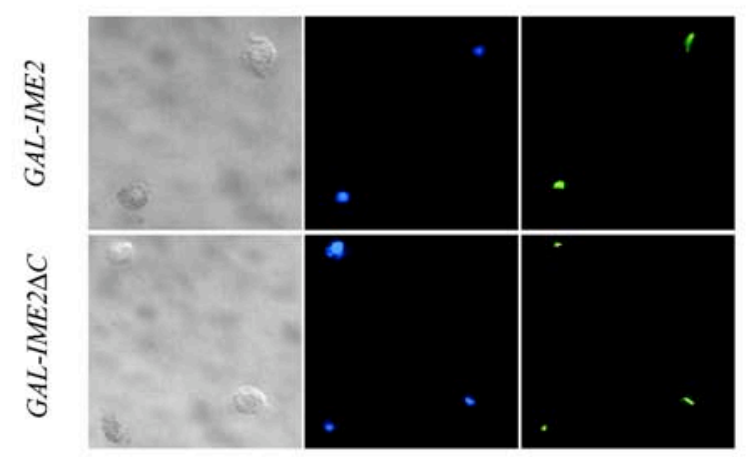

Nomarski

DAPI

anti-Tubulin

E

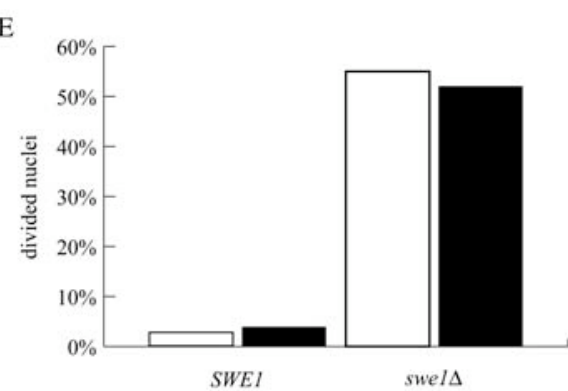

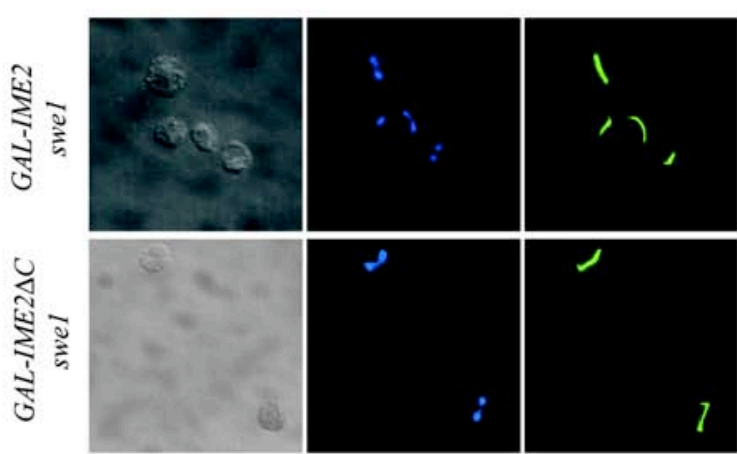

Nomarski

DAPI

\section{Figure 26: Mitotic Cell Cycle Arrest of GAL-IME2 and GAL-IME2 $\triangle C$ Overexpressing Cells}

Graph A shows the percentage of budded cells in log-phase YP-raffinose cultures consisting of haploid strains containing either a GAL-IME2 (S379) or GAL-IME2 $C$ (S1 including GAL-IME2 $\triangle C$ ) construct. The strains were pre-grown in YP-raffinose, diluted to an $\mathrm{OD}_{600}$ of 0.2 , before galactose $(2 \%)$ was added to induce the full-length $I M E 2$ or truncated $I M E 2 \triangle C$ construct, respectively. At the indicated time points, $2 \mathrm{ml}$ of the cultures were harvested by centrifugation and observed under the light microscope. Graph B shows the percentage of budded cells in cultures of strains containing either a GAL-IME2 (S454) or GAL-IME2 $\triangle C$ (S436 including GAL-IME2 $\triangle C$ ) construct in addition to a swe1 $\Delta$ deletion. Figures $\mathrm{C}$ and D illustrate the major phenotype ascertained in the graphs above by light microscopy (Nomarski), DNA (DAPI) or spindle (anti-Tubulin) staining. Graph E demonstrates the percentage of cells with divided nuclei when the morphogenesis checkpoint is active (SWE1) or deleted (swe14). 
Thus, in the absence of the morphogenesis checkpoint, cells containing high levels of Ime $2 \Delta \mathrm{C}$ are defective primarily late in mitosis, similar to cells containing full-length Ime2.

These results show that the kinase activity of Ime 2 and Ime $2 \Delta \mathrm{C}$ inhibits budding and causes a similar cell cycle arrest in mitosis. Both enzymes seem to be highly functional when expressed in mitotic cells.

\subsubsection{Truncated Ime2 $\Delta C$ Triggers Phosphorylation of Cdh1 and Stabilization of Clb2}

Construction of the systematic deletion set (Meyer 2003) revealed that Ime2 degradation signals are located in the last 241 amino acids proved by stabilization of the Ime $2 \Delta \mathrm{C}$ mutant. Truncation of smaller, 60 amino acid parts within the C-terminus did not result in a stable Ime2 protein. Thus, we conclude that this region contains two or more proteolytic signals required for Ime2 proteolysis. The N-terminal half in contrast, bears a putative kinase motif around K 97, which seems to be responsible for Ime2's essential kinase function. Earlier data showed that IME2 expression results in Cdh1 phosphorylation and stabilization of APC/C substrates, such as $\mathrm{Clb} 2$, in $\mathrm{G} 1$ arrested cells. We next tested whether the truncated Ime2 is still able to trigger phosphorylation of Cdh1 (Figure 27).

For this purpose, we arrested strains of a GALL-HA-CDH1 background and looked for slower migrating bands in the Western Blot indicating Cdh1 species with an increased mass due to phosphorylation by Ime2. Two strains containing GALL-HA-CDH1 in combination with either a $G A L-I M E 2$ or a $G A L-I M E 2 \triangle C$ construct were used in addition to a control strain bearing only $G A L L-H A-C D H 1$. Yeast strains were pregrown in YP-raffinose to log phase and arrested by $\alpha$-factor addition in G1-phase where the cyclin/Cdc28 complex has already lost its activity. Subsequently, galactose (2\%) was added for $90 \mathrm{~min}$ to turn on $I M E 2$ or $I M E 2 \triangle C$ overexpression respectively and moderate $H A-C D H 1$ expression from the shortened GAL1-10 promoter (GALL). By using an anti-HA antibody, slower migrating bands representing phosphorylated Cdh1 in IME2 or IME2 $\triangle C$ strains should appear due to kinase activity by Ime 2 or Ime $2 \Delta$ C. In fact, slower migrating bands could be observed in both strains 
overexpressing the native or the truncated Ime2 protein. This indicates again that the truncated Ime $2 \Delta \mathrm{C}$ protein is a functional kinase.

WT GAL-IME2 $\triangle C \quad G A L-I M E 2$

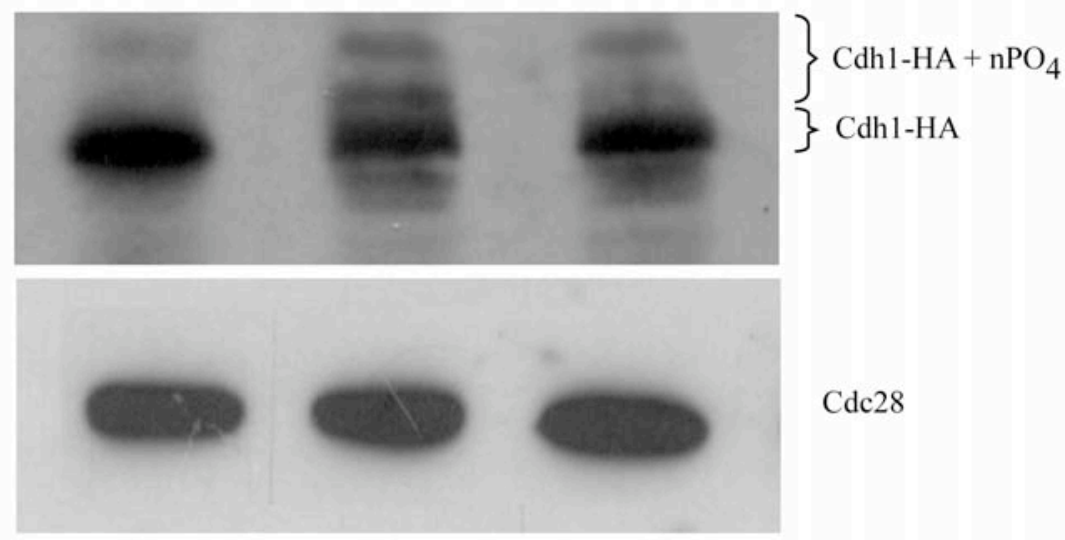

Figure 27: HA-Cdh1 Phosphorylation by Ectopically Expressed IME2AC

Three strains carrying only a GALL-HA-CDHI construct (S437) and two carrying in addition the truncated IME2 $\triangle C$ (S437 with integrated GAL-IME2 $\triangle C$ ) or the full length IME2 (S 457) respectively were pre-grown in YP raffinose and arrested with $\alpha$-factor. Subsequent galactose (2\%) addition induced moderately GALL-HA-CDHI or overexpressed IME2 either in the full length or the truncated version. After 90 minutes, cells were collected by centrifugation and treated for Western Blot analysis.

Next, we wanted to find out, whether Ime $2 \Delta \mathrm{C}$ is capable to stabilize the cyclin $\mathrm{Clb} 2$ in G1 cells. Clb2 is normally highly unstable in G1 cells, due to its rapid degradation by APC/C (Amon et al. 1994). However, ectopic expression of IME2 resulted in Clb2 accumulation because the $\mathrm{APC} / \mathrm{C}$ is inactivated by this kinase (Bolte et al. 2002). For this purpose, we transformed a GAL-CLB2 strain with plasmids containing either a GAL-IME2-HA or a GAL-IME2 $\triangle C-H A$ construct. Together with the untransformed control, these two strains were grown to log-phase in YP-raffinose and arrested with $\alpha$-factor before galactose (2\%) was added to induce $C L B 2$ as well as IME2 or $I M E 2 \Delta C$ expression. Samples were collected before galactose addition (0min) and two hours after the induction start (120min). Despite overexpression, only traces of $\mathrm{Clb} 2$ are detectable in the control. In contrast, strains containing either IME2 or $I M E 2 \triangle C$ accumulated $\mathrm{Clb} 2$ to a high extend (Figure 28). 
The findings that IME2 $\triangle C$ is able to trigger Cdh1 phosphorylation as well as Clb2 accumulation in a similar manner than the full-length $I M E 2$ suggest that Ime $2 \Delta \mathrm{C}$ is a highly active kinase.

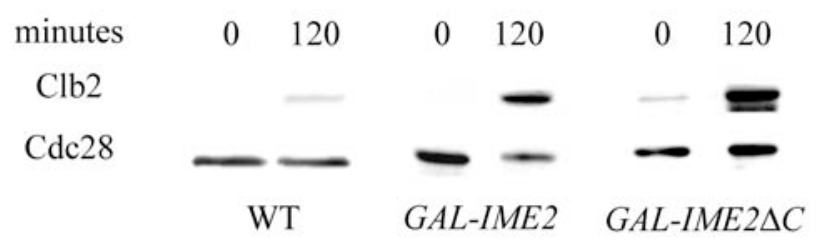

Figure 28: Clb2 Accumulates in Strains Overexpressing IME2 $\triangle C$

A $G A L-C L B 2$ strain (S16) was transformed with plasmids containing either a GAL-IME2-HA (pME 2116) or a GAL-IME2 $\triangle C-H A$ (pME 2595) construct. Together with the untransformed control (S16), these two transformed strains were grown to log-phase in YP-raffinose lacking uracil and arrested with $\alpha$-factor before galactose ( $2 \%$ ) was added to induce $C L B 2$ as well as IME2 or IME2 $\triangle C$ overexpression. Samples were collected before galactose addition (0min) and two hours after the induction start (120min) and treated for Western Blot. Clb2 was detected using Clb2 antibodies (R 98.5).

\subsubsection{Truncated Ime2 $\Delta C$ is Stable Throughout Meiosis}

Given the fact that IME2 is expressed throughout meiosis (Chu et al. 1998), its instability might bear a regulating mechanism by specific proteolysis. Thus, a stable Ime 2 mutant protein is interesting to study failures occurring in meiosis altered by stabilized Ime2 (Bolte et al. 2002). This could indicate whether the activity of this kinase might be regulated via its proteolytic destruction. First, we compared protein levels of Ime 2 and Ime $2 \Delta \mathrm{C}$ in synchronous sporulating cultures for which we used strains from the efficiently sporulating SK1 background.

For this purpose, diploid strains either being homozygous for a wildtype (IME2MYC9/IME2-MYC9, S504) or carrying one truncated (IME2 $\triangle C-H A / I M E 2, \mathrm{~S} 591)$ allele of IME2 were grown to stationary phase in YPD for $36 \mathrm{~h}$. Subsequent 1:50 dilution in YP-acetate (2\% KOAc) induced starvation for fermentable carbon sources. After 13,5 h the cells were harvested and washed with sterile distilled water to remove residual nutrients. Shifting to SPO medium induced sporulation, which was observed at least every hour (Figure 29) by collection of samples for Western Blot analysis. 
In agreement with earlier investigations (Bolte 2004), levels of Ime2 were high at the beginning of meiosis, decreased after 4-5 $\mathrm{h}$ in SPO medium and rose again at the end of meiosis. In contrast, levels of the truncated Ime $2 \Delta \mathrm{C}$ protein increased steadily, peaked around 4-5 $\mathrm{h}$ and remained high throughout the experiment. Thus, the $\mathrm{C}$ terminal truncation in the Ime $2 \Delta \mathrm{C}$ protein evokes a complete stabilization during meiosis.
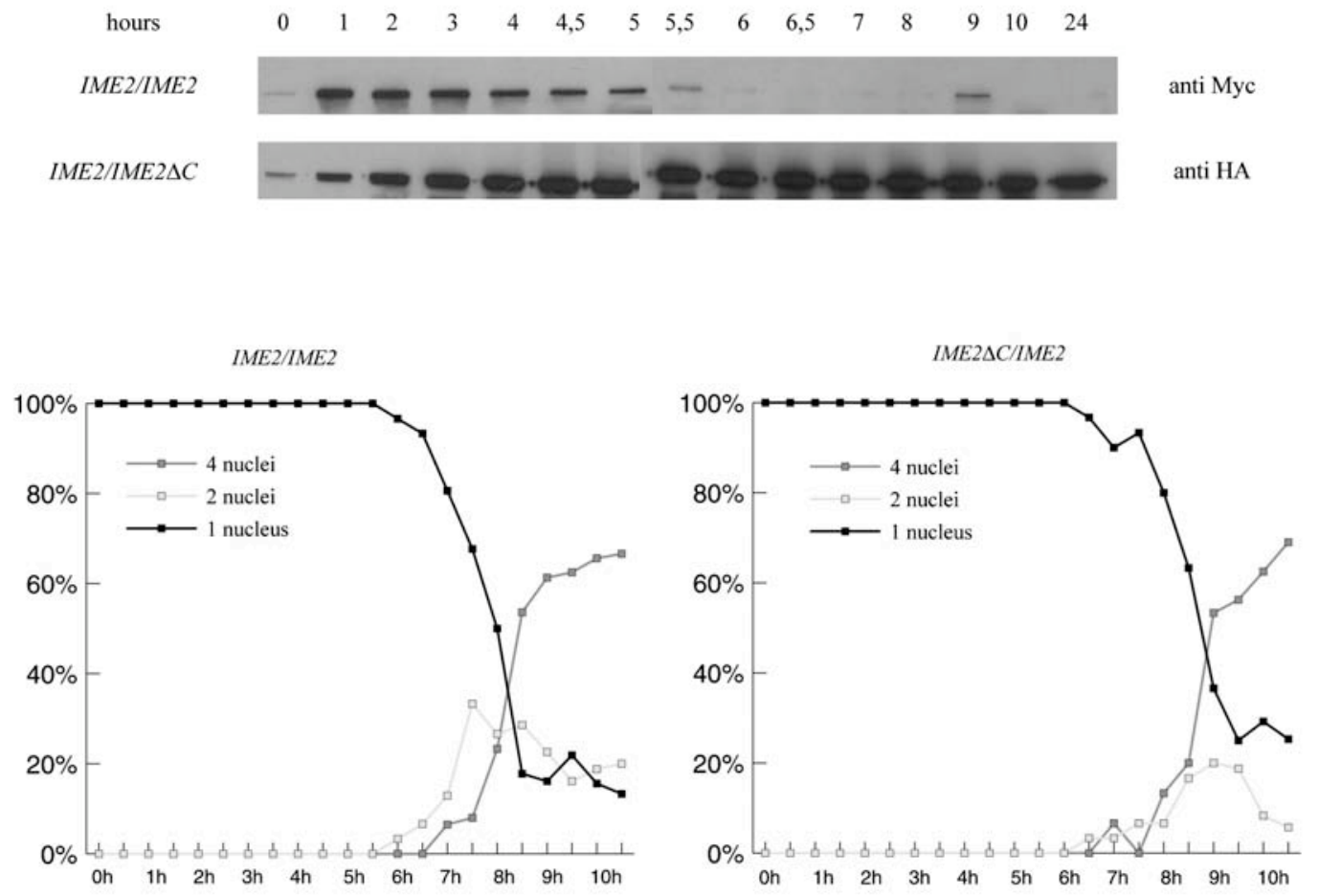

Figure 29: Ime2 $\Delta C$ is Stable Throughout Meiosis

A synchronously sporulating culture of the diploid SK1 strains, either being homozygous for a wildtype (IME2-MYC9/IME2-MYC9, S504) or carrying one truncated (IME2 $\triangle C-H A / I M E 2$, S591) allele of Ime2, was used for investigation of altered Ime2 levels due to truncation of the C-terminal domain. Ime2-HA or Ime2-Myc levels respectively were detected by Western Blot analysis and samples were taken at the indicated time points. Synchronicity of sporulation was monitored by counting the nuclei (see graphs).

To determine synchronicity of sporulation, samples taken at the indicated time points, were collected and analyzed under the light microscope. The graphs (Figure 29) show that the cells enter the first meiotic division around 6-7 $\mathrm{h}$ and divide a second time approximately one hour later. Cells heterozygous for the truncated IME2 $\triangle C$ allele carried out the meiotic steps slightly later compared to cells homozygous for the 
wildtype IME2 allele. We conclude that Ime $2 \Delta \mathrm{C}$ is similarly stabilized in meiosis as previously found in experiments with mitotic cells (Meyer 2003).

\subsubsection{C-terminal Truncation of Ime2 Causes an Arrest in Meiosis II}

We proved above that the truncated Ime $2 \Delta \mathrm{C}$ protein is still a functional kinase despite its instability is prevented by the shortening of the protein. As Ime2's activity seems to be regulated by proteolysis, it would be interesting to observe the effects evoked by perpetual presence of Ime 2 in meiosis.

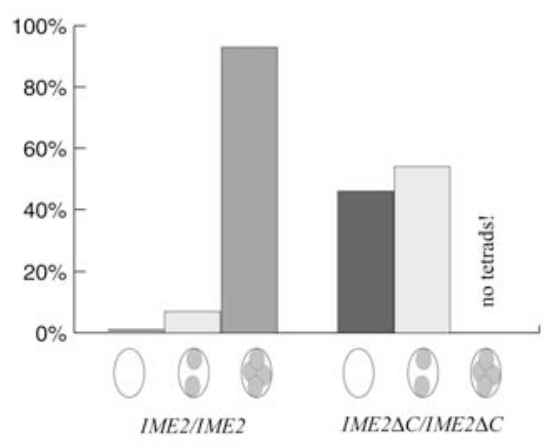

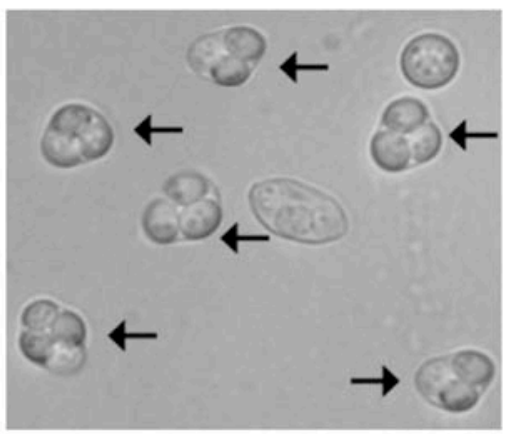

IME2/IME2

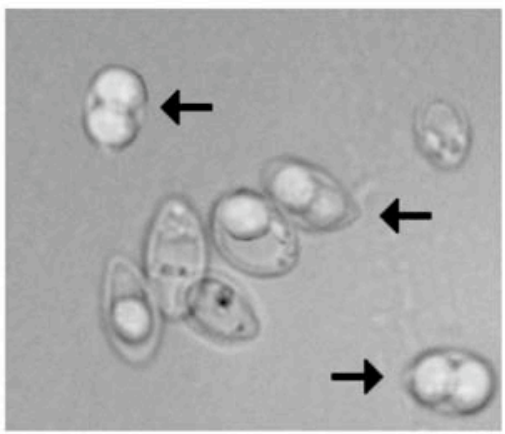

$I M E 2 \triangle C / I M E 2 \Delta C$

\section{Figure 30: Sporulation Defect Caused by Stabilized Ime2 $\Delta C$}

Wildtype IME2/IME2 or homozygous IME2 $\triangle C / I M E 2 \triangle C$ strains both from the efficiently sporulating SK1 background were pre-grown in YPD medium and incubated overnight in acetate medium before they were finally shifted to SPO medium. Samples of the sporulating cultures were taken at the indicated time points and scored after $48 \mathrm{~h}$ under the light microscope for non-sporulating cells, dyads and tetrades. All spores appearing in the picture taken from the IME2/IME2 culture are four-spore asci as the fourth spore is hidden below the three visible. Dyads in the IME2 $\triangle C / I M E 2 \triangle C$ and tetrades in the $I M E 2 / I M E 2$ strain are indicated by arrows. 
For this purpose, wildtype or homozygous $I M E 2 \triangle C / I M E 2 \Delta C$ strains from the efficiently sporulating SK1 background were pre-grown in YPD medium and incubated overnight in acetate medium before they were finally shifted to SPO medium. Samples of the sporulating cultures were taken at the indicated time points and scored for non-sporulating cells, dyads and tetrades under the light microscope. After $48 \mathrm{~h}$ in SPO medium, 90\% of the wildtype cells finished sporulation. In contrast, only $55 \%$ of the strains homozygous for IME2 $\triangle C$ produced asci but obviously failed to undergo meiosis II (Figure 30). Almost all of these asci contained only two spores. It is not clear yet whether this is due to stabilization of Ime 2 or rather due to the loss of function, caused by removal of the C-terminal region. Additional experiments will be required to distinguish between these two possibilities. 


\section{Discussion}

\subsection{Smt3/SUMO and Ubc9 are Required for Efficient Securin Degradation in Budding Yeast}

In chapter 4.1, we have analyzed the roles of the budding yeast SUMO protein Smt3 and of the SUMO-conjugating enzyme Ubc9 in cell cycle progression and in proteolysis mediated by the anaphase-promoting complex/cyclososme (APC/C). Consistent with previous reports (al-Khodairy et al. 1995; Seufert et al. 1995; Tanaka et al. 1999; Biggins et al. 2001), our data showed that Smt3 and Ubc9 have pivotal functions during mitosis. A large proportion of cells depleted of either Ubc9 or Smt3 accumulated as large budded cells, which contained short mitotic spindles, undivided nuclei and high levels of securin Pds1. These findings imply that SUMO modification is an essential process for the metaphase/anaphase transition.

\subsubsection{A Role for SUMO in the Onset of Anaphase and in Chromosome}

\section{Segregation}

The onset of anaphase requires proteolytic destruction of securins, which act as inhibitors of separases (Nasmyth 2002). Since Ubc9 or Smt3 depleted cells arrest with stable Pds1 protein, we addressed the question whether the metaphase arrest of cells impaired in SUMOylation is caused by a failure to degrade Pds1. We found that a deletion of PDS1 allowed a significant fraction of $u b c 9 \Delta$ cells to elongate their spindles and to start segregation of their chromosomes, suggesting that Pds1 proteolysis is indeed an important function of SUMO at the metaphase/anaphase transition. Since a fraction of $u b c 9 \Delta p d s 1 \Delta$ cells still contained short spindles and a single mass of DNA, it is likely that SUMO has important roles other than securin proteolysis for the onset of anaphase. In contrast to the PDSI deletion, cells impaired in SUMOylation were not affected by a deletion of the spindle checkpoint gene MAD2 suggesting that the mitotic delay is not a consequence of the checkpoint activation.

We have presented evidence that SUMOylation is, in addition to the onset of anaphase, also required for proper chromosome segregation. A fraction of Ubc9 or Smt3 depleted cells had elongated spindles and these mostly contained DNA masses 
dispersed along the elongated spindle. Temperature-sensitive $u b c 9-2$ and smt3-331 mutants displayed similar defects. Interestingly, the temperature-sensitive smt3-331 mutant was initially identified in a screen for mutants defective in chromosome segregation (Biggins et al. 2001). In Schizosaccharomyces pombe, cells lacking either the SUMO gene pmt3 or the UBC9 homologue hus5 were found to have abortive mitosis, and it was suggested that this was due to defects in chromosome segregation (al-Khodairy et al. 1995; Tanaka et al. 1999). In conclusion, these and our data imply that SUMOylation plays an important role in sister chromatid separation and in chromosome segregation.

\subsubsection{A Role for SUMO in APC/C-mediated Proteolysis}

We have demonstrated that Ubc9 and Smt3 are needed for efficient securin proteolysis in cells arrested in G1 phase, a period of the cell cycle where APC/C is highly active (Amon et al. 1994). Similar to securin degradation, proteolysis of mitotic cyclins was also delayed in $u b c 9-2$ and smt3-331 mutants. These data are consistent with the previously demonstrated defect of $u b c 9-1$ mutants in degradation of $\mathrm{Clb} 2$ and $\mathrm{Clb} 5$ (Seufert et al. 1995). The findings that APC/C-mediated proteolysis is comprised in these mutants implies that SUMOylation is required for efficient function of the APC/C.

In contrast to mutants in $\mathrm{APC} / \mathrm{C}$ subunit genes, we found however, that $u b c 9-2$ and smt3-331 mutants display only partial defects in Pds1 degradation during mitosis of synchronous cultures and in G1 arrested cells. It is possible that SUMO modification plays only a minor role for proper APC/C function, for example for the fine-tuning of its activity. Alternatively, a residual activity in SUMOylation in $u b c 9-2$ and smt3-331 mutants at restrictive temperatures may be sufficient for degradation of APC/C substrates, at least with reduced kinetics. Consistent with this hypothesis, we found that low levels of Ubc9 and Smt3 are sufficient for viability of yeast cells (Figure 1A). How may SUMO affect APC/C-mediated proteolysis? We have provided evidence that Ubc9 and Smt3 are not needed for proteolysis in general. Unstable proteins, which are not APC/C substrates, such as the $\mathrm{SCF}^{\mathrm{Cdc} 4}$ substrate Gcn4, were normally degraded in $u b c 9-2$ and smt3-331 mutants, suggesting that the 26S proteasome is functional. These data favour the model that specifically $\mathrm{APC} / \mathrm{C}$ function may be affected in these mutants. 
At present, it is unknown how SUMO modification influences this ubiquitin ligase. Previously, proteins with important roles in mitosis were found to be modified with SUMO. One of these is Top2, DNA topoisomerase II. It was shown that modification of Top2 is required for the control of chromosome cohesion at centromeric regions (Bachant et al. 2002) SUMO-modified Top2 was unable to promote centromeric cohesions and this may indicate a regulatory role for SUMO in dissolving the cohesion between sister chromatids. However, there is no evidence that Top2 modification may affect securin stability or APC/C activity. Other recently identified yeast substrates known to be modified by SUMO are the septins Cdc3, Cdc11 and Sep7, which form a ring at the yeast bud neck (Johnson and Blobel 1999; Takahashi et al. 2001). Since yeast strains expressing septins lacking SUMO conjugation sites did not display defects in cell cycle progression, it is rather unlikely that a failure to modify these septins contributes the mitotic defects of Ubc9 and Smt3 depleted cells. It remains to be shown whether factors directly involved in APC/C-mediated proteolysis are modified by SUMO. By using an HA-tagged version of SMT3, we did not detect modifications of immunoprecipitated APC/C subunits $\mathrm{Cdc} 16$ and $\mathrm{Cdc} 23$ or of the substrates Pds1 and Clb2 (data not shown).

Various different functions for SUMO have been identified in the last few years and it is tempting to speculate that one of these is also required for promoting APC/Cmediated proteolysis. For example, SUMO was shown to modulate nucleocytoplasmic transport, subcellular localization or protein-protein interactions (Muller et al. 2001; Wilson and Rangasamy 2001a). Since functional nucleocytoplasmic transport is needed for proteolytic destruction of various APC/C substrates (Loeb et al. 1995; Baumer et al. 2000b), we tested whether the nuclear localization of APC/C or of its substrates is defective when SUMOylation is disturbed. We found that the APC/C subunit Cdc16, the activator protein Cdc20 and the substrates Pds1 were localized in the nucleus in $u b c 9-2$ and smt3-331 mutants similarly as in wild-type strains indicating that nuclear import of these factors is not distinctly affected. Furthermore, it is conceivable that defects in nucleocytoplasmic transport would also interfere with Gen 4 proteolysis in these mutants. $\mathrm{SCF}^{\mathrm{Cdc} 4}$ activity is restricted to the nucleus (Blondel et al. 2000) and nuclear localization of Gen 4 is required for its efficient degradation (Pries et al. 2002). We suggest that SUMOylation rather affects APC/C inside the nucleus. 
A possible function of SUMO may be the proper localization of APC/C or its substrates to specific subcellular elements. APC/C is known to be associated with centrosomes and mitotic spindles (Tugendreich et al. 1995). Substrates such as securins and cyclins were also localized to spindles (Jensen et al. 2001; Raff et al. 2002) and it is conceivable that the association of APC/C with the mitotic spindle is important for destruction of spindle-associated substrates. Since SUMOylation has been implicated in regulating protein-protein interactions, a further possibility could be that this modification is critical for the association of $\mathrm{APC} / \mathrm{C}$ with regulatory proteins or for substrate recognition.

Proteomics may be a promising approach to reveal the SUMO targets essential for mitosis and APC/C function. Then, it will be interesting to elucidate whether SUMOylation is a novel mechanism for the regulation of this ubiquitin-ligase. 


\subsection{Two Different Mechanisms of Cyclin Clb5 Proteolysis}

The aim of the second project of this thesis was the characterization of cyclin Clb5's proteolysis during the mitotic cell cycle. Clb5 is an S-phase cyclin and like other $\mathrm{Clb}$ cyclins a target of the APC/C (Irniger and Nasmyth 1997). Previous experiments led to conflicting models concerning the importance of $\mathrm{APC} / \mathrm{C}$ in $\mathrm{Clb} 5$ proteolysis (Shirayama et al. 1999; Wasch and Cross 2002).

We were able to show that $\mathrm{Clb5}$ is degraded by an APC/C independent mechanism throughout the cell cycle and that this pathway is probably a reason for the viability of $C L B 5 \triangle D B$ mutants reported by Wäsch (Wasch and Cross 2002). This finding disproved a widely accepted assumption derived from a screen of Shirayama et al. (Shirayama et al. 1999). They found the APC/C-mediated degradation of Clb5 to be essential as viability of $p d s 1 \Delta c d c 20 \Delta$ mutants could be restored by a Clb5 deletion.

These conflicting data published on Clb5 proteolysis prompted us to study in detail the role of the APC/C in this process. Earlier findings showed that in G1-arrested cells, Clb5 is degraded even in mutants defective in APC/C (Irniger and Nasmyth 1997). Thus, APC/C-independent mechanisms might be involved in Clb5 degradation. Here we found that in $c d c 23-1$ cycling cells, Clb5 is indeed still unstable. We suggest the following model: Besides previously identified APC/C-dependent mechanisms (Irniger and Nasmyth 1997) a second, alternative degradation pathway seems to be obviously independent of the APC/C. This alternative mechanism might explain why Wäsch and Cross found that $\mathrm{Clb5} \Delta \mathrm{DB}$ does not block the mitotic exit. We conclude that $\mathrm{APC} / \mathrm{C}$-dependent and $\mathrm{APC} / \mathrm{C}$-independent mechanisms have redundant functions for restricting Clb5 activity in the cell cycle.

\subsubsection{APC/C Independent Clb5 Degradation Suffices Under Physiological}

\section{Conditions to Initiate Exit from Mitosis}

Presently, it is widely accepted that the exit from mitosis is initiated by a dropping Cdk-activity in early anaphase. This drop is essential for the exit from mitosis and achieved by an APC/C-Cdc20 mediated fragmentary degradation of $\mathrm{Clb} 2$. In wildtype cells, complete $\mathrm{Clb}$ destruction and Cdk inactivation is dispensable for the exit from mitosis as indicated by the viability of $c d h 1 \Delta$ mutants. A dropping Cdk activity in early anaphase is thought to evoke Cdc14 phosphatase release from the nucleolus 
leading in turn to the dephosphorylation and activation of a further Cdk antagonist Sic1 (for review see (Irniger 2002)). Whereas the Cdc14 release is essential, activation of Sic1 in contrast seems to be optional as shown by Wäsch who found $c d h 1 \Delta$ sicl $\Delta$ cells to be able to exit from mitosis (Wasch and Cross 2002).

In the same report, Wäsch and Cross proved that unlike CLB5 $\triangle D B$ strains, $C L B 2 \triangle D B$ mutants fail to exit from mitosis proving the dependency of $\mathrm{Clb} 2$ proteolysis on the APC/C. The fact that Clb2 is not degraded alternatively (Amon et al. 1994; Wasch and Cross 2002) like Clb5 might be the reason that in CLB2 $\triangle D B$ mutants the essential drop in $\mathrm{Clb} / \mathrm{Cdk}$ activity cannot be achieved. In contrast, $C L B 5 \triangle D B$ mutants allow the exit from mitosis by the destruction box and $\mathrm{APC} / \mathrm{C}$ independent $\mathrm{Clb} 5$ proteolysis. In brief: The fact that $\mathrm{Clb} 5$ is targeted by an $\mathrm{APC} / \mathrm{C}$ independent degradation mechanism turns it into a dispensable APC/C-Cdc20 target in contrast to $\mathrm{Clb} 2$.

\subsubsection{What Might Trigger APC/C-independent Clb5 Proteolysis?}

It can only be speculated how Clb5 is degraded independently from APC/C activity. However, it cannot be ruled out that ubiquitination by an unknown E3-ligase triggers Clb5 degradation, the results show that Clb5 a $c d c 34-2$ mutation does not positively influence Clb5 half-life and that these SCF mutants can cope with a CLB5 overexpression. Thus, the obtained data indicates that the SCF complex is not involved in APC/C-independent degradation.

Also a ubiquitin-independent degradation is possible as in the past few years, many publications have given evidence for the $20 \mathrm{~S}$ and the $26 \mathrm{~S}$ proteasome to be involved in ubiquitin-independent proteolysis. However, ubiquitin-independent proteolysis has not attracted much attention yet but the number of proteins, known to be recognized without previous ubiquitination is increasing (for review see (Orlowski and Wilk 2003)). Also established targets of ubiquitination can in part be degraded without prior ubiquitination either by the $26 \mathrm{~S}$ proteasome under ATP consumption or by the free $20 \mathrm{~S}$ proteasome directly. This is the case in the complex degradation of the transcriptional activator c-Jun, which is the mammalian GCN4 homologue. It is degraded mainly by a ubiquitin-dependent manner but a ubiquitin-independent proteolysis is also reported (Salvat et al. 1999).

Thus, the instability of destruction box mutants immune to recruitment by the $\mathrm{APC} / \mathrm{C}$ and obviously also not degraded by the second large ubiquitin ligase, the SCF 
complex, makes a ubiquitin-independent degradation likely. Further work has to prove this theory.

\subsubsection{APC/C-mediated Clb5 Degradation Becomes Essential When Clb5} Levels Are Elevated

Our results showed that under physiological conditions, the APC/C-independent mechanism suffices to lower Clb5 levels sufficiently. To get additional insights into the roles of APC/C-dependent and independent mechanisms, we asked whether, under conditions of abnormally high $\mathrm{Clb} 5$ protein levels, these two mechanisms have still redundant functions.

We found that under special conditions, the threshold in Cdk activity, which allows exit from mitosis, can be overshot by Clb5. An overexpression of CLB5 alone is not sufficient as cells can tolerate high levels of this cyclin by degrading it efficiently in the APC/C-dependent manner. Furthermore, cells can even cope with endogenously expressed Clb5 $\Delta \mathrm{DB}$. But a combination of both, high levels of Clb5 and deficient APC/C-mediated proteolysis, is lethal as shown in GAL-CLB5 cdc23 or GAL$C L B 5 \triangle D B$ mutants. Thus, as soon as Clb5 is expressed to high levels the alternative, $\mathrm{APC} / \mathrm{C}$-independent mechanism is unable to carry out sufficient $\mathrm{Clb5}$ proteolysis.

In this case, $\mathrm{APC} / \mathrm{C}-\mathrm{Cdc} 20$ mediated $\mathrm{Clb} 5$ proteolysis becomes unphysiologically essential as observed by Shirayama in $c d c 20 \Delta p d s 1 \Delta$ cells (Shirayama et al. 1999). Also a sicl deletion can make yeast strains sensitive to endogenously expressed CLB5 $\triangle D B$ (Wasch and Cross 2002).

When Clb5 was expressed in G1-arrested cells, we observed similar effects. In the absence of APC/C-mediated proteolysis of Clb5 (by using Clb5 $\triangle \mathrm{DB}$ ), elevated CLB5 expression triggered efficiently DNA replication and phosphorylation of Cdh1.

In summary, under normal conditions the two mechanisms of Clb5 degradation are redundant and the $\mathrm{APC} / \mathrm{C}$ is not essential. But under abnormal conditions, such as elevated Clb5 expression, the APC/C becomes essential for proteolysis of this cyclin. 


\subsection{Meiotic APC/C Regulation by IME2}

Bolte et al. identified Ime 2 as a possible regulator for APC/C-mediated proteolysis in the meiotic cell cycle (Bolte 2004). As Ime2 is itself an unstable protein (Bolte 2004), destruction could bear a regulatory mechanism. For this purpose Meyer and Bolte constructed a systematic deletion set (Bolte 2004); (Meyer 2003) resulting in the identification of a truncated, stable version of Ime2, which lacked the last C-terminal 241 amino acids. This stable construct was used to answer the question which impact an Ime2 stabilization would have on the meiotic cell cycle and if Ime2 proteolysis might be a possible mechanism to regulate the activity of this meiosis-specific kinase. First, it was aimed to clarify whether the truncated Ime $2 \Delta \mathrm{C}$ is still a functional kinase like the wildtype.

\subsubsection{Truncation of 241 C-terminal Amino Acids Does Not Affect IME2's} Kinase Activity

We analyzed the mitotic cell cycle arrest caused by an overexpression of $I M E 2 \triangle C$ from the GAL1-10 promoter and compared it to full-length IME2 from the same promoter. When Ime2 was expressed from the GAL1-10 promoter in cycling cells, the majority of the cultivated strains arrested as large, round cells without buds. This phenotype is similar to strains overexpressing the full-length IME2.

However, analysis of DAPI and tubulin staining under the fluorescence microscope revealed that large portions of the cells were able to segregate their DNA despite they were unbudded. This indicates that phosphorylation by Ime 2 or Ime $2 \Delta \mathrm{C}$ specifically inhibits $\mathrm{APC} / \mathrm{C}^{\mathrm{Cdh} 1}$ activity and not $\mathrm{APC} / \mathrm{C}$ proteolysis in general. If this is the case, APC/C-Cdc20-mediated degradation of the anaphase inhibitor protein Pds1 would as well be abolished disabling cells to segregate their DNA masses. Indeed, proteolysis of Pds1 is in contrast to severely inhibited $\mathrm{Clb}$ degradation only slightly delayed in IME2 overexpressing cells (Bolte et al. 2002). We conclude that Ime $2 \Delta \mathrm{C}$ is a fully functional kinase.

These results are supported by Western Blot experiments, in which G1-arrested strains co-expressing GALL-HA-CDH1 and a copy of either GAL-IME2 or GAL$I M E 2 \triangle C$ displayed slower migrating bands of Ha-Cdh1 indicating an increased phosphorylation. We conclude that this is due to phosphorylation by Ime 2 or Ime $2 \Delta \mathrm{C}$ 
as no other kinase is active in G1-phase. This strengthens the finding that Ime $2 \Delta \mathrm{C}$ is despite the truncation a functional kinase, which is able to phosphorylate Cdh1.

Furthermore, five copies of native IME2 showed comparable kinase activity to a single copy of $I M E 2 \triangle C$ determined by scoring the mitotic arrest and the observed degree in Cdh1 phosphorylation. From this fact, we conclude that the truncated Ime2 is hyperactive. We suggest that this is due to elevated protein levels caused by an altered degradation of the truncated Ime $2 \Delta \mathrm{C}$, which lacks the degradation signals located in the $\mathrm{C}$-terminal region.

\subsubsection{Stable Ime2 $\Delta C$ Interferes With Meiosis II}

Ime2 activity seems to be mediated by the amount of protein in the cell, as no activating cyclins (in contrast to $\mathrm{Cdc} 28$ ) are yet known. Also, no kinase inhibitors have been found. In contrast, Ime2 regulation is thought to take place on the transcriptional level (Mitchell et al. 1990; Mitchell 1994) and most likely on the proteolytic level as suggested by Bolte (Bolte 2004). By constructing a proteolyticresistant version of Ime2, we obtained a tool to study alterations in sporulation by continued presence of Ime2.

In wildtype cells, IME2 transcription is triggered by Ime1, which is itself regulated mainly by the presence of a non-fermentable carbon source. Consistently, we found Ime2 levels to be high at the beginning of meiosis one hour after shifting cells from acetate to SPO medium. In this period Ime2 is thought to antagonize Sic1 (Dirick et al. 1998) thereby promoting meiotic S-phase and triggering transcription of early meiotic genes (Mitchell et al. 1990). Furthermore Ime2 destabilizes Ime1 (GuttmannRaviv et al. 2002) and initializes expression of the transcription factor NDT80 (Hepworth et al. 1998). When meiotic cells enter G2/M transition, Ime2 is required to promote events after metaphase and to execute meiosis II (Benjamin et al. 2003) perhaps by phosphorylating Ndt80. Interestingly, we observed a complete decline in the Ime2 protein level when wildtype cells entered the first meiotic division.

Thus, after having triggered meiosis I, Ime2 seems to be dispensable and is peaking again at the end of meiosis when about $60 \%$ of the cells had finished germination. This peak in late meiosis is consistent with the findings of Benjamin showing a role of Ime2 in meiosis II (Benjamin et al. 2003). However, sporulating cells are able to 
tolerate elevated Ime2 levels as heterozygous IME2 $\triangle C / I M E 2$ cells carried out sporulation with an efficiency comparable to the wildtype.

In these strains Ime 2 was present throughout meiosis and no drop in protein levels was observed. This experiment demonstrates that Ime $2 \Delta \mathrm{C}$ is indeed stabilized in meiosis, similar to previous experiments in mitotic cells (Meyer 2003). The efficient sporulation in the presence of a stabilized Ime $2 \Delta \mathrm{C}$ however suggests that Ime2 instability is not essential for progression through meiosis.

The situation severely changes in homozygous $I M E 2 \triangle C / I M E 2 \triangle C$ strains which, failed completely to accomplish meiosis II as indicated by one half of the cells arresting as dyads and no cell able to form proper 4-spore asci.

The question now occurs whether sporulating cells are a) unable to tolerate high levels of stable Ime $2 \Delta \mathrm{C}$ protein expressed from to truncated $I M E 2 \Delta C$ alleles or b) if a pivotal functional feature of Ime2 was altered by truncation of the C-terminal 241 amino acids.

Model a) is less favorable as heterozygous IME2/IME2 $\triangle C$ went through meiosis despite high levels of Ime $2 \Delta \mathrm{C}$ similar to the wildtype only with a slight delay. Nevertheless, it cannot be ruled out that two copies of permanently stable $I M E 2 \triangle C$ overshoot a threshold in Ime $2 \Delta \mathrm{C}$ kinase activity, which the cell can tolerate. The failure in meiosis II that we observed coincides with a late peak of Ime2 activity described by Benjamin (Benjamin et al. 2003). These late meiotic functions of Ime2 depend on interplay between Ime2, Cdc28 and Ndt80. These three proteins are connected in a positive feedback loop, in which Ime2 triggers NDT80 transcription leading to the transcription of cyclins, which promote Cdc28 kinase activity that in turn closes the loop by promoting IME2 transcription. It is not known, how high levels of hyperactive, stable Ime $2 \Delta \mathrm{C}$ would interfere with this cycle. By observing an ime $2 \Delta / M E 2 \Delta C$ strain in meiosis, the question whether high levels of Ime $2 \Delta \mathrm{C}$ are responsible for the meiotic arrest in these cells could be answered. Up to now, we could not yet test this, because an ime $2 \Delta$ mutation in the SK1 background could not be constructed. This is due to the difficulties in transforming this strain. Future experiments will be required to receive ime $2 \Delta$ cells and test effects of Ime $2 \Delta C$ in this strain.

If ime $2 \Delta / I M E 2 \Delta C$ cells were able to accomplish meiosis, then high Ime $2 \Delta \mathrm{C}$ levels were the cause for the observed meiotic arrest in IME2 $\triangle C / I M E 2 \Delta C$ strains. If this 
strain showed a failure during meiosis II, then an unknown function beside Ime2's kinase activity, which we proved to be intact, was disturbed by truncating $241 \mathrm{C}$ terminal amino acids. For example the C-terminal region might be required for recognition of specific substrates or for proper subcellular localization of Ime2.

That Ime2 has a function in meiosis II is supported by results of Benjamin and colleagues who depleted meiotic cells from Ime2 and observed that these cells arrested before meiosis II (Benjamin et al. 2003). Thus, Ime2 is unable to fulfill one of its pivotal functions most likely due to an essential substrate recognition site that is located within the deleted $241 \mathrm{C}$-terminal amino acids.

If the truncation perturbed the interaction of Ime 2 with one of its essential substrates, then analysis of the interaction partners of Ime 2 and Ime $2 \Delta \mathrm{C}$ could shed light on unknown roles of Ime 2 in meiosis. For this purpose, a tagged version of Ime 2 and Ime $2 \Delta \mathrm{C}$ could be constructed to study the "Ime2-Interactome" by purification of Ime2 and its interaction partners. 


\section{Outlook and Supplement}

\subsection{Continuing the Characterization of SUMOylation}

This work branded functional SUMOylation as pivotal for efficient mitotic proteolysis. But the mechanism, by which a defective SUMOylation impairs APC/Cmediated ubiquitination, remains still unclear. Clues to determine SUMO's role in the cell cycle could arise by identifying new targets of SUMOylation.

\subsubsection{Strategies for Identification of Yeast SUMO-Targets by Mass} Spectrometry

As it is still unclear how SUMO affects APC/C function in yeast, identification of yet unknown SUMO targets could shed light on the underlying mechanism. Since previous co-immunoprecipitation of a MYC-tagged version of the $\mathrm{APC} / \mathrm{C}$ core subunit Cdc23 with HA-tagged Smt3 protein (data not shown) did not produce any clues that the APC/C could be directly SUMOylated, we conceived a new approach involving the small protein tag "STREP". The STREP-tag consists of only six amino acids in addition with two spacer amino acids and binds to avidin. Binding and elution conditions can be chosen very mildly so that also large complexes can be purified.

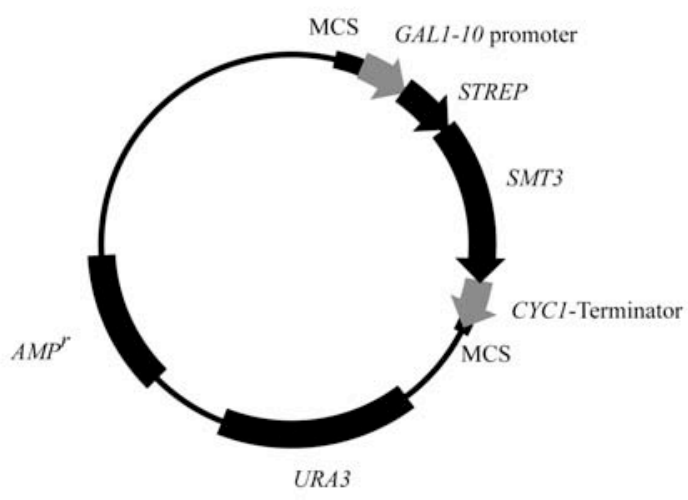

PD-SMT3-FW : $5^{\circ}$-GCACGTGGATCCTCGGACTCAGAAGTCAAT-3 PD-SMT3-BW : 5'-TTGCCGAAGCTTCTAATACGTAGCACCACC-3'
Figure 31: Vector Map of STREP-SMT3 Construct

Plasmid pME2536 containing an $\mathrm{N}$ terminally STREP tagged version of PHA2 was digested with BamHI and HindIII to cut out PHA2. The SMT3 ORF was amplified using primers PD-SMT3-FW and PD-SMT3BW containing either a $B a m H I$ site $(\mathrm{N}-$ terminus or a HindIII site (C-terminus). The digested amplicon was finally ligated into the restricted vector between the GAL1-10 promoter and the $C Y C l$ terminator. The STREP-tag was provided by IBA GMBH (http://www.iba-go.de), Göttingen. 
For a first approach, STREP-SMT3 was cloned into a high copy vector behind the GAL1-10 promoter and transformed into a W303 wildtype yeast strain (Figure 31).

To test functionality of the STREP-SMT3 construct, it was transformed into the temperature-sensitive smt3-331 strain. Two days of growth at the restrictive temperature showed that the STREP-SMT3 construct conferred resistance to the elevated temperature (Figure 32).
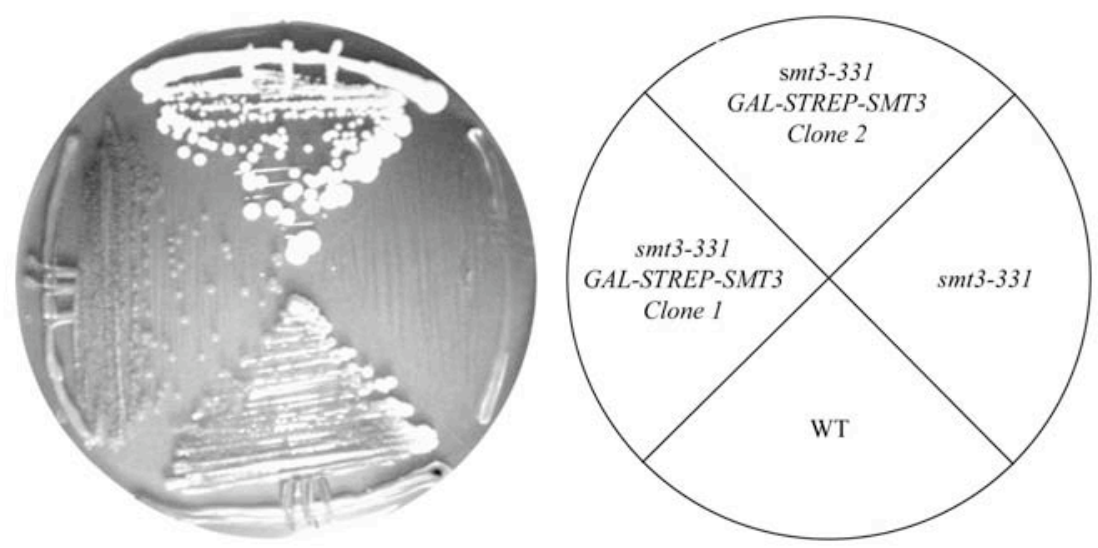

\section{Figure 32: Functionality Test of the GAL-STREP-SMT3 Construct}

The GAL-STREP-SMT3 construct was transformed in a strain carrying a temperature sensitive smt3331 mutation (S542) and grown on galactose plates for two days at the restrictive temperature $\left(37^{\circ} \mathrm{C}\right)$. The strain containing the STREP-Smt3 fusion protein showed uninhibited growth in contrast to the smt3-331 mutant cells.

To test expression of the GAL-STREP-SMT3 construct, a wildtype and a strain containing the fusion protein overnight in raffinose minimal medium (lacking uracil when selection for the GAL-STREP-SMT3 plasmid was necessary) were grown to log phase and galactose (2\%) was added for two hours to induce GAL-STREP-SMT3 expression. The cells were broken up as described (see materials \& methods) and purified on a Streptactin Superflow ${ }^{\circledR}$ column. Of each culture, the unspecific flowthrough and three fractions of the specifically eluted proteins were collected. The fusion protein was detected by Western blotting using anti-STREP antibodies. 


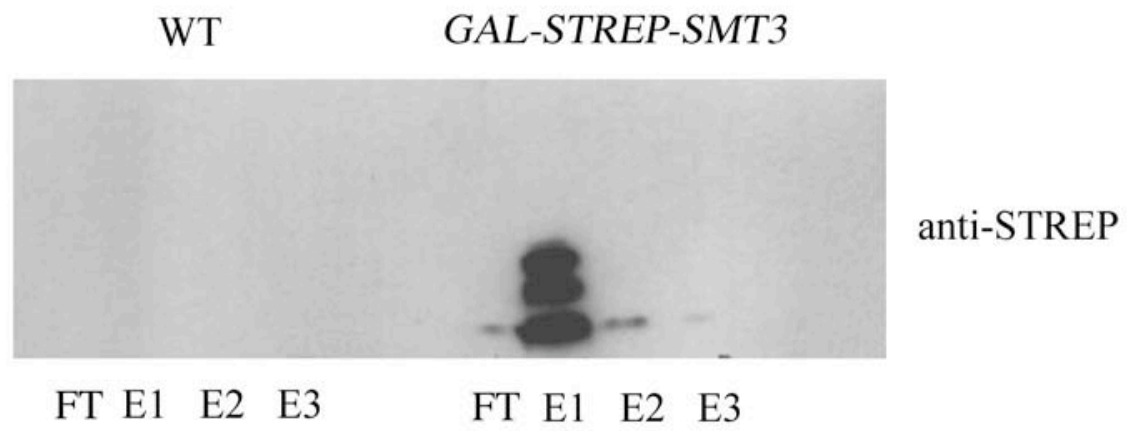

Figure 33: Western Blot Detection of STREP-Smt3 Fusion Proteins

A wildtype and a strain containing the fusion protein were grown overnight in raffinose medium to log phase. Galactose (2\%) was added for two hours to induce GAL-STREP-SMT3 expression. The cells were broken up as described and purified on a Streptactin Superflow ${ }^{\circledR}$ column. Of each culture, the unspecific flow-through (FT) and three fractions (E1, E2, E3) of the specificly eluted proteins were collected. The fusion protein was detected by Western blotting using anti-STREP antibodies (IBA GMBH). Only in the first fraction of the specific elution three bands could be detected.

In the first fraction of the specific elution, three bands could be detected, either representing SUMO-polymers or SUMO bound to one of its targets. To shed light on this riddle, we put the collected fractions of untagged wildtype and GAL-STREPSMT3 cultures on an SDS-Gel (Figure 34). Silver staining revealed a very prominent band with a mass around $20 \mathrm{kD}$, which corresponds to SUMO confirmed by mass spectrometry. The other prominently stained protein bands appear also in the eluates of the purified wildtype cell extracts indicating that they represent unspecificly bound proteins. Thus, the only difference that can be determined in a single dimension SDSgel is the purified STREP-Smt3 protein as indicated by an arrow.

To find SUMOylated proteins, a more precise separation of proteins in a two dimensional SDS-gel is necessary. Therefore concentrated purifications of wildtype as well as GAL-STREP-SMT3 strains will be produced and separated in two dimensions. Spots that appear exclusively in the tagged samples will be cut out of the gel and analyzed by mass spectrometry. To avoid side effects, SUMO levels should be lowered with respect to detection limits by expressing STREP-SMT3 from promoters with different strengths. Furthermore, an $\operatorname{smt} 3 \Delta$ deletion will be created to deplete the cell from endogenous SUMO. That might force the cell to fuse the STREP-tagged SMT3 to target proteins, which can then be identified. 


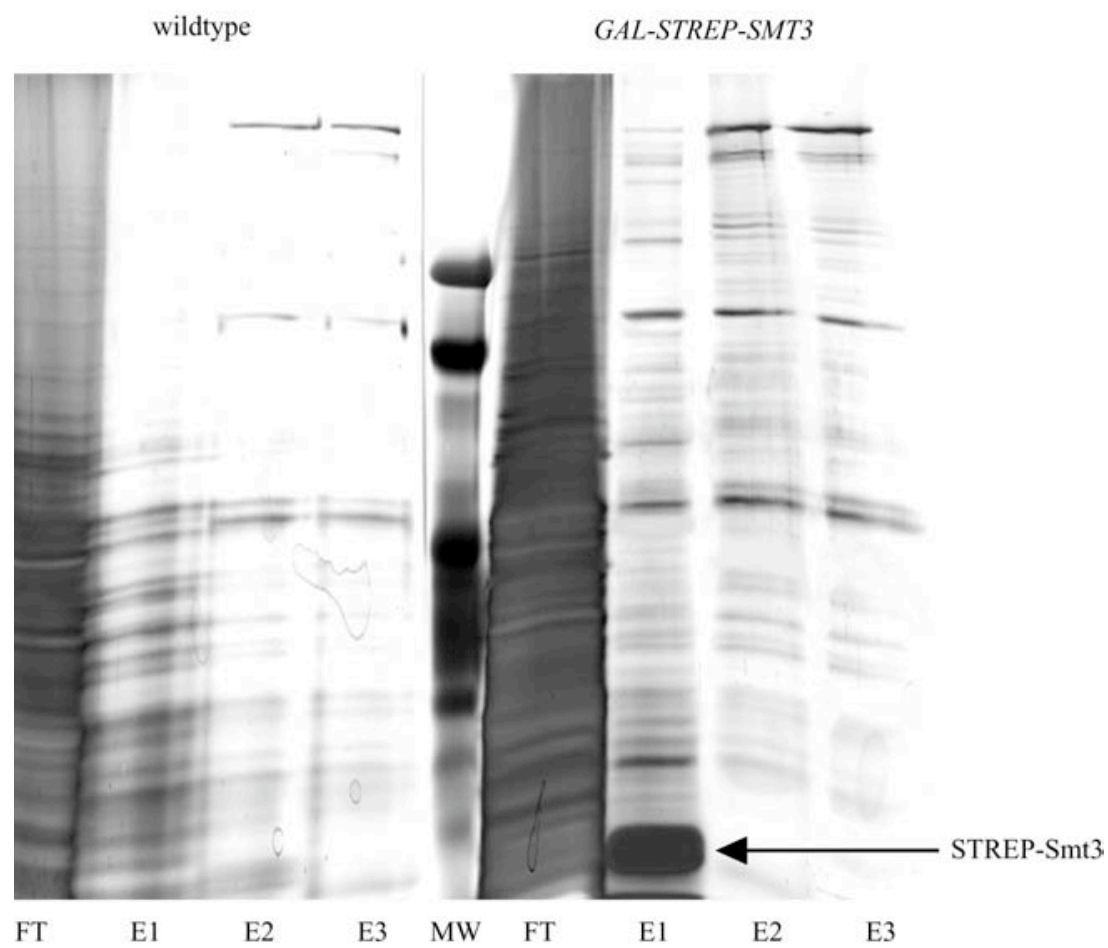

Figure 34: Purification of STREP-tagged SMT3

Cultures of a wildtype strain and a strain carrying a high-copy plasmid with a GAL-STREP-SMT3 construct were grown in minimal media containing galactose $(2 \%)$. In the case of the plasmid-carrying strain, the medium lacked uracil to select for the GAL-STREP-SMT3 plasmid. Cells were harvested and broken up. The cell extracts were centrifuged at maximum speed for one hour and put on an equilibrated Streptactin Superflow ${ }^{\circledR}$ column (IBA GMBH). The loaded columns were washed and fractions $(\mathrm{FT}=$ flow through, E1 - E3 = different specific eluates) were separated on an SDS-gel and protein bands were stained by silver. Size determination was carried out by comparing the bands with the pre-stained molecular weight marker obtained from FERMENTAS.

\subsubsection{Initial Characterization of ubcI, an A.nidulans Orthologue of UBC9}

Up to now, it is unknown whether SUMOylation is important for mitosis in organisms other than yeast. We therefore aimed to study SUMOylation in a more complex organism. We chose the filamentous fungus Aspergillus nidulans as subject of investigation. It offers established genetics in combination with a high degree of differentiation. In addition, nothing is known about the requirement of SUMO for 
A.nidulans' different life cycle stages. As SUMO is not essential in S.pombe (Tanaka et al. 1999), it is not sure that this gene is required for life of all fungi.

As a first step, we screened for genes in an A.nidulans GAL-cDNA library (Krappmann et al. 1999), which help yeast to overcome the lethality of a $u b c 9-2$ tsmutation at the restrictive temperature. $U B C 9$ is an essential gene in yeast, so that only cells are able to survive expressing $G A L$-cDNA coding for an A.nidulans orthologue of the yeast $U B C 9$ gene. Accordingly, we transformed yeast cells with the A.nidulans $G A L$-cDNA library let them grow $24 \mathrm{~h}$ on -Ura at the permissive temperature $\left(25^{\circ} \mathrm{C}\right)$ and screened subsequently for clones able to grow on galactose plates at the restrictive temperature $\left(37^{\circ} \mathrm{C}\right)$.

All obtained clones owed complementation of the ts-mutation to the same piece of cDNA. Subsequent sequencing and a comparison (Broad-Institute) of the identified cDNA revealed that it coded for an A.nidulans orthologue of the yeast $U B C 9$ gene with $58 \%$ amino acid identity.

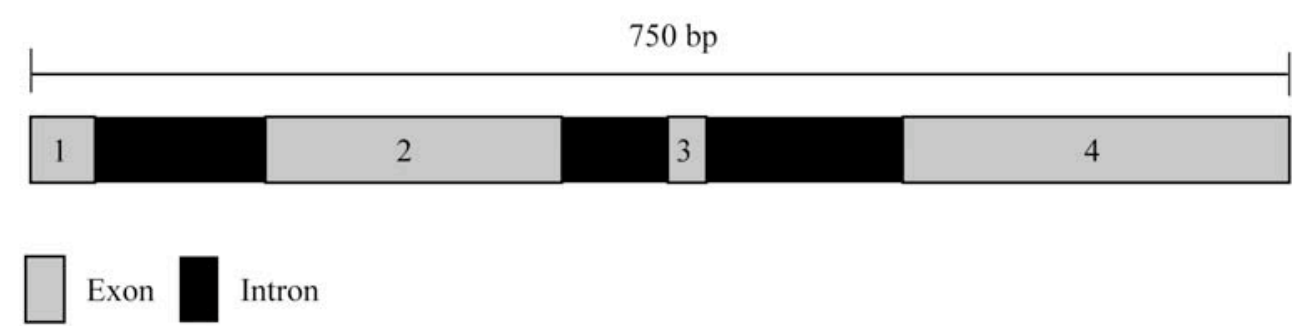

S.cerev: MSLCLQRLQEERKK -WRKDHPFGFYAKPVKKADGSMDLQKWEAGIPGKEGTN A.nidu: MSLCLNRLTEERRKQWRKDHPFAFYAKPHRAQGVLDMKR - WECGIPGKKGTI S.cerev: WAGGVYPIT VEYPNEYPSKPPKVKFP AGFHPNVYPSGTI CLSILNEDQDWRPA A.nidu: WEGGLFKLDVTF PDEYPTKPPKCKFVALFHPNVYPSGTVCLSILNEDEAWKPA

S.cerev: ITLKQIVLGVQDLLDSPNPNSPAQEPAWRSFSRNKAE - YDKKVLLQAKQYSK A.nidu: ITLKQILLG I QDLLDDPNPESPAQAEAYNMYKKDRAAYEKRVKQVVKENP AL

Figure 35: Structure of the A.nidulans ubcI Gene, Sharing $58 \%$ Identity to the Yeast $U B C 9$ gene The A.nidulans UBC9 orthologue $u b c I$ contains four exons, which are interrupted by three introns. The total size of the genomic ORF is $750 \mathrm{bp}$. The identity between the Saccharomyces cerevisiae and the A.nidulans gene is $58 \%$. Cys98, which binds SUMO as a thioester (Giraud et al. 1998), is also conserved. Identical amino acids are bold.

By aligning the sequenced cDNA with the genomic DNA found in the databank (Broad-Institute) we were able to determine the intron-exon arrangement of the 750 
bp A.nidulans $U B C 9$ orthologue (Figure 35). According to the applicable regulations, we baptized the A.nidulans orthologue of the Saccharomyces cerevisiae UBC9 gene, ubcI.

\subsubsection{Functionality of the A.nidulans ubcI Gene in Saccharomyces cerevisiae}

The screening for functional Aspergillus orthologues of the yeast $U B C 9$ gene proved, that the identified $u b c I$ gene was able to complement a yeast $u b c 9-2$ ts-mutation. To demonstrate the functionality of $u b c I$ in Saccharomyces cerevisiae more in detail, we sporulated heterozygous $U B C 9 / u b c 9 \Delta$ strains containing the $G A L-u b c I$ cDNA and obtained ubc9 $\Delta$ mutants carrying the A.nidulans $u b c I$ (Figure 36). On glucose, the transformants displayed only restricted growth. In contrast on galactose plates, transformants showed comparable growth to the wildtype when the A.nidulans ubcI gene was expressed indicating a complementation of the $u b c 9 \Delta$ mutation. Thus, the highly homologous $u b c I$ gene of A.nidulans is functional in Saccharomyces cerevisiae. Future results from the filamentous fungus might thus also be assignable to yeast.

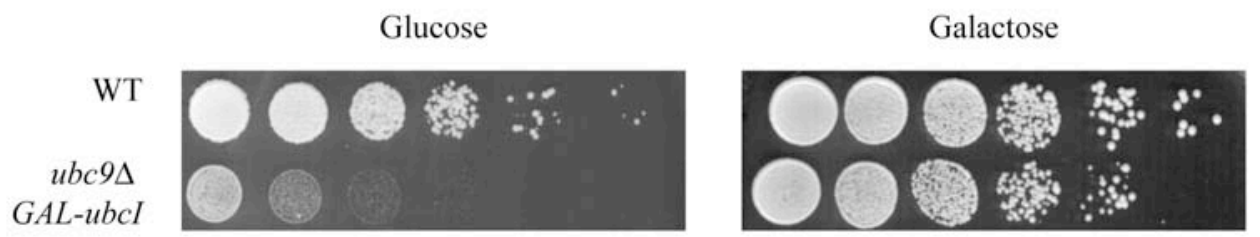

Figure 36: A.nidulans $u b c I$ is Able to Complement a $u b c 9 \Delta$ Deletion Mutation.

Whereas, the $u b c 9 \Delta G A L-u b c I$ dells displayed restricted growth due to $G A L$-promoter "leakage" on glucose, they displayed no distinct growth defect when the A.nidulans ubcI gene was expressed on galactose indicating a complementation of the $u b c 9 \Delta$ mutation.

\subsubsection{Analysis of ubcI Expression in A.nidulans}

To get a clue for which developmental stages SUMO conjugation, carried out by UbcI, is necessary, performed a Northern blot analysis of mRNA prepared during vegetative, asexual and sexual development treated with the $300 \mathrm{bp}$ radio-labeled $\mathrm{Xma} / \mathrm{SalI} u b c I$ fragment as probe. 


\section{$u b c I$}

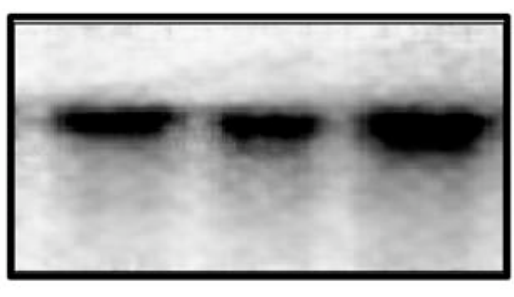

veg. sex. asex.

Figure 37: Northern Blot Detection of A.nidulans mRNA Taken at Different Developmental Stages

A.nidulans mRNA from three different developmental stages (donation of Dr. Silke Busch) was treated with the radio labeled $\mathrm{Xma} / \mathrm{SalI} u b c I$ fragment as probe. Obviously, UbcI-mediated SUMO conjugation is required throughout A.nidulans' life.

In these preparatory steps, we found that that the $u b c I$ gene is required for various stages in A.nidulans life cycle, because mRNA could be detected during vegetative, asexual and sexual growth.

\subsubsection{Construction of a ubcI Deletion Cassette}

The next step would be to construct a genomic $u b c I \Delta$ deletion. For this purpose, a cloning strategy (Figure 38) based on a deletion cassette with flanking regions of about $4 \mathrm{~kb}$ will be used to create a $u b c I \Delta$ A.nidulans deletion strain. At first, the $u b c I$ ORF and flanking regions of about $4 \mathrm{~kb}$ will be cut out of a bacterial artificial chromosome (BAC) and cloned into the pBluescript vector. Then, $300 \mathrm{bp}$ adjacent to the $u b c I$ ORF will be cloned flanking to the bifunctional marker cassette, which carries a zeocin marker for selection in E.coli and the pyrG auxotrophy A.nidulans marker. To obtain the gene disruption, the bifunctional marker cassette will be cut out with the $300 \mathrm{bp}$ flanking regions and transformed together with the BAC DNA containing pBluescript vector into the an E.coli strain expressing arabinose inducible $\lambda$-recombinase. 
Step1: Identification and cloning of $u b c I$ genomic region from BAC library into pBluescript

Bacterial Artificial Chromosome (BAC) Library

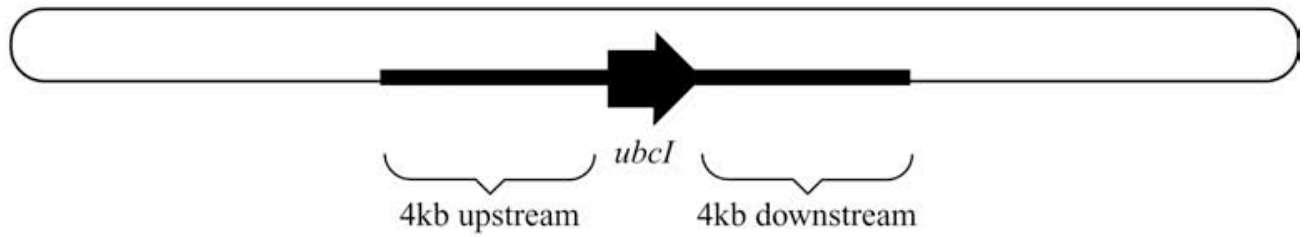

Step2: Cloning of 300bp up- and downstream DNA into the plasmid carrying the bifunctional marker. Step3: Recombination in E.coli strain expressing RED-recombinase, hosting plasmid with $u b c I$.

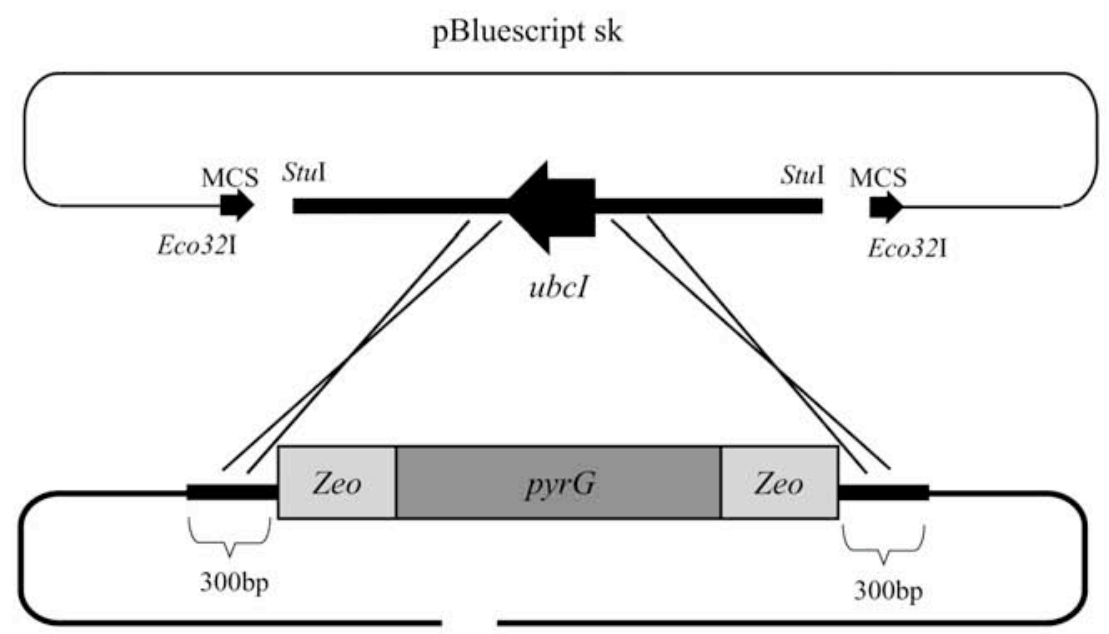

Step4: Use linearized recombinant DNA for transformation.

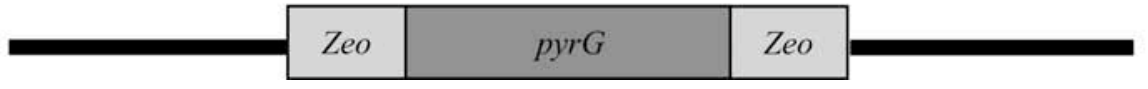

Figure 38: Cloning Strategy for a Genomic Deletion of $u b c I$

A large DNA fragment (in the form of a bacterial artificial chromosome, BAC) containing A.nidulans $u b c I$ gene was isolated from a BAC library (http://www.genome.clemson.edu/groups/bac/). Digestion with $S t u I$ resulted in a $10 \mathrm{~kb}$ fragment, which was cloned into the Pbluescript sk vector and transformed into an E.coli strain expressing arabinose inducible $\lambda$-red recombinase. In a further step, a second plasmid containing a bifunctional marker for selection in E.coli (zeocin) and A.nidulans (pyrG) with $300 \mathrm{bp}$ up- and downstream homologous regions adjacent to the $u b c I$ gene would be transformed into the same strain. Cultivation of the transformed E.coli strain in medium containing arabinose will result in a recombinant DNA fragment, which is suitable for transformation with A.nidulans. 
Treatment with arabinose induced recombination of the marker cassette into the BAC DNA results in a pBluescript vector carrying the bifunctional marker flanked by $4 \mathrm{~kb}$ A.nidulans DNA. This construct is adequate for transformation in A.nidulans.

If a $u b c I$ deletion was lethal, a transformed diploid strain should be nevertheless viable. Subsequent germination should reveal whether spores containing a $u b c I$ deletion are viable or not indicating if SUMOylation is essential in A.nidulans. In addition, if $u b c I$ was essential, an approach via repressible promoters or a temperature-sensitive mutation can be used to determine phenotypes of cells defective in sporulation.

Future projects could involve the investigation of mitosis in A.nidulans to find out whether $u b c I$ mutants show defects in this process similar to yeast $u b c 9-2$ cells. 


\section{References}

Agarwal, R., Z. Tang, H. Yu, and O. Cohen-Fix. 2003. Two distinct pathways for inhibiting Pds1 ubiquitination in response to DNA damage. J Biol Chem 278: 45027-33.

al-Khodairy, F., T. Enoch, I.M. Hagan, and A.M. Carr. 1995. The Schizosaccharomyces pombe hus 5 gene encodes a ubiquitin conjugating enzyme required for normal mitosis. J Cell Sci 108 ( Pt 2): 475-86.

Amon, A., S. Irniger, and K. Nasmyth. 1994. Closing the cell cycle circle in yeast: G2 cyclin proteolysis initiated at mitosis persists until the activation of G1 cyclins in the next cycle. Cell 77: 1037-50.

Amon, A., M. Tyers, B. Futcher, and K. Nasmyth. 1993. Mechanisms that help the yeast cell cycle clock tick: G2 cyclins transcriptionally activate $\mathrm{G} 2$ cyclins and repress G1 cyclins. Cell 74: 993-1007.

Bachant, J., A. Alcasabas, Y. Blat, N. Kleckner, and S.J. Elledge. 2002. The SUMO-1 isopeptidase Smt4 is linked to centromeric cohesion through SUMO-1 modification of DNA topoisomerase II. Mol Cell 9: 1169-82.

Bardin, A.J., R. Visintin, and A. Amon. 2000. A mechanism for coupling exit from mitosis to partitioning of the nucleus. Cell 102: 21-31.

Baumer, M., G.H. Braus, and S. Irniger. 2000a. Two different modes of cyclin clb2 proteolysis during mitosis in Saccharomyces cerevisiae. FEBS Lett 468: 1428.

Baumer, M., M. Kunzler, P. Steigemann, G.H. Braus, and S. Irniger. 2000b. Yeast Ran-binding protein Yrb1p is required for efficient proteolysis of cell cycle regulatory proteins Pds1p and Sic1p. J Biol Chem 275: 38929-37.

Bayer, P., A. Arndt, S. Metzger, R. Mahajan, F. Melchior, R. Jaenicke, and J. Becker. 1998. Structure determination of the small ubiquitin-related modifier SUMO1. J Mol Biol 280: 275-86.

Benjamin, K.R., C. Zhang, K.M. Shokat, and I. Herskowitz. 2003. Control of landmark events in meiosis by the CDK Cdc28 and the meiosis-specific kinase Ime2. Genes Dev 17: 1524-39.

Betting, J. and W. Seufert. 1996. A yeast Ubc9 mutant protein with temperaturesensitive in vivo function is subject to conditional proteolysis by a ubiquitinand proteasome-dependent pathway. J Biol Chem 271: 25790-6.

Bies, J., J. Markus, and L. Wolff. 2002. Covalent attachment of the SUMO-1 protein to the negative regulatory domain of the c-Myb transcription factor modifies its stability and transactivation capacity. J Biol Chem 277: 8999-9009.

Biggins, S., N. Bhalla, A. Chang, D.L. Smith, and A.W. Murray. 2001. Genes involved in sister chromatid separation and segregation in the budding yeast Saccharomyces cerevisiae. Genetics 159: 453-70.

Blondel, M., J.M. Galan, Y. Chi, C. Lafourcade, C. Longaretti, R.J. Deshaies, and M. Peter. 2000. Nuclear-specific degradation of Far1 is controlled by the localization of the F-box protein Cdc4. Embo J 19: 6085-97.

Bolte, M. 2004. Regulation of the anaphase promoting complex (APC/C) in the mitotic and meiotic cell cycle of Saccharomyces cerevisiae. In MathematischNaturwisenschaftliche Fakultät der Georg-August-Universität zu Göttingen. Georg-August-Universität zu Göttingen, Göttingen. 
Bolte, M., P. Steigemann, G.H. Braus, and S. Irniger. 2002. Inhibition of APCmediated proteolysis by the meiosis-specific protein kinase Ime2. Proc Natl Acad Sci U S A 99: 4385-90.

Bradford, M.M. 1976. A rapid and sensitive method for the quantitation of microgram quantities of protein utilizing the principle of protein-dye binding. Anal Biochem 72: 248-54.

Broad-Institute. Aspergillus Nidulans Database. In. Genome Center.

Buonomo, S.B., R.K. Clyne, J. Fuchs, J. Loidl, F. Uhlmann, and K. Nasmyth. 2000. Disjunction of homologous chromosomes in meiosis I depends on proteolytic cleavage of the meiotic cohesin Rec8 by separin. Cell 103: 387-98.

Burton, J.L. and M.J. Solomon. 2001. D box and KEN box motifs in budding yeast Hsl1p are required for APC-mediated degradation and direct binding to Cdc20p and Cdh1p. Genes Dev 15: 2381-95.

Cao, L., E. Alani, and N. Kleckner. 1990. A pathway for generation and processing of double-strand breaks during meiotic recombination in S. cerevisiae. Cell 61: 1089-101.

Carlson, M. 1999. Glucose repression in yeast. Curr Opin Microbiol 2: 202-7.

Cha, R.S., B.M. Weiner, S. Keeney, J. Dekker, and N. Kleckner. 2000. Progression of meiotic DNA replication is modulated by interchromosomal interaction proteins, negatively by Spo11p and positively by Rec8p. Genes Dev 14: 493503.

Chen, R.H., A. Shevchenko, M. Mann, and A.W. Murray. 1998. Spindle checkpoint protein Xmad1 recruits Xmad2 to unattached kinetochores. J Cell Biol 143: 283-95.

Chu, S., J. DeRisi, M. Eisen, J. Mulholland, D. Botstein, P.O. Brown, and I. Herskowitz. 1998. The transcriptional program of sporulation in budding yeast. Science 282: 699-705.

Ciechanover, A. and A.L. Schwartz. 1998. The ubiquitin-proteasome pathway: the complexity and myriad functions of proteins death. Proc Natl Acad Sci US A 95: 2727-30.

Cohen-Fix, O., J.M. Peters, M.W. Kirschner, and D. Koshland. 1996. Anaphase initiation in Saccharomyces cerevisiae is controlled by the APC-dependent degradation of the anaphase inhibitor Pds1p. Genes Dev 10: 3081-93.

Colomina, N., E. Gari, C. Gallego, E. Herrero, and M. Aldea. 1999. G1 cyclins block the Imel pathway to make mitosis and meiosis incompatible in budding yeast. Embo J 18: 320-9.

Copeland, B.R., S.A. Todd, and C.E. Furlong. 1982. High resolution two-dimensional gel electrophoresis of human erythrocyte membrane proteins. Am J Hum Genet 34: 15-31.

Covitz, P.A. and A.P. Mitchell. 1993. Repression by the yeast meiotic inhibitor RME1. Genes Dev 7: 1598-608.

Cross, F.R. 1995. Starting the cell cycle: what's the point? Curr Opin Cell Biol 7: 7907.

Cross, F.R. and A.H. Tinkelenberg. 1991. A potential positive feedback loop controlling CLN1 and CLN2 gene expression at the start of the yeast cell cycle. Cell 65: 875-83.

Dahmann, C. and B. Futcher. 1995. Specialization of B-type cyclins for mitosis or meiosis in S. cerevisiae. Genetics 140: 957-63.

DeSalle, L.M. and M. Pagano. 2001. Regulation of the G1 to S transition by the ubiquitin pathway. FEBS Lett 490: 179-89. 
Deshaies, R.J. and J.E. Ferrell, Jr. 2001. Multisite phosphorylation and the countdown to S phase. Cell 107: 819-22.

Desterro, J.M., J. Thomson, and R.T. Hay. 1997. Ubch9 conjugates SUMO but not ubiquitin. FEBS Lett 417: 297-300.

Dirick, L., L. Goetsch, G. Ammerer, and B. Byers. 1998. Regulation of meiotic S phase by Ime2 and a Clb5,6-associated kinase in Saccharomyces cerevisiae. Science 281: 1854-7.

Dumitrescu, T.P. and W.S. Saunders. 2002. The FEAR Before MEN: networks of mitotic exit. Cell Cycle 1: 304-7.

Endter, C., J. Kzhyshkowska, R. Stauber, and T. Dobner. 2001. SUMO-1 modification required for transformation by adenovirus type 5 early region $1 \mathrm{~B}$ 55-kDa oncoprotein. Proc Natl Acad Sci U S A 98: 11312-7.

Enomoto, T. 2001. Functions of RecQ family helicases: possible involvement of Bloom's and Werner's syndrome gene products in guarding genome integrity during DNA replication. J Biochem (Tokyo) 129: 501-7.

Epstein, C.B. and F.R. Cross. 1992. CLB5: a novel B cyclin from budding yeast with a role in S phase. Genes Dev 6: 1695-706.

Evans, T., E.T. Rosenthal, J. Youngblom, D. Distel, and T. Hunt. 1983. Cyclin: a protein specified by maternal mRNA in sea urchin eggs that is destroyed at each cleavage division. Cell 33: 389-96.

Feldman, R.M., C.C. Correll, K.B. Kaplan, and R.J. Deshaies. 1997. A complex of Cdc4p, Skp1p, and Cdc53p/cullin catalyzes ubiquitination of the phosphorylated CDK inhibitor Sic1p. Cell 91: 221-30.

Fitch, I., C. Dahmann, U. Surana, A. Amon, K. Nasmyth, L. Goetsch, B. Byers, and B. Futcher. 1992. Characterization of four B-type cyclin genes of the budding yeast Saccharomyces cerevisiae. Mol Biol Cell 3: 805-18.

Foiani, M., E. Nadjar-Boger, R. Capone, S. Sagee, T. Hashimshoni, and Y. Kassir. 1996. A meiosis-specific protein kinase, Ime2, is required for the correct timing of DNA replication and for spore formation in yeast meiosis. Mol Gen Genet 253: 278-88.

Freese, E.B., M.I. Chu, and E. Freese. 1982. Initiation of yeast sporulation of partial carbon, nitrogen, or phosphate deprivation. J Bacteriol 149: 840-51.

Galbraith, A.M., S.A. Bullard, K. Jiao, J.J. Nau, and R.E. Malone. 1997. Recombination and the progression of meiosis in Saccharomyces cerevisiae. Genetics 146: 481-9.

Gieffers, C., P. Dube, J.R. Harris, H. Stark, and J.M. Peters. 2001. Three-dimensional structure of the anaphase-promoting complex. Mol Cell 7: 907-13.

Gietz, R.D. and A. Sugino. 1988. New yeast-Escherichia coli shuttle vectors constructed with in vitro mutagenized yeast genes lacking six-base pair restriction sites. Gene 74: 527-34.

Gimeno, C.J., P.O. Ljungdahl, C.A. Styles, and G.R. Fink. 1992. Unipolar cell divisions in the yeast $S$. cerevisiae lead to filamentous growth: regulation by starvation and RAS. Cell 68: 1077-90.

Giraud, M.F., J.M. Desterro, and J.H. Naismith. 1998. Structure of ubiquitinconjugating enzyme 9 displays significant differences with other ubiquitinconjugating enzymes which may reflect its specificity for sumo rather than ubiquitin. Acta Crystallogr D Biol Crystallogr 54 ( Pt 5): 891-8.

Glickman, M.H. and A. Ciechanover. 2002. The ubiquitin-proteasome proteolytic pathway: destruction for the sake of construction. Physiol Rev 82: 373-428. 
Gmachl, M., C. Gieffers, A.V. Podtelejnikov, M. Mann, and J.M. Peters. 2000. The RING-H2 finger protein Apc11 and the E2 enzyme Ubc4 are sufficient to ubiquitinate substrates of the anaphase-promoting complex. Proc Natl Acad Sci U S A 97: 8973-8.

Gostissa, M., A. Hengstermann, V. Fogal, P. Sandy, S.E. Schwarz, M. Scheffner, and G. Del Sal. 1999. Activation of p53 by conjugation to the ubiquitin-like protein SUMO-1. Embo J 18: 6462-71.

Grandin, N. and S.I. Reed. 1993. Differential function and expression of Saccharomyces cerevisiae B-type cyclins in mitosis and meiosis. Mol Cell Biol 13: 2113-25.

Guttmann-Raviv, N., S. Martin, and Y. Kassir. 2002. Ime2, a meiosis-specific kinase in yeast, is required for destabilization of its transcriptional activator, Ime1. Mol Cell Biol 22: 2047-56.

Hagan, I.M., N. Jones, and A.M. Carr. 2001. New insights into development from mitosis of a unicellular yeast. Dev Cell 1: 158-60.

Harper, J.W., J.L. Burton, and M.J. Solomon. 2002. The anaphase-promoting complex: it's not just for mitosis any more. Genes Dev 16: 2179-206.

Hay, R.T., L. Vuillard, J.M. Desterro, and M.S. Rodriguez. 1999. Control of NFkappa B transcriptional activation by signal induced proteolysis of I kappa B alpha. Philos Trans R Soc Lond B Biol Sci 354: 1601-9.

Hepworth, S.R., H. Friesen, and J. Segall. 1998. NDT80 and the meiotic recombination checkpoint regulate expression of middle sporulation-specific genes in Saccharomyces cerevisiae. Mol Cell Biol 18: 5750-61.

Hochstrasser, M. 2002. New structural clues to substrate specificity in the "ubiquitin system". Mol Cell 9: 453-4.

Hoege, C., B. Pfander, G.L. Moldovan, G. Pyrowolakis, and S. Jentsch. 2002. RAD6dependent DNA repair is linked to modification of PCNA by ubiquitin and SUMO. Nature 419: 135-41.

Hoffman, C.S. and F. Winston. 1987. A ten-minute DNA preparation from yeast efficiently releases autonomous plasmids for transformation of Escherichia coli. Gene 57: 267-72.

Holmes, D.S. and M. Quigley. 1981. A rapid boiling method for the preparation of bacterial plasmids. Anal Biochem 114: 193-7.

Honigberg, S.M. and K. Purnapatre. 2003. Signal pathway integration in the switch from the mitotic cell cycle to meiosis in yeast. J Cell Sci 116: 2137-47.

Hoyt, M.A. 2000. Exit from mitosis: spindle pole power. Cell 102: 267-70.

Hui, C.M., A. Campistrous, and D.T. Stuart. 2002. Purification and some properties of Saccharomyces cerevisiae meiosis-specific protein kinase Ime2. Protein Expr Purif 26: 416-24.

Inoue, H., H. Nojima, and H. Okayama. 1990. High efficiency transformation of Escherichia coli with plasmids. Gene 96: 23-8.

Irniger, S. 2002. Cyclin destruction in mitosis: a crucial task of Cdc20. FEBS Lett 532: 7-11.

Irniger, S. and G.H. Braus. 2003. Controlling transcription by destruction: the regulation of yeast Gcn4p stability. Curr Genet 44: 8-18.

Irniger, S. and K. Nasmyth. 1997. The anaphase-promoting complex is required in G1 arrested yeast cells to inhibit B-type cyclin accumulation and to prevent uncontrolled entry into S-phase. J Cell Sci 110 ( Pt 13): 1523-31.

Jackson, P.K. 2001. A new RING for SUMO: wrestling transcriptional responses into nuclear bodies with PIAS family E3 SUMO ligases. Genes Dev 15: 3053-8. 
Jacobson, M.D., S. Gray, M. Yuste-Rojas, and F.R. Cross. 2000. Testing cyclin specificity in the exit from mitosis. Mol Cell Biol 20: 4483-93.

Jaspersen, S.L., J.F. Charles, and D.O. Morgan. 1999. Inhibitory phosphorylation of the APC regulator Hct1 is controlled by the kinase Cdc28 and the phosphatase Cdc14. Curr Biol 9: 227-36.

Jensen, S., M. Geymonat, and L.H. Johnston. 2002. Mitotic exit: delaying the end without FEAR. Curr Biol 12: R221-3.

Jensen, S., M. Segal, D.J. Clarke, and S.I. Reed. 2001. A novel role of the budding yeast separin Esp1 in anaphase spindle elongation: evidence that proper spindle association of Esp1 is regulated by Pds1. J Cell Biol 152: 27-40.

Johnson, E.S. and G. Blobel. 1997. Ubc9p is the conjugating enzyme for the ubiquitin-like protein Smt3p. J Biol Chem 272: 26799-802.

Johnson, E.S. and G. Blobel. 1999. Cell cycle-regulated attachment of the ubiquitinrelated protein SUMO to the yeast septins. J Cell Biol 147: 981-94.

Johnson, E.S. and A.A. Gupta. 2001. An E3-like factor that promotes SUMO conjugation to the yeast septins. Cell 106: 735-44.

Joseph, J., S.H. Tan, T.S. Karpova, J.G. McNally, and M. Dasso. 2002. SUMO-1 targets RanGAP1 to kinetochores and mitotic spindles. J Cell Biol 156: 595602.

Kim, K.I., S.H. Baek, and C.H. Chung. 2002. Versatile protein tag, SUMO: its enzymology and biological function. J Cell Physiol 191: 257-68.

Kornitzer, D. and A. Ciechanover. 2000. Modes of regulation of ubiquitin-mediated protein degradation. $J$ Cell Physiol 182: 1-11.

Kotaja, N., U. Karvonen, O.A. Janne, and J.J. Palvimo. 2002. The nuclear receptor interaction domain of GRIP1 is modulated by covalent attachment of SUMO1. J Biol Chem 277: 30283-8.

Krappmann, S., K. Helmstaedt, T. Gerstberger, S. Eckert, B. Hoffmann, M. Hoppert, G. Schnappauf, and G.H. Braus. 1999. The aroC gene of Aspergillus nidulans codes for a monofunctional, allosterically regulated chorismate mutase. $\mathrm{J} \mathrm{Biol}$ Chem 274: 22275-82.

Kron, S.J. 1997. Filamentous growth in budding yeast. Trends Microbiol 5: 450-4.

Laemmli, U.K. 1970. Cleavage of structural proteins during the assembly of the head of bacteriophage T4. Nature 227: 680-5.

Lehembre, F., S. Muller, P.P. Pandolfi, and A. Dejean. 2001. Regulation of Pax3 transcriptional activity by SUMO-1-modified PML. Oncogene 20: 1-9.

Li, D. and R. Roberts. 2001. WD-repeat proteins: structure characteristics, biological function, and their involvement in human diseases. Cell Mol Life Sci 58: 208597.

Li, R. and A.W. Murray. 1991. Feedback control of mitosis in budding yeast. Cell 66: 519-31.

Li, Y., C. Gorbea, D. Mahaffey, M. Rechsteiner, and R. Benezra. 1997. MAD2 associates with the cyclosome/anaphase-promoting complex and inhibits its activity. Proc Natl Acad Sci U S A 94: 12431-6.

Liakopoulos, D., G. Doenges, K. Matuschewski, and S. Jentsch. 1998. A novel protein modification pathway related to the ubiquitin system. Embo J 17: 2208-14.

Lim, H.H., P.Y. Goh, and U. Surana. 1998. Cdc20 is essential for the cyclosomemediated proteolysis of both Pds1 and Clb2 during M phase in budding yeast. Curr Biol 8: 231-4. 
Liu, H., J. Krizek, and A. Bretscher. 1992. Construction of a GAL1-regulated yeast cDNA expression library and its application to the identification of genes whose overexpression causes lethality in yeast. Genetics 132: 665-73.

Loeb, J.D., G. Schlenstedt, D. Pellman, D. Kornitzer, P.A. Silver, and G.R. Fink. 1995. The yeast nuclear import receptor is required for mitosis. Proc Natl Acad Sci U S A 92: 7647-51.

Longhese, M.P., M. Clerici, and G. Lucchini. 2003. The S-phase checkpoint and its regulation in Saccharomyces cerevisiae. Mutat Res 532: 41-58.

Mandel, M. and A. Higa. 1970. Calcium-dependent bacteriophage DNA infection. $J$ Mol Biol 53: 159-62.

Mao, Y., S.D. Desai, and L.F. Liu. 2000a. SUMO-1 conjugation to human DNA topoisomerase II isozymes. $J$ Biol Chem 275: 26066-73.

Mao, Y., M. Sun, S.D. Desai, and L.F. Liu. 2000b. SUMO-1 conjugation to topoisomerase I: A possible repair response to topoisomerase-mediated DNA damage. Proc Natl Acad Sci U S A 97: 4046-51.

Matunis, M.J., E. Coutavas, and G. Blobel. 1996. A novel ubiquitin-like modification modulates the partitioning of the Ran-GTPase-activating protein RanGAP1 between the cytosol and the nuclear pore complex. J Cell Biol 135: 1457-70.

Megidish, T., J.H. Xu, and C.W. Xu. 2002. Activation of p53 by protein inhibitor of activated Stat1 (PIAS1). J Biol Chem 277: 8255-9.

Meimoun, A., T. Holtzman, Z. Weissman, H.J. McBride, D.J. Stillman, G.R. Fink, and D. Kornitzer. 2000. Degradation of the transcription factor Gcn4 requires the kinase Pho85 and the SCF(CDC4) ubiquitin-ligase complex. Mol Biol Cell 11: 915-27.

Mendenhall, M.D. and A.E. Hodge. 1998. Regulation of Cdc28 cyclin-dependent protein kinase activity during the cell cycle of the yeast Saccharomyces cerevisiae. Microbiol Mol Biol Rev 62: 1191-243.

Meyer, W. 2003. Ime2 und die Rgulation des Anaphase Promoting Complex (APC) im meiotischen Zellzyklus von Saccharomyces cerevisiae. In Institut für Mikrobiologie und Genetik. Georg-August-Universität Göttingen, Göttingen.

Mitchell, A.P. 1994. Control of meiotic gene expression in Saccharomyces cerevisiae. Microbiol Rev 58: 56-70.

Mitchell, A.P., S.E. Driscoll, and H.E. Smith. 1990. Positive control of sporulationspecific genes by the IME1 and IME2 products in Saccharomyces cerevisiae. Mol Cell Biol 10: 2104-10.

Moll, T., E. Schwob, C. Koch, A. Moore, H. Auer, and K. Nasmyth. 1993. Transcription factors important for starting the cell cycle in yeast. Philos Trans R Soc Lond B Biol Sci 340: 351-60.

Morgan, D.O. 1995. Principles of CDK regulation. Nature 374: 131-4.

Morgan, D.O. 1997. Cyclin-dependent kinases: engines, clocks, and microprocessors. Annu Rev Cell Dev Biol 13: 261-91.

Muller, S., C. Hoege, G. Pyrowolakis, and S. Jentsch. 2001. SUMO, ubiquitin's mysterious cousin. Nat Rev Mol Cell Biol 2: 202-10.

Nakagawa, K. and H. Yokosawa. 2002. PIAS3 induces SUMO-1 modification and transcriptional repression of IRF-1. FEBS Lett 530: 204-8.

Nasmyth, K. 2002. Segregating sister genomes: the molecular biology of chromosome separation. Science 297: 559-65.

Ohta, T., J.J. Michel, and Y. Xiong. 1999. Association with cullin partners protects ROC proteins from proteasome-dependent degradation. Oncogene 18: 675866. 
Orlowski, M. and S. Wilk. 2003. Ubiquitin-independent proteolytic functions of the proteasome. Arch Biochem Biophys 415: 1-5.

Peters, J.M. 2002. The anaphase-promoting complex: proteolysis in mitosis and beyond. Mol Cell 9: 931-43.

Petronczki, M., M.F. Siomos, and K. Nasmyth. 2003. Un menage a quatre: the molecular biology of chromosome segregation in meiosis. Cell 112: 423-40.

Pfleger, C.M., E. Lee, and M.W. Kirschner. 2001. Substrate recognition by the Cdc20 and Cdh1 components of the anaphase-promoting complex. Genes Dev 15: 2396-407.

Pichler, A., A. Gast, J.S. Seeler, A. Dejean, and F. Melchior. 2002. The nucleoporin RanBP2 has SUMO1 E3 ligase activity. Cell 108: 109-20.

Pries, R., K. Bomeke, S. Irniger, O. Grundmann, and G.H. Braus. 2002. Amino aciddependent Gen $4 p$ stability regulation occurs exclusively in the yeast nucleus. Eukaryot Cell 1: 663-72.

Pringle, J.R., A.E. Adams, D.G. Drubin, and B.K. Haarer. 1991. Immunofluorescence methods for yeast. Methods Enzymol 194: 565-602.

Raff, J.W., K. Jeffers, and J.Y. Huang. 2002. The roles of Fzy/Cdc20 and Fzr/Cdh1 in regulating the destruction of cyclin B in space and time. J Cell Biol 157: 113949.

Rechsteiner, M. and S.W. Rogers. 1996. PEST sequences and regulation by proteolysis. Trends Biochem Sci 21: 267-71.

Rodriguez, M.S., J.M. Desterro, S. Lain, C.A. Midgley, D.P. Lane, and R.T. Hay. 1999. SUMO-1 modification activates the transcriptional response of p53. Embo J 18: 6455-61.

Saiki, R.K., S. Scharf, F. Faloona, K.B. Mullis, G.T. Horn, H.A. Erlich, and N. Arnheim. 1985. Enzymatic amplification of beta-globin genomic sequences and restriction site analysis for diagnosis of sickle cell anemia. Science $\mathbf{2 3 0}$ : 1350-4.

Salvat, C., C. Aquaviva, I. Jariel-Encontre, P. Ferrara, M. Pariat, A.M. Steff, S. Carillo, and M. Piechaczyk. 1999. Are there multiple proteolytic pathways contributing to c-Fos, c-Jun and p53 protein degradation in vivo? Mol Biol Rep 26: 45-51.

Schwab, M., A.S. Lutum, and W. Seufert. 1997. Yeast Hct1 is a regulator of Clb2 cyclin proteolysis. Cell 90: 683-93.

Schwab, M., M. Neutzner, D. Mocker, and W. Seufert. 2001. Yeast Hct1 recognizes the mitotic cyclin $\mathrm{Clb} 2$ and other substrates of the ubiquitin ligase APC. Embo $J$ 20: $5165-75$.

Schwartz, D.C. and M. Hochstrasser. 2003. A superfamily of protein tags: ubiquitin, SUMO and related modifiers. Trends Biochem Sci 28: 321-8.

Schwarz, S.E., K. Matuschewski, D. Liakopoulos, M. Scheffner, and S. Jentsch. 1998. The ubiquitin-like proteins Smt3 and SUMO-1 are conjugated by the Ubc9 E2 enzyme. Proc Natl Acad Sci U S A 95: 560-4.

Schwob, E., T. Bohm, M.D. Mendenhall, and K. Nasmyth. 1994. The B-type cyclin kinase inhibitor p40SIC1 controls the G1 to S transition in S. cerevisiae. Cell 79: 233-44.

Schwob, E. and K. Nasmyth. 1993. CLB5 and CLB6, a new pair of B cyclins involved in DNA replication in Saccharomyces cerevisiae. Genes Dev 7: 1160-75.

Seeler, J.S. and A. Dejean. 2003. Nuclear and unclear functions of SUMO. Nat Rev Mol Cell Biol 4: 690-9. 
Seufert, W., B. Futcher, and S. Jentsch. 1995. Role of a ubiquitin-conjugating enzyme in degradation of S- and M-phase cyclins. Nature 373: 78-81.

Shirayama, M., A. Toth, M. Galova, and K. Nasmyth. 1999. APC(Cdc20) promotes exit from mitosis by destroying the anaphase inhibitor Pds1 and cyclin Clb5. Nature 402: 203-7.

Shirayama, M., W. Zachariae, R. Ciosk, and K. Nasmyth. 1998. The Polo-like kinase Cdc5p and the WD-repeat protein Cdc20p/fizzy are regulators and substrates of the anaphase promoting complex in Saccharomyces cerevisiae. Embo J 17: 1336-49.

Shonn, M.A., R. McCarroll, and A.W. Murray. 2000. Requirement of the spindle checkpoint for proper chromosome segregation in budding yeast meiosis. Science 289: 300-3.

Sobko, A., H. Ma, and R.A. Firtel. 2002. Regulated SUMOylation and ubiquitination of DdMEK1 is required for proper chemotaxis. Dev Cell 2: 745-56.

Stegmeier, F., R. Visintin, and A. Amon. 2002. Separase, polo kinase, the kinetochore protein Slk19, and Spo12 function in a network that controls Cdc14 localization during early anaphase. Cell 108: 207-20.

Stuart, D. and C. Wittenberg. 1998. CLB5 and CLB6 are required for premeiotic DNA replication and activation of the meiotic S/M checkpoint. Genes Dev 12: 2698710.

Stuart, D.T. 1994. The cell cycle. by Andrew Murray and Tim Hunt, W. H. Freeman, 1993. pound 15.95 (251 pages) ISBN 071677040 6. Trends Cell Biol 4: 26970.

Sullivan, M., C. Lehane, and F. Uhlmann. 2001. Orchestrating anaphase and mitotic exit: separase cleavage and localization of Slk19. Nat Cell Biol 3: 771-7.

Surana, U., A. Amon, C. Dowzer, J. McGrew, B. Byers, and K. Nasmyth. 1993. Destruction of the $\mathrm{Cdc} 28 / \mathrm{Clb}$ mitotic kinase is not required for the metaphase to anaphase transition in budding yeast. Embo J 12: 1969-78.

Takahashi, Y., T. Kahyo, E.A. Toh, H. Yasuda, and Y. Kikuchi. 2001. Yeast Ull1/Siz1 is a novel SUMO1/Smt3 ligase for septin components and functions as an adaptor between conjugating enzyme and substrates. $J$ Biol Chem 276: 48973-7.

Tanaka, K., J. Nishide, K. Okazaki, H. Kato, O. Niwa, T. Nakagawa, H. Matsuda, M. Kawamukai, and Y. Murakami. 1999. Characterization of a fission yeast SUMO-1 homologue, pmt3p, required for multiple nuclear events, including the control of telomere length and chromosome segregation. Mol Cell Biol 19: 8660-72.

Tesfaigzi, J., W. Smith-Harrison, and D.M. Carlson. 1994. A simple method for reusing western blots on PVDF membranes. Biotechniques 17: 268-9.

Theesfeld, C.L., T.R. Zyla, E.G. Bardes, and D.J. Lew. 2003. A monitor for bud emergence in the yeast morphogenesis checkpoint. Mol Biol Cell 14: 3280-91.

Tinker-Kulberg, R.L. and D.O. Morgan. 1999. Pds1 and Esp1 control both anaphase and mitotic exit in normal cells and after DNA damage. Genes Dev 13: 193649.

Toone, W.M., B.L. Aerne, B.A. Morgan, and L.H. Johnston. 1997. Getting started: regulating the initiation of DNA replication in yeast. Annu Rev Microbiol 51: 125-49.

Towbin, H., T. Staehelin, and J. Gordon. 1979. Electrophoretic transfer of proteins from polyacrylamide gels to nitrocellulose sheets: procedure and some applications. Proc Natl Acad Sci U S A 76: 4350-4. 
Tugendreich, S., J. Tomkiel, W. Earnshaw, and P. Hieter. 1995. CDC27Hs colocalizes with $\mathrm{CDC} 16 \mathrm{Hs}$ to the centrosome and mitotic spindle and is essential for the metaphase to anaphase transition. Cell 81: 261-8.

Tyers, M., G. Tokiwa, and B. Futcher. 1993. Comparison of the Saccharomyces cerevisiae G1 cyclins: Cln 3 may be an upstream activator of $\mathrm{Cln} 1, \mathrm{Cln} 2$ and other cyclins. Embo J 12: 1955-68.

Uhlmann, F., D. Wernic, M.A. Poupart, E.V. Koonin, and K. Nasmyth. 2000. Cleavage of cohesin by the CD clan protease separin triggers anaphase in yeast. Cell 103: 375-86.

Visintin, R., S. Prinz, and A. Amon. 1997. CDC20 and CDH1: a family of substratespecific activators of APC-dependent proteolysis. Science 278: 460-3.

Wang, H., D. Liu, Y. Wang, J. Qin, and S.J. Elledge. 2001. Pds1 phosphorylation in response to DNA damage is essential for its DNA damage checkpoint function. Genes Dev 15: 1361-72.

Wasch, R. and F.R. Cross. 2002. APC-dependent proteolysis of the mitotic cyclin $\mathrm{Clb} 2$ is essential for mitotic exit. Nature 418: 556-62.

Wassmann, K. and R. Benezra. 2001. Mitotic checkpoints: from yeast to cancer. Curr Opin Genet Dev 11: 83-90.

Watanabe, Y. and P. Nurse. 1999. Cohesin Rec8 is required for reductional chromosome segregation at meiosis. Nature 400: 461-4.

Wilson, V.G. and D. Rangasamy. 2001a. Intracellular targeting of proteins by sumoylation. Exp Cell Res 271: 57-65.

-. 2001b. Viral interaction with the host cell sumoylation system. Virus Res 81: 17-27.

Wittenberg, C., K. Sugimoto, and S.I. Reed. 1990. G1-specific cyclins of $S$. cerevisiae: cell cycle periodicity, regulation by mating pheromone, and association with the p34/Cdc28 protein kinase. Cell 62: 225-37.

Yamamoto, A., V. Guacci, and D. Koshland. 1996. Pds1p is required for faithful execution of anaphase in the yeast, Saccharomyces cerevisiae. J Cell Biol 133: 85-97.

Yeong, F.M., H.H. Lim, C.G. Padmashree, and U. Surana. 2000. Exit from mitosis in budding yeast: biphasic inactivation of the $\mathrm{Cdc} 28-\mathrm{Clb} 2$ mitotic kinase and the role of Cdc20. Mol Cell 5: 501-11.

Yeong, F.M., H.H. Lim, Y. Wang, and U. Surana. 2001. Early expressed Clb proteins allow accumulation of mitotic cyclin by inactivating proteolytic machinery during S phase. Mol Cell Biol 21: 5071-81.

Zachariae, W. and K. Nasmyth. 1999. Whose end is destruction: cell division and the anaphase-promoting complex. Genes Dev 13: 2039-58.

Zachariae, W., A. Shevchenko, P.D. Andrews, R. Ciosk, M. Galova, M.J. Stark, M. Mann, and K. Nasmyth. 1998. Mass spectrometric analysis of the anaphasepromoting complex from yeast: identification of a subunit related to cullins. Science 279: 1216-9. 


\section{Danksagung}

An dieser Stelle möchte ich mich bei allen bedanken, die mir beim Erstellen der vorliegenden Arbeit geholfen haben.

An erster Stelle steht Prof. Dr. Gerhard H. Braus, der mir meine Promotion in einer Arbeitsgruppe aus lauter "gesunden Gelehrten" ermöglichte, in der ich mich immer wohl fühlte und die mir ideale Vorraussetzungen geboten hat. Auch bei PD Dr. Stefan Irniger möchte ich mich für seine Ideen, die enge Betreuung, die Bereitstellung des Themas und das gewissenhafte Korrektur lesen bedanken.

Die Ergebnisse von Herrn cand. biol. Fatih Sari haben ebenfalls während seiner Diplomarbeit entscheidend zur Charakterisierung der IME2 $\triangle C$-Mutante und damit zum Gelingen dieser Arbeit beigetragen.

Für die Übernahme des Korreferates und die Hilfe bei Computercrashs möchte ich Herrn Prof. Dr. Hans-Ulrich Mösch danken.

Große Hilfe wurde mir auch von Dr. Oliver Valerius zu teil, der zusammen mit Verena Pretz bei der massenspektrometrischen Identifikation vermeintlich SUMOylierter Proteine mitwirkte. Genauso stand mir Dr. Sven Krappmann bei allen Aspergillus-spezifischen Fragen mit Rat und Tat zur Seite. Ebenfalls im Outlook-Kapitel wurde das STREP-PHA2-Plasmid von Dipl. Biol. Andrea Pfeil und die Northern Membran von Dr. Silke Busch gezeigt - vielen Dank dafür.

Die Riege besonders hilfsbereiter Kollegen führt Dr. Melanie Bolte an, die direkt neben mir im Labor die Höhen und Tiefen des Promovierens miterlebte. Auch Ingrid Bahr, Yasemin Sancak, Wibke Meyer, Jessica Jabin, Peixin Zhu, Krystyna Nahlik (allergrößten Dank für die Korrektur der Einleitung in einer stressigen Zeit) und Marc Dumkow haben großen Anteil an den vorliegenden Ergebnissen.

Niemals kann so eine Arbeit gelingen, wenn man nicht auch einmal von ihr abgelenkt wird. Insofern wäre ich wohl ohne Anne, Claudia, Katrin, Lars, Malte (SVW), Ole, Olli, Ötzi, Stefan B., Sven und Verena gescheitert. Ob ich's je mal wieder so schön haben werde?

Meinem mittlerweile langjährigen Weggefährten Wolle, sei gesagt, dass sich nun der Spieß umdreht und er nun mir, anstatt ich ihm folgen muss, damit wir noch ein paar Nächte durchtanzen können.

Nicht mit Worten zu danken ist meinen Eltern und meiner Schwester, die mich über zehn Jahre Ausbildung hinweg mit viel mehr als nur finanzieller Hilfe unterstützt haben. Am besten werde ich Euch mal ganz fest und lange umarmen. Darauf muss sich auch meine Freundin Britta gefasst machen, der ich damit zeigen möchte, dass die hier mit ihr in Göttingen verbrachten Jahre die schönsten meines Lebens waren.

Ich hoffe, noch einige solch erfüllte Zeiten erleben zu dürfen und freue mich schon jetzt auf das neue Lebenskapitel, das nun in Berlin von uns beiden aufgeschlagen wird. 


\section{Curriculum Vitae}

Name: $\quad$ Patrick Dieckhoff

Geburtsdatum: 12. Mai 1975

Geburtsort: Diepholz

$1981-1985$

Grundschule an der Hindenburgstraße, Diepholz

$1985-1987$

Orientierungsstufe der Jahnschule, Diepholz

1987-1994

Graf-Friedrich-Schule, Diepholz

Juni 1994

Abitur (Leistungskurse: Chemie, Biologie; Prüfungsfächer:

Englisch, Sozialkunde)

1994-1995

Zivildienst im Sonderkindergarten der Lebenshilfe, Diepholz

1995-1999

Studium Diplom Chemie an der Westfälischen WilhelmsUniversität Münster

Okt. 1999

Diplomprüfungen

Hauptfach: Biochemie

Nebenfächer: Organische, Physikalische und Anorg. Chemie

$1999-2000$

Diplomarbeit im Institut für Biochemie der ETH Zürich bei

Prof. Dr. Christoph Richter „Untersuchungen zur Freisetzung von Cytochrom C aus Mitochondrien"

03/2001-04/2004 Anfertigung der Doktorarbeit im Institut für Mikrobiologie und Genetik der Georg-August-Universität-Göttingen im Arbeitskreis von Prof. Dr. Gerhard H. Braus

Thema: "Protein Modification and Degradation in the Cell Cycle of the Yeast Saccharomyces cerevisiae" 